
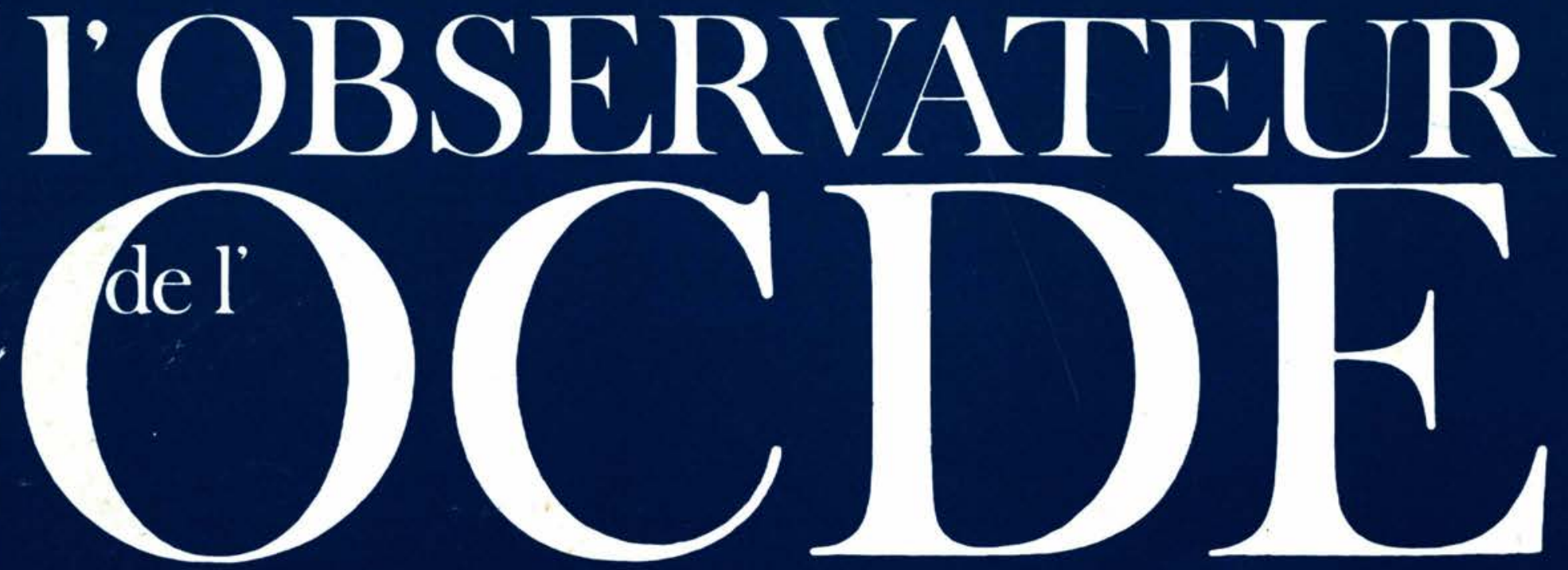

Problémes provoqués par le renchérissement du pétrole

Nouvelles initiatives internationales

pour les résoudre - le Fonds de soutien financier - coopération dans le domaine de l'éneruic

Conséquences pour les flux financiers vers le tiers monde - apports publics

- investissements privés - le problème

de l'endettement

Pourquoi les fusions doivent être contrôlées par les pouvoirs publics

\title{
L'elfet des
} régimes d'imposition et de prestations sociales surle revenu des ouvriers

Les pavs Membres de l'OCDE:

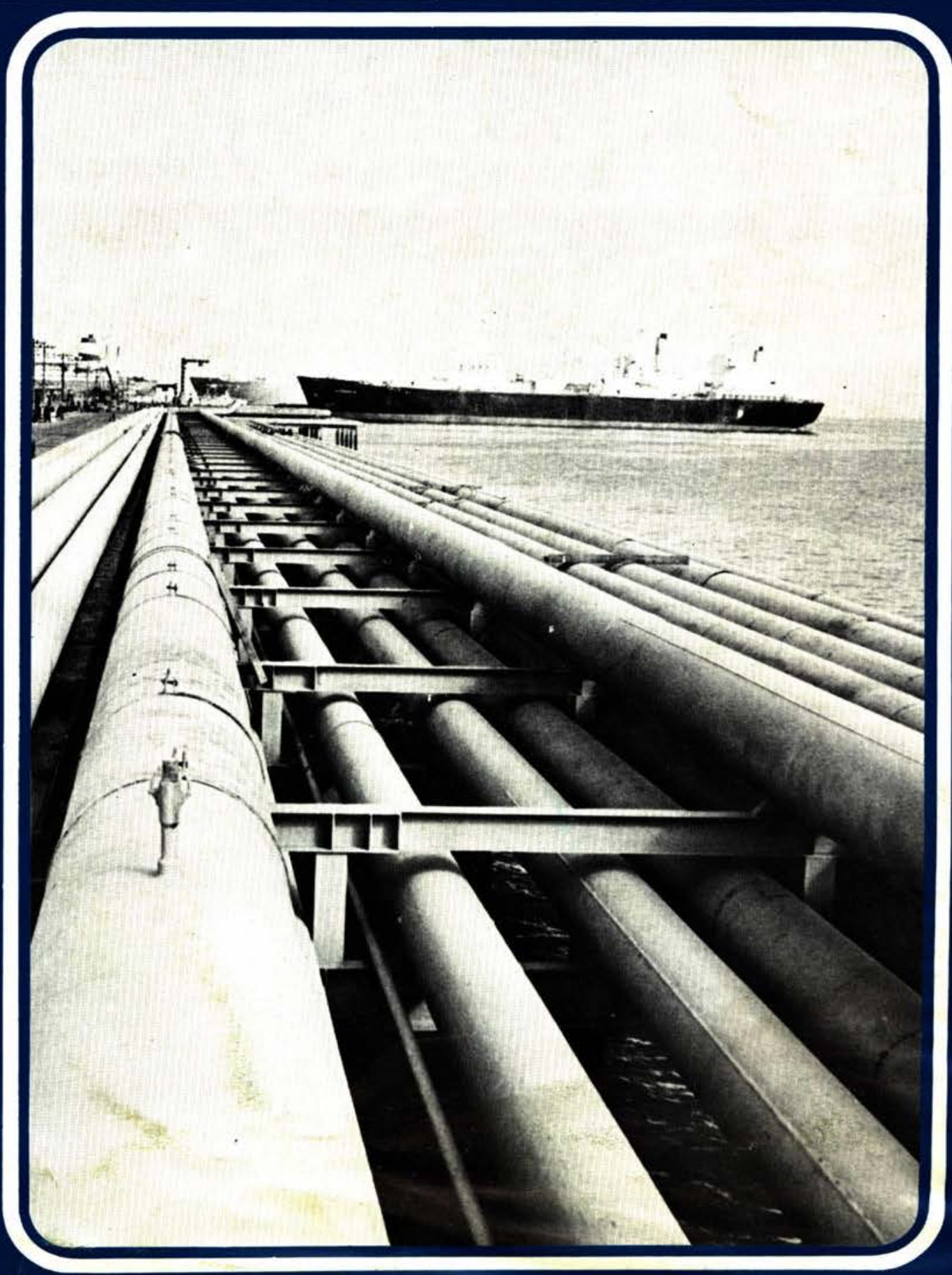




\section{SOMMAIRE}

LA POLITIQUE DE L'ÉNERGIE ET SES INCIDENCES SUR LA SITUATION MONÉTAIRE INTERNATIONALE

par Emile van Lennep, Secrétaire général de l'OCDE

Nouvelles initiatives en matière de coopération internationale

- Le fonds de soutien finANCIER de L'OCDE

- ÉNERGIE : ÉCONOMIES ET DÉVELOPPEMENT

DE SOURCES DE SUBSTITUTION

- LE COMITÉ DE L'INVESTISSEMENT INTERNATIONAL

ET DES ENTREPRISES MULTINATIONALES DE L'OCDE

Flux financiers vers le tiers monde

- Les apPorts de DiVERSES SOURCES Aux PAYS EN DÉVELOPPEMENT : CHANGEMENTS RÉCENTS

- APPORTS DE CAPITAUX PRIVÉS VERS LES PAYS EN DÉVELOPPEMENT : LE SCHÉMA CHANGE

- LES PROBLĖMES D'ENDETTEMENT DES PAYS EN DÉVELOPPEMENT

LES PAYS MEMBRES DE L'OCDE

LE ROLE DU MARCHÉ DES EUROCRÉDITS

POURQUOI LES FUSIONS DOIVENT ETRE CONTROLÉES

PAR LES POUVOIRS PUBLICS

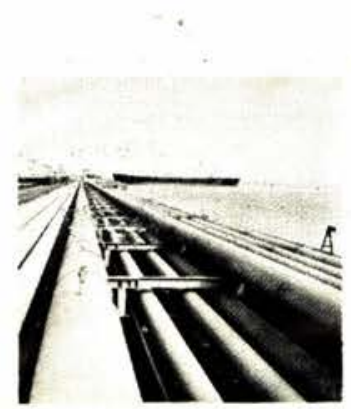

Le renchérissement du pétrole a modifié les flux financiers internationaux et amené les pays de l'OCDE à chercher de nouveaux types de coopération. Couverture : terminal pétrolier en Arabie Saoudite.

\section{l'OBSERVATEUR de I} No 74

Publication bimestrielle en anglais et en français éditée par L'ORGANISATION DE COOPERATION ET DE DÉVELOPPEMENT ÉCONOMIQUES.

BUREAUX DE LA RÉDACTION : Service de l'Information de l'OCDE, Château de la Muette, 2 rue André-Pascal, F 75775 PARIS CEDEX 16.

Les articles sans copyright peuvent être reproduits à condition d'être accompagnés de la mention " Reproduit de L'OBSERVATEUR DE L'OCDE » en précisant la date du numéro. Deux exemplaires justificatifs devront être envoyés au rédacteur en chef. Les articles signés ne pourront être reproduits qu'avec la signature de leur auteur.

L'Organisation n'est pas tenue de rendre les manuscrits qu'elle n'a pas sollicités. Les articles signés expriment l'opinion de leurs auteurs et non pas nécessairement celle de l'OCDE.

Abonnement (un an) :

F $18 ; £ 1,80 ; \$ 4,50$.

Le numéro :

F 4,$00 ; £ 0,40 ; \$ 1,00$.

RÉDACTEUR EN CHEF : Jane Bussière

Rédacteur en Chef Adjoint :

Ulla Jeanneney

Direction Artistique et Technique :

Marc Delemme

Recherche PhotographiQue :

Silvia Lépot

Toute la correspondance doit être adressée au rédacteur en chef.

PHOTOS: Couverture: Alain Nogues Sygma; pages 9 et $15:$ L. Jouan - OCDE; page 16: René Maltête - Rapho. 


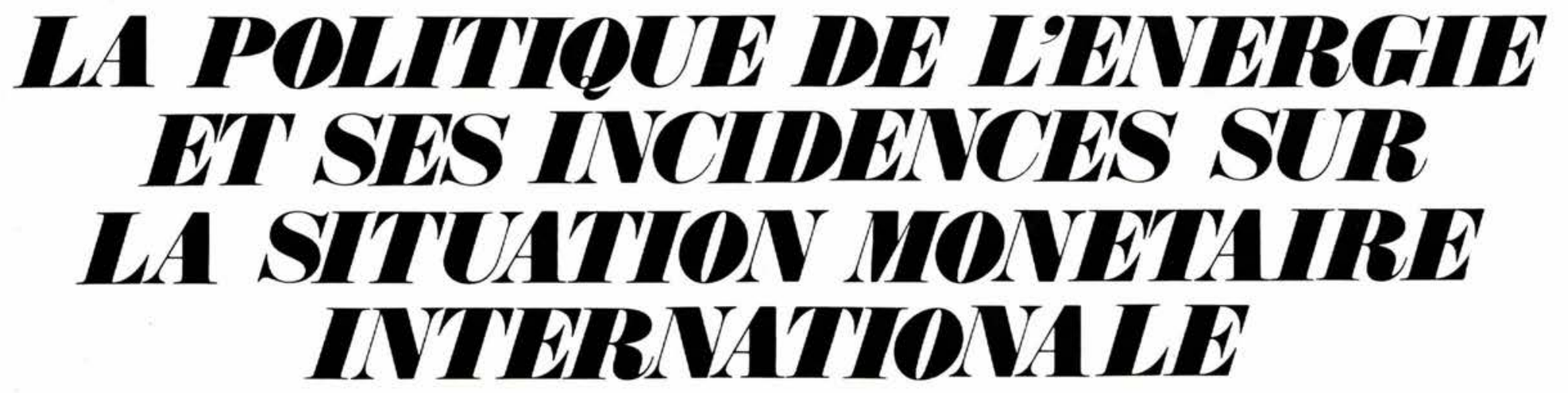

par Emile van Lennep, Secrétaire général de l'OCDE (1)

La hausse soudaine et importante du prix du pétrole a eu une profonde incidence sur l'économie mondiale, qu'il s'agisse des pays industrialisés consommateurs de pétrole, des pays en voie de développement producteurs de pétrole ou du groupe, beaucoup plus important, des pays en développement ne disposant que de ressources pétrolières insignifiantes.

Il va de soi que ni les pays de l'OCDE, ni les pays en développement ne constituent un groupe homogène. Toutefois, en examinant les problèmes aussi bien globalement qu'individuellement on peut espérer pouvoir se faire une idée plus précise des domaines où une réaction collective est nécessaire et de ceux où la responsabilité de l'action incombe en premier lieu à chaque pays.

\section{Incidence sur les payss de I'DCIDE}

L'incidence sur les pays de l'OCDE de la hausse du prix du pétrole a été triple : une forte impulsion à l'inflation; un effet dépressif sur la production et l'emploi; un retournement de la situation des balances des opérations courantes, devenues déficitaires. D'autre part, la zone OCDE est en train de se transformer en importatrice nette de capitaux.

\section{- Conséquences inflationnistes}

L'impulsion donnée à l'inflation a été le phénomène le plus évident et le plus douloureux. En 1973 et 1974, la hausse des prix des importations nettes de pétrole a correspondu à quelque $1,75 \%$ du total des dépenses intérieures. Mais, l'effet total sur le niveau global des prix a été sensiblement plus fort. Plusieurs raisons ont en effet incité les gouvernements à faire largement appel au mécanisme des prix pour diminuer leur degré de dépendance à l'égard des sources extérieures d'énergie : les limitations de l'offre à la fin de 1973 et au début de 1974, la menace de pénurie qui en a résulté, la nécessité de réduire le montant des importations lorsque leur coût a quadruplé et même quintuplé. A divers degrés, les gouvernements ont laissé les prix à la production de l'énergie intérieure suivre la hausse des coûts des importations de pétrole et de gaz, et les prix à l'exportation de l'énergie ont naturellement été intégralement ajustés aux prix mondiaux. Plusieurs gouvernements ont, d'autre part, augmenté les taxes sur l'énergie. En tenant compte de ces facteurs, on peut estimer à quelque 3,5\% I'incidence de la hausse des prix de l'énergie sur le niveau global des prix (tableau 1). Sur cette base, on peut imputer à l'augmentation des prix de l'énergie environ la moitié de l'accélération de la hausse des prix à la consommation au cours de 1974 (près de $15 \%$ contre $8 \%$ en 1973).

II est cependant à peu près certain que l'effet a, en fait, été plus

(1) Cet article reprend de larges extraits d'une conférence donnée par le Secrétaire général devant la Société allemande de politique étrangère à Bonn le 18 février 1975. Le texte intégral de cette conférence a été publié, en allemand, dans la revue EuropaArchiv. important. L'inflation est, par excellence, un processus dynamique et toute influence extérieure se trouve amplifiée. Son accélération inattendue, due à la hausse des prix du pétrole, a donné naissance à une nouvelle course entre les salaires et les prix du fait qu'elle a réduit les salaires réels et déclenché des tentatives visant à compenser les pertes par des salaires nominaux plus élevés.

\section{HAUSSE DU COUT DE L'ÉNERGIE (a) EN 1973 ET 1974}

en pourcentage du total des dépenses intérieures

\begin{tabular}{|c|c|c|}
\hline . & $\begin{array}{c}\text { Total de } 1973 \\
\text { et } 1974 \\
\end{array}$ & $\begin{array}{l}\text { Dont : } \\
\text { pétrole }\end{array}$ \\
\hline Canada & 2,3 & 1,7 \\
\hline États-Unis & 2,2 & 1,4 \\
\hline Japon & 4,3 & 3,3 \\
\hline Australie et & & \\
\hline Nouvelle-Zélande & 3,4 & 2,3 \\
\hline France & 3,6 & 2,9 \\
\hline Allemagne & 3,1 & 1,9 \\
\hline Italie & 5,9 & 5,3 \\
\hline Royaume-Uni & 5,5 & 3,9 \\
\hline $\begin{array}{l}\text { Autres pays de l'Europe } \\
\text { septentrionale (b) }\end{array}$ & 3,9 & 3,0 \\
\hline $\begin{array}{l}\text { Autres pays de l'Europe } \\
\text { méridionale (c) }\end{array}$ & 4,3 & 3,8 \\
\hline Total OCDE (d) & 3,3 & $2,3(\mathrm{e})$ \\
\hline OECD Europe (d) & 4,1 & 3,0 \\
\hline
\end{tabular}

(a) Pétrole, houille et gaz naturel : prix à l'importation et prix à la production intérieure; ne comprend pas les majorations au niveau du gros et du détail. Ni l'énergie hydro-électrique ni l'énergie nucléaire ne sont comprises. (b) Autriche, Belgique-Luxembourg, Danemark, Finlande, Irlande, Norvège, Pays-Bas, Suède, Suisse. (c) Espagne, Grèce, Portugal, Turquie. (d) Sur la base des pondérations du PNB 1973. (e) Y compris $1,8 \%$ pour des importations de pétrole en provenance de l'extérieur de la zone $O C D E$. 
En outre, la hausse du prix du pétrole s'est produite à un mauvais moment pour les économies industrialisées. Elle est intervenue à un moment où, depuis plusieurs mois, les pressions de la demande dans pratiquement tout le monde industrialisé étaient si fortes qu'elles entraînaient des pénuries répétées et des anticipations inflationnistes. Cela a permis aux entreprises de répercuter pleinement la hausse de leurs coûts liée à l'énergie sur les prix de vente et - fréquemment - d'élargir en même temps leurs marges bénéficiaires brutes. Si la hausse du prix du pétrole était intervenue en une période de faible demande globale, on aurait pu en limiter plus aisément les retombées - en effet, les entreprises auraient été contraintes d'absorber une partie de la hausse des coûts due à l'énergie. La crise du pétrole s'est produite au moment précis où certains signes laissaient présager que l'envolée des prix des produits de base, qui durait depuis un an, commençait à fléchir : en fait elle a donné à cette hausse une nouvelle impulsion.

On ne parviendra jamais à démêler avec précision l'influence de ces différents facteurs. Il est intéressant de noter, cependant, que juste avant la hausse du pétrole, en octobre 1973, le Secrétariat de l'OCDE avait prévu que le niveau général des prix dans les pays industrialisés pourrait augmenter de quelque $7 \%$ au cours de l'année 1974. En fait, les prix ont monté d'environ $15 \%$.

\section{- Effets dépressifs}

L'effet dépressif de la hausse du prix du pétrole sur la production et l'emploi a mis plus de temps à se faire sentir. Il ne s'est pas tellement manifesté du côté monétaire : en effet, l'argent transféré aux producteurs de pétrole semble être en grande partie revenu sous forme de paiements de produits et de services ou sous forme d'investissements sur les marchés monétaires et des capitaux. L'effet dépressif est plutôt dû à une interruption dans le flux des revenus et des dépenses. Les revenus réels des pays consommateurs ont été réduits; les dépenses réelles des pays producteurs ont beaucoup moins augmenté que leurs recettes parce que ces pays n'ont pas été en mesure de dépenser tant d'argent aussi rapidement. Toutefois, cette contraction a été temporairement masquée, au début de 1974, par le fait que l'on a tout d'abord pris conscience de la poussée des prix. Prévoyant, en plus, les répercussions que la hausse n'allait pas manquer d'avoir sur les autres prix des produits de base, les ménages et les entreprises ont tenté de "gagner de vitesse " l'inflation en constituant des stocks aux prix anciens, et d'une manière plus générale, en effectuant des achats d'anticipation. Ce comportement a donné un coup de fouet temporaire à la demande et a exacerbé les hausses des prix, notamment sur les marchés des produits de base.

Le taux d'inflation particulièrement élevé qui a marqué le début de l'année 1974 a incité bon nombre de gouvernements à aller au-delà des mesures qu'ils avaient prises en 1973 pour freiner la demande globale. Pour certains d'entre eux, les difficultés de la balance des paiements, aggravées par le prix du pétrole, ont été une raison supplémentaire d'aller dans ce sens. Le résultat en a été qu'à partir du milieu de 1974 le niveau d'activité a fléchi sous l'influence de trois facteurs : les politiques de régulation de la demande, la décélération spontanée de la phase de haute conjoncture - avec le ralentissement progressif de la constitution de stocks à titre spéculatif - et l'effet de contraction dû au transfert de revenus des pays de l'OCDE vers les pays de l'OPEP.

\section{- Déficits des balances des opérations courantes}

Les responsables politiques ont été impressionnés par la modification brutale intervenue dans la structure de la balance courante de la zone OCDE et par l'ampleur et la durée probable du déficit global. Jusqu'en 1973, l'OCDE enregistrait un léger excédent des opérations courantes avec tous les pays en développement considérés en tant que groupe. En 1974, l'excédent résultant des opérations avec les pays non producteurs de pétrole a continué de s'accroître, passant de quelque 5 à quelque 17 milliards de dollars. Le déficit avec les pays de l'OPEP s'est, au contraire, brusquement élevé, passant de 3 à 50 milliards de dollars environ, ce qui a entraîné pour la zone OCDE un déficit de la balance courante de quelque 33,5 milliards de dollars. Ce chiffre est inférieur à celui qu'on attendait au début de 1974, mais ce meilleur résultat est dû, pour une bonne part, au ralentissement, à la suite de la récession, des importations en provenance de pays tiers, à la fois des pays de l'OPEP et des autres pays en développement. C'est essentiellement pour la même raison que le déficit global continuera vraisemblablement à diminuer en 1975, mais il faudra plusieurs années avant de l'éliminer complètement.

Le déficit de la balance courante des pays de l'OCDE, en tant que groupe, avec l'OPEP est "inévitable», en ce sens qu'il ne peut être réduit par des ajustements des taux de change ou par une politique de régulation de la demande. Ce genre de mesures ne ferait que transférer le déficit d'un pays à un autre.

Ayant admis que, en tant que groupe, il leur fallait accepter l'existence de déficits aussi importants pendant plusieurs années, les pays de l'OCDE ont rejeté la politique du "chacun pour soi ». Ils ont adopté en mai 1974 une Déclaration par laquelle ils se sont engagés, pour un an, à ne pas restreindre les importations et à ne pas subventionner les exportations dans le but d'améliorer individuellement leur balance commerciale. Ils ont également maintenu, en chiffres réels, le niveau de l'aide au pays en développement. Mais il ne suffit pas d'accepter collectivement l'existence d'un déficit de la balance courante : il faut aussi le financer. Pour la zone OCDE dans son ensemble, cela n'est pas un problème insoluble. Réparti proportionnellement au revenu national des différents pays, un déficit de la balance courante de l'ordre de $1 \%$ du PNB reste très inférieur aux niveaux qui ont été atteints, par un certain nombre de pays industrialisés, à plusieurs reprises depuis la guerre sans constituer pour autant un déséquilibre fondamental.

On fait fréquemment valoir que nos pays ne peuvent continuer à accumuler des dettes de cette ampleur pendant plusieurs années. Là encore, il semblerait que, pour les pays de l'OCDE pris en tant que groupe, la charge assumée vis-à-vis de l'OPEP soit supportable. D'après des projections récentes, l'excédent cumulatif de l'OPEP atteindra probablement au début des années 1980 son maximum : peut-être 225 à 250 milliards de dollars aux prix 1974. Cela correspond à quelque $6 \%$ de notre PNB en 1974. On trouve, dans l'histoire économique des pays industrialisés, de nombreux exemples où l'endettement à l'égard de l'étranger a atteint des niveaux beaucoup plus élevés.

\section{- Problèmes sectoriels}

En dehors de ses conséquences pour la balance des paiements, l'effet macro-économique de la hausse du prix du pétrole et du moment où elle s'est produite posent de sérieux problèmes pour les pays de l'OCDE, aussi bien au niveau de la régulation de la demande globale que sur le plan sectoriel. On sait que les excédents enregistrés par l'OPEP représentent un accroissement de l'épargne mondiale qui ne s'accompagne pas d'une progression équivalente de la propension à investir, car celle-ci a besoin de temps pour s'installer et, chose plus importante, le monde se trouve en période de récession.

Il est, par conséquent, nécessaire de prendre des mesures temporaires visant à souten $\mathrm{r}$ non seulement les investissements mais également la consommation. Toutefois, dès que l'économie de la zone OCDE se redressera la pression exercée sur les ressources peut s'accroître rapidement à mesure que de nouveaux investissements seront nécessaires pour la production et les économies d'énergie, pour l'amélioration de l'environnement, et éventuellement, pour la production des industries de base, y compris l'industrie alimentaire. Dans ces conditions, il faudra diminuer, au profit des investissements et des exportations vers les pays de l'OPEP, la part des ressources qui est aujourd'hui consacrée à la consommation. Ceci exigera des changements de structures susceptibles de créer des problèmes sectoriels en particulier dans les pays qui ont une capacité insuffisante dans les domaines des biens d'équipement et des industries de base. 


\section{EXPORTATIONS DE CERTAINS PAYS DE L'OCDE VERS LES PAYS DE L'OPEP ET PAYS VOISINS (a) \\ (trimestre le plus récent)}

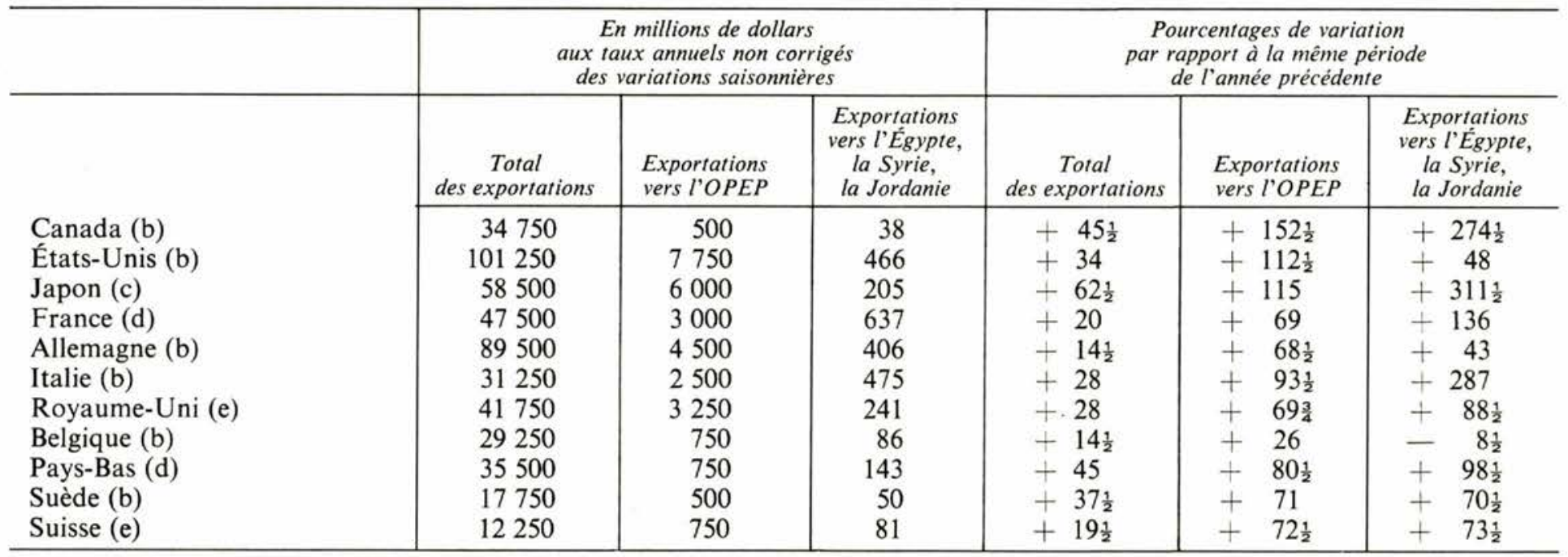

(a) Le tableau comprend ces derniers pays car l'on considère que l'évolution du murché de l'OPEP peut y avoir certaines répercussions par l'intermédiaire d'apports d'aide publics, de transferts privés, etc. $\quad$ (b) Août, septembre et octobre 1974. $\quad$ (c) Juin, juillet et août 1974. $\quad$ (d) Juillet, août et septembre 1974. (e) Septembre, octobre et novembre 1974.

\section{Incidence sur les pays de I'OPEP}

Les recettes des exportations des pays producteurs ont augmenté l'année dernière d'environ 70 milliards de dollars (de 35 à 105). De ce revenu accru ils n'ont pu dépenser en importations de biens et de services qu'un peu moins du quart (tableau 2). Un dixième environ a, par ailleurs, été mis à la disposition des autres pays en développement par la voie de dons et de prêts. La plus grande partie du reste a été investie, sous une forme ou sous une autre, dans la zone OCDE.

Ainsi, la hausse du prix du pétrole a entraîné, à l'échelon mondial, une assez importante redistribution des revenus et des richesses. Dans la mesure où les pays les plus pauvres ont profité de cette évolution - et certains des pays producteurs de pétrole sont encore très pauvres - on ne saurait, du point de vue moral, avoir une réaction négative, surtout lorsqu'on considère que les pays industrialisés sont en retard sur les objectifs d'aide qu'ils s'étaient fixés pour la "deuxième décennie du développement ". Dans l'état actuel des choses, cependant, la plus grande partie des réserves pétrolières est concentrée dans un petit nombre de pays à très faible population. Par ailleurs, l'histoire économique nous enseigne que les tentatives visant à redistribuer le revenu par une manipulation du mécanisme des prix, risquent fort - même si elles sont tout à fait souhaitables du point de vue de la justice sociale - de ne donner que peu de résultats ou même d'échouer si elles vont à l'encontre des tendances profondes et vigoureuses de l'offre et de la demande.

\section{- Importations de pétrole}

C'est pourquoi l'une des questions importantes que doivent se poser les pays producteurs de pétrole est de savoir si le prix de ce dernier n'a pas trop augmenté par rapport à l'évolution probable, à court et à moyen terme, de l'offre et de la demande dans le secteur de l'énergie. Les importations de pétrole de l'OCDE, sous l'action conjuguée de prix beaucoup plus élevés et de tendances récessionnistes généralisées, ont diminué d'environ $4 \%$ l'année dernière. Il est peu vraisemblable qu'elles se redressent cette année : elles resteront sans doute très inférieures aux tendances antérieures et à la capacité de production des pays producteurs. L'évaluation récemment achevée par l'OCDE des perspectives énergétiques jusqu'en 1985, indique que, aux prix actuels, il est probable que cette tendance se poursuivra. Dans ces conditions, les forces du marché pourraient, avec le temps, entraîner une baisse brutale du prix du pétrole, avec le risque de voir s'instaurer un cycle qui, se renouvellant constamment, se traduirait par des fluctuations excessives des prix à la hausse et à la baisse. Ce phénomène est typique de certains autres produits primaires et il est extrêmement préjudiciable tant aux pays producteurs qu'aux pays consommateurs.

\section{- Comment investir les capitaux excédentaires?}

L'autre grand problème auquel les producteurs doivent faire face est de savoir comment investir les capitaux excédentaires qui s'accumulent rapidement chez eux - ils s'élevaient, en 1974, à environ 55 milliards de dollars. Dans un monde hautement inflationniste avec des taux de change flottants et une grande incertitude sur le plan monétaire, c'est une tâche qui est loin d'être aisée. D'après les informations dont on dispose, il semble que les pays de l'OPEP ont sensiblement modifié leur politique d'investissement au cours des derniers mois de 1974 , diminuant la part qu'ils consacraient aux placements directs en avoirs libellés en dollars sur le marché américain et sur le marché de l'eurodollar. Cette évolution reflète sans aucun doute en partie un ajustement à de nouvelles conditions monétaires et aux différences entre les taux d'intérêt. Toutefois, elle peut aussi marquer, chez les pays de l'OPEP, un désir plus profond de diversifier leur portefeuille pour acquérir plus d'actifs réels et d'actifs financiers à long terme, et aussi plus d'actifs libellés dans les monnaies européennes fortes.

\section{Incidence sur les pays: en developpement non producleurs de peilnole}

L'incidence de la hausse du prix du pétrole sur ces pays a suscité, dès le départ, un intérêt considérable. Ils n'importent pas de grandes quantités de pétrole brut, mais leur balance courante risquait fort d'être affectée dans des proportions analogues, en termes relatifs, à celles des pays de l'OCDE. Naturellement, on attendait que la plupart d'entre eux, tout simplement, ne soient pas en mesure de faire face à cette nouvelle charge.

En fait, la situation a évolué de manière quelque peu différente. En premier lieu, les pays en développement disposant d'importantes ressources naturelles ont bénéficié, jusqu'au milieu de 1974, 
de l'envol des prix des produits de base. Ayant réussi à accumuler au cours de cette période des réserves considérables, ils ont pu continuer, jusqu'à une date très récente, à financer leurs importations sans rencontrer de sérieuses difficultés. En second lieu, ils ont, ainsi que certains autres pays en développement, pu continuer d'emprunter à une large échelle sur les euromarchés. Troisièmement, les pays politiquement ou géographiquement proches de l'OPEP et/ou ceux qui sont tout simplement incapables de payer la note du pétrole ont reçu des pays producteurs d'importants prêts et dons, et ils ont obtenu des conditions de paiement spéciales pour leurs importations de pétrole. Quatrièmement, les pays en développement non producteurs de pétrole ont bénéficié du mécanisme pétrolier du FMI et d'autres formes d'aide financière internationale.

Tout cela explique que les pays en développement non producteurs de pétrole ont été en mesure de financer, en 1974, une augmentation de leur déficit commercial de quelque 15 milliards de dollars dont les deux tiers avec l'OPEP et un tiers avec l'OCDE.

La chute des prix des matières premières industrielles et le fléchissement du volume des exportations tant des produits de base que d'articles manufacturés ont eu comme effet que, au second semestre 1974 , les recettes des exportations des pays en développement non producteurs de pétrole ont commencé à baisser. Elles continueront de le faire cette année. Étant donné que le volant de réserves dont ils disposaient est maintenant à peu près épuisé, ils verront diminuer, en 1975, le volume de leurs importations. Il va sans dire que certains pays en développement pourraient avoir de sérieux problèmes de ressources et être contraints à réduire des importations essentielles. Ainsi, après avoir soutenu l'activité des pays industrialisés en 1974, le commerce avec les pays en développement non producteurs de pétrole risque fort de devenir un facteur de dépression en 1975, à moins que n'interviennent une amélioration sur les marchés des produits de base et un accroissement des flux financiers non commerciaux.

\section{Incidence sur les: differents payss industrialises:}

L'incidence réelle de la crise pétrolière est très variable selon les différents pays industrialisés. L'accroissement du coût des importations et l'effet de contraction qu'il a exercé ont pris des proportions comparables pour tous les principaux pays européens. Ils ont pris sensiblement plus d'ampleur au Japon et beaucoup moins en Amérique du Nord. Cela dit, pour ce qui est de l'inflation et de la balance des paiements, la hausse du prix du pétrole n'a fait qu'accuser les différences qui existaient déjà entre les Membres de l'OCDE. C'est ainsi que les pays qui se trouvaient au départ dans une position de faiblesse ont généralement connu une aggravation de leurs difficultés, tandis que les pays dont la position était plus forte ont amélioré leur position relative.

Si le «déficit pétrolier» (c'est-à-dire l'augmentation de la note pétrolière moins l'accroissement des exportations vers les pays de l'OPEP) peut encore être établi pour l'OCDE dans son ensemble et s'il reste par conséquent utile comme instrument d'analyse, il devient de plus en plus difficile à le déterminer pour chaque pays individuel. En 1974, quatre pays (France, Italie, Japon et RoyaumeUni), représentant ensemble $30 \%$ du PNB de l'OCDE, totalisaient $81 \%$ du déficit de la balance courante de la zone (tableau 3 ). En ajouınt quelques petits pays, on porte le total à $90 \%$.

\section{- Mécanismes de financement pour les pays "faibles"}

Dans une situation marquée par un tel déséquilibre, les problèmes de financement des pays faibles devait nécessairement prendre des proportions considérables. Aussi la question de leur endettement est-elle devenue préoccupante.

Jusqu'ici, les systèmes de financement existants ont permis à ces pays de surmonter leurs problèmes sans rencontrer des difficultés aiguës. L'euromarché, bénéficiant du soutien des banques cen-

\begin{tabular}{|c|c|c|c|}
\hline \multicolumn{4}{|c|}{$\begin{array}{l}\text { 3. BALANCES COURANTES } 1974 \\
\text { (estimations) } \\
\text { en milliards de dollars } E .-U .\end{array}$} \\
\hline $\begin{array}{l}\text { Canada } \\
\text { États-Unis } \\
\text { Japon } \\
\text { France } \\
\text { Allemagne } \\
\text { Italie }\end{array}$ & $\begin{array}{l}-1 \frac{3}{4} \\
-1 \frac{3}{4} \\
-4 \frac{1}{2} \\
-6 \\
+9 \frac{1}{2} \\
-7 \frac{1}{2}\end{array}$ & $\begin{array}{l}\text { Royaume-Uni } \\
\text { Belgique- } \\
\quad \text { Luxembourg } \\
\text { Pays-Bas } \\
\text { Suède } \\
\text { Autres pays de } \\
\text { l'OCDE }\end{array}$ & $\begin{array}{l}-9 \\
-\quad \frac{1}{4} \\
+\quad 1 \frac{3}{4} \\
-\quad \frac{1}{2} \\
-13 \frac{1}{2}\end{array}$ \\
\hline \multicolumn{3}{|r|}{ Total OCDE } & $-33 \frac{1}{2}$ \\
\hline
\end{tabular}

trales, a bien résisté à la tension, et un financement complémentaire est devenu disponible grâce au mécanisme pétrolier du FMI et aux crédits bilatéraux accordés par les pays de l'OPEP et dans le cadre de l'OCDE. Celle-ci est par ailleurs en train de constituer un Fonds de soutien financier d'un montant de 25 milliards de dollars (2).

Le principe de base de ce Fonds est que le déficit global de la zone résulte, certes, de l'augmentation du prix du pétrole, mais que les déficits des pays pris individuellement reflètent essentiellement la faiblesse plus profonde de leur position, aggravée par la crise du pétrole. C'est pourquoi le Fonds de soutien fournira seulement un financement conditionnel comportant une surveillance continue, par les pays prêteurs, des politiques de réglementation de la demande et des politiques énergétiques suivies par les gouvernements emprunteurs. Le Fonds ne contribuera pas à prolonger les déséquilibres entre les pays de l'OCDE.

L'existence de ce nouveau mécanisme permettra aux pays faibles d'éviter une trop forte dépendance à l'égard des emprunts bilatéraux. Les pays participants ayant un déficit extérieur seront protégés des formes indésirables de pression de la part de leurs créanciers quels qu'ils soient. En adoptant une approche de financement multilatérale, les pays de l'OCDE montreront leur solidarité financière, renforceront leur position de négociation en tant que groupe et limiteront la concurrence qu'ils se font entre eux pour attirer les capitaux de l'OPEP.

Le Fonds de soutien de l'OCDE est essentiellement un mécanisme défensif conçu dans un but spécifique. Son objectif n'est pas de remplacer d'autres modalités de financement ou de recyclage. Il est au contraire entendu qu'avant d'y recouvrir, un pays doit avoir fait un usage approprié des autres moyens de financement qui existent par ailleurs. De l'autre côté, il est évident que l'on n'attendrait pas qu'un pays se trouve au bord de la catastrophe pour lui accorder un prêt.

Il s'ensuit que le Fonds de soutien n'est pas censé résoudre par lui-même tous les problèmes que pose l'accumulation de pétrodollars. Sa raison d'être est beaucoup plus de constituer une base solide sur laquelle il sera possible de rechercher en commun, par la voie de la coopération, des solutions à ces problèmes, notamment en renforçant la confiance dans la capacité des gouvernements à poursuivre des politiques aptes à faire face aux tendances inflationnistes et récessionnistes actuelles.

\section{- Les problèmes des pays "forts"}

Les pays industrialisés les plus forts sont ceux qui ne devraient pas, dans un avenir prévisible, connaître des problèmes de financement de leurs importations. Ils comprennent les États-Unis (la récente tendance à l'affaiblissement du dollar ne reflète en rien la position plus profonde de compétitivité des producteurs américains), le Japon, l'Allemagne et probablement la Belgique, les Pays-Bas et la Suisse.

Dans le cas de ces pays, l'effet de la situation énergétique pourrait s'exercer de façon assez particulière. Ils se trouvent placés comme

(2) Voir p. 9. 
les pays faibles devant le phénomène de la hausse du prix des importations pétrolières. En effet, sur l'accroissement, en 1974, de la note pétrolière de l'OCDE : 65 milliards de dollars, quelque 40 milliards ont été à la charge de ces pays forts.

L'originalité essentielle de leur situation tient à deux phénomènes qui sont clairement liés. Premièrement, avant la crise du pétrole, l'Allemagne, la Belgique et les Pays-Bas connaissaient déjà un excédent très substantiel de la balance des paiements au titre des opérations courantes. Et les États-Unis, grâce aux modifications des taux de change et à l'essor des exportations agricoles, passaient rapidement d'une situation déficitaire à une situation excédentaire. Deuxièmement, la plupart de ces pays enregistraient - et enregistrent encore - un taux d'inflation nettement inférieur à ceux d'autres pays industrialisés. C'est le cas des États-Unis qui, même avec une hausse des prix manifestement excessive, ont au moins maintenu leur taux d'inflation au-dessous de la moyenne de l'OCDE. C'est aussi et tout particulièrement le cas de l'Allemagne et des partenaires du Benelux dans le "serpent " européen. La réussite peut cependant être source de problèmes qui ne sont parfois pas plus faciles à résoudre que ceux qui résultent d'un échec. Ainsi en est-il de la charge que peut entraîner, sur le plan des ressources, une structure industrielle très compétitive, et des complications provenant des entrées de capitaux. Les excédents attirent les excédents - même, apparemment, lorsque l'on ne se trouve plus dans un régime à taux de change fixes. Un pays se fait une réputation d'efficacité industrielle et de relative stabilité des prix. La conséquence en est un afflux de capitaux de l'étranger qui risque de faire monter excessivement le taux de change, mais qui rend sans aucun doute extrêmement difficile l'utilisation de la politique monétaire comme instrument de stabilisation intérieure.

\section{- L'afflux de capitaux pétroliers}

Depuis quelque temps, il existe une nouvelle source de capitaux. Les pays de l'OPEP accumulent des quantités énormes d'argent qu'ils sont obligés d'investir dans les pays industrialisés (tableau 4). Le problème est de s'assurer que ces capitaux sont répartis à peu près équitablement entre les pays receveurs et ne sont pas trop concentrés dans un petit nombre d'économies nationales "de première catégorie ". Certains des problèmes que posera l'hyperconcentration de ces capitaux ressembleront à ceux qu'avaient entraînés auparavant les flux de dollars : effets tendant à déséquilibrer les conditions monétaires intérieures et à exercer des pressions indésirables sur les taux de change. Il suffit, à cet égard, de considérer ce qui s'est passé récemment en Suisse. Mais d'autres problèmes touchant à la propriété et au contrôle étrangers commencent depuis quelque temps à se faire sentir dans certains pays de l'OCDE.

Il n'est pas nécessairement impossible de trouver des solutions à ces problèmes et, d'autre part, on ne devrait peut-être pas extrapoler indéfiniment dans l'avenir certaines tendances très récentes. Elles ne sont pas non plus, à l'échelon mondial, d'une très grande ampleur. On peut supposer que les pays producteurs de pétrole voudront diversifier raisonnablement leurs portefeuilles entre les pays car il s'agit de capitaux qu'ils doivent investir pour les générations futures. Les règles qui s'appliqueront seront plus ou moins celles que dicte la prudence normale en matière d'investissement : ils voudront diversifier leurs portefeuilles entre avoirs à court et à long terme, et entre investissements en actifs réels, d'une part, et avoirs financiers portant un intérêt fixe, de l'autre.

Toutefois, la répartition de ces avoirs risque de causer des difficultés aux pays d'accueil. Appliquant des règles de prudence, les pays producteurs de pétrole voudront participer aux secteurs les plus avancés dans les économies les plus fortes. Les apports seront suffisamment importants pour risquer de perturber ces dernières.

\section{Solutions possibles:}

Que peuvent faire les pays de l'OCDE pour atténuer ce problème? Il serait tout à fait regrettable de recourir à un contrôle généralisé des mouvements internationaux de capitaux. Le code de l'OCDE s'efforce d'assurer la liberté des flux internationaux des capitaux à long terme en raison du rôle important que joue pour l'augmentation maximale du bien-être la liberté d'investir à l'étranger. Si le principe de base de la liberté économique des mouvements de capitaux devait être en partie sacrifié pour faire face aux capitaux pétroliers, les pays de l'OCDE compromettraient leur faculté d'adapter leurs économies au véritable défi que nous devons relever aujourd'hui : nous devons faire au cours des prochaines années des efforts d'investissement dans les domaines de la production et des économies d'énergie, et dans ceux qui sont susceptibles d'accroître notre capacité d'exportation. On doit être conscient du fait qu'une tentative de résoudre le problème des capitaux pétroliers en recourant surtout à des contrôles reviendrait, en fait, à mettre directement en cause ce code, car, pour être efficaces, les

\section{APPORTS DE FONDS EN PROVENANCE DES PAYS DE L'OPEP EN 1974}

Le tableau ci-dessous montre des estimations préliminaires pour 1974 concernant les apports de fonds en provenance des pays de l'OPEP. On estime actuellement que l'excédent financier extérieur global des pays producteurs de pétrole atteint 50 à 60 milliards de dollars. En raison du décalage dans le temps entre les livraisons de pétrole et les paiements, la répartition de ce total sur l'année a été très irrégulière : environ 19,5 milliards de dollars au premier semestre et plus de 37 milliards de juillet à décembre.

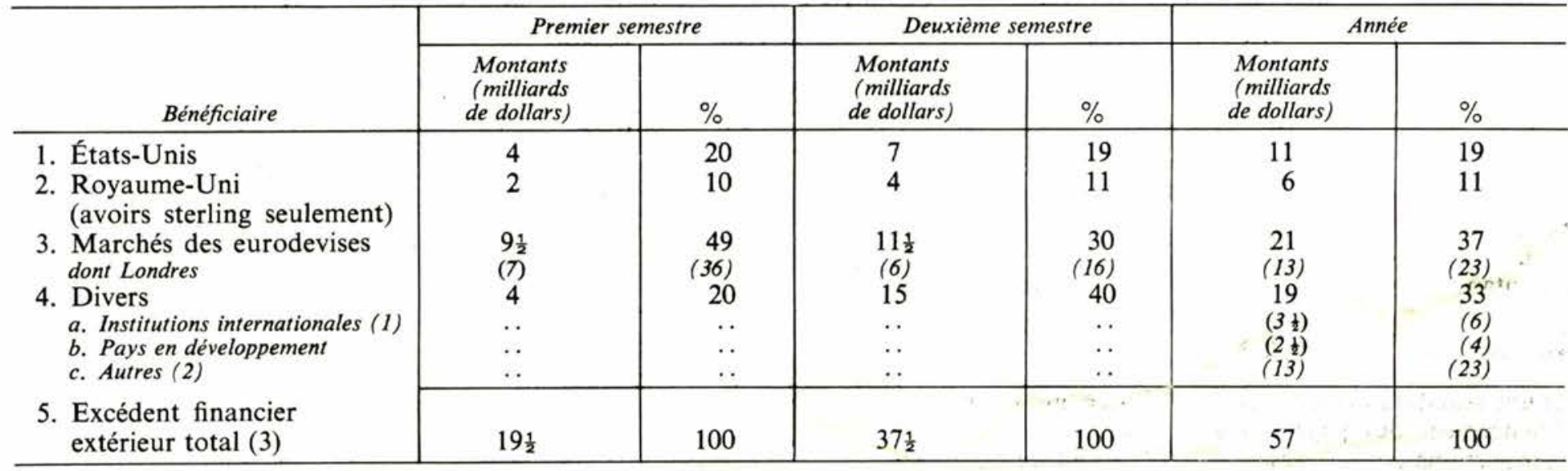

(1) Y compris le mécanisme pétrolier du FMI. (2) Prêts gouvernementaux; investissements directs, acquisitions de titres, biens immobiliers, etc., ailleurs qu'aux États-Unis et au Royaume-Uni; opérations non identifiées. (3) Les estimations concernant l'excédent financier global des pays de l'OPEP gardent un caractère nettement provisoire. Les statistiques préliminaires semblent indiquer que l'excédent global ne s'écartera vraisemblablement pas beaucoup des 55 à 60 milliards de dollars prévus. 
contrôles devraient s'appliquer à tous les mouvements internationaux de capitaux : on ne peut dans la réalité exercer une discrimination contre des capitaux de telle provenance spécifique. Il se peut, cependant, qu'une certaine surveillance ne soit pas inappropriée. Sans appliquer des restrictions aux flux internationaux de capitaux en général, on pourrait mettre en place des mécanismes adéquats destinés à faire face aux investissements dans des secteurs particulièrement sensibles.

\section{- La nécessité de la coopération}

L'évolution récente du marché pétrolier créera selon toute probabilité des difficultés pour les pays pris individuellement, mais il n'est pas raisonnable de penser que les pays, agissant seuls, puissent résoudre ces problèmes : des solutions de coopération internationale sont nécessaires.

Une des choses importantes que doivent faire les pays industrialisés de l'OCDE est de s'assurer que les attitudes de leurs gouvernements à l'égard des entrées de capitaux sont au moins semblables. Sans vouloir rechercher une uniformité des attitudes, qui varient forcément selon les circonstances, il existe certains domaines où il faut prévenir l'apparition de trop grandes discordances dans le traitement que les pays réservent aux capitaux étrangers. Il est souhaitable d'éviter une concurrence nationale indue, visant à attirer les investissements, par un traitement de faveur sur le plan fiscal ou sur celui des dividendes. Il faut en particulier empêcher que les accords bilatéraux dans le domaine des capitaux ne conduisent à une bilatéralisation croissante des échanges commerciaux.

En considérant le problème par l'autre bout, il est souhaitable d'harmoniser quelque peu les mécanismes de surveillance destinés à faire face aux apports d'investissements étrangers. Sans une telle harmonisation, certains pays seront plus vulnérables que d'autres aux investissements étrangers indésirables et aux effets monétaires préjudiciables des entrées de capitaux, le fardeau étant supporté par les pays qui observent le plus scrupuleusement le précepte de la liberté des mouvements internationaux de capitaux. Je voudrais suggérer que les pays de l'OCDE envisagent la possibilité de convenir de certaines lignes directrices communes, ou principes directeurs, en ce qui concerne leurs attitudes à l'égard des flux d'investissements étrangers.

\section{- Initiatives constructives}

Il y a cependant des raisons d'aller bien au-delà de ce genre de coopération à caractère défensif, et de réfléchir en termes d'initiatives plus constructives qui permettraient d'atténuer, d'une manière qui soit profitable tant aux pays producteurs qu'aux pays consommateurs de pétrole, les difficultés que soulève l'absorption de capitaux pétroliers. Peut-être le moment est-il venu de se demander sérieusement, au sein de l'OCDE, s'il n'y a pas place pour un nouvel arrangement institutionnel en coopération avec les gouvernements de l'OPEP. Des suggestions ont été faites, notamment en Allemagne et aux États-Unis, pour établir, sous une forme ou sous une autre, un fonds international d'investissement qui collecterait une partie des capitaux que les producteurs de pétrole souhaitent investir en actifs réels dans la zone OCDE. Le fonds les canaliserait ensuite, à l'aide des compétences techniques qui sont si nombreuses dans notre communauté financière, vers des débouchés qui seraient profitables pour l'investisseur, qui serait peutêtre garar:is contre les risques politiques, mais qui ne soulèveraient pas - sous la forme aiguë que laissent entrevoir certains événements récents - les problèmes de la propriété étrangère.

Des problèmes délicats peuvent se présenter à cet égard, dont celui de la transparence de la propriété. Son ampleur devrait cependant pouvoir être réduite dans la mesure où le mécanisme que l'on envisage est vraiment intergouvernemental. Si la mise en place d'institutions de cet ordre peut aider à résoudre certains problèmes, elle ne peut les résoudre tous. En particulier, dans la mesure où l'institution en question serait gérée selon des critères commerciaux, elle ne limiterait que jusqu'à un certain point la tendance des capitaux à affluer de façon concentrée vers les économies les plus fortes.

Cependant, une formule de ce genre pourrait avoir de nombreux avantages. Elle atténuerait le caractère volatil que peuvent présenter les capitaux pétroliers. Et surtout, elle servirait à forger - ou à renforcer - des liens d'intérêt commun entre pays investisseurs et pays receveurs, exprimant sous une forme tangible le sentiment - déjà formulé par les dirigeants des États producteurs de pétrole - que le sort des exportateurs de pétrole et celui des importateurs est indissolublement lié.

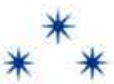

Je crois avoir montré que, bien que les problèmes devant lesquels nous nous trouvons placés soient complexes et graves, ils doivent pouvoir être surmontés si se manifeste une réaction appropriée.

Au niveau national, une grande responsabilité incombe, en premier lieu, aux pays qui connaissent des taux d'inflation élevés et d'importants déficits des balances des paiements courants. Le succès des mesures prises par ces pays pour réduire l'inflation est essentiel, et pas seulement dans leur propre intérêt : une faiblesse persistante compromettrait sérieusement les efforts collectifs destinés à rétablir un meilleur équilibre de l'économie mondiale.

En second lieu, les pays les plus puissants doivent s'assurer qu'il est donné un coup d'arrêt à la présente régression des échanges et de la production dans le monde avant qu'elle n'aille trop loin.

Au niveau international, les pays de l'OCDE ont fait des progrès considérables pour élaborer des positions communes permettant de réagir collectivement là où c'est le plus nécessaire. Les principaux éléments qui sont en place ou qui sont sur le point de l'être sont les suivants :

- défenses supplémentaires contre les restrictions des échanges et des paiements, restrictions qui iraient à l'encontre du but recherché

- arrangements en vue de répartir le pétrole en cas d'urgence

- politiques de coopération visant à encourager les économies d'énergie et un accroissement de la production énergétique

- un nouveau et important mécanisme financier qui doit constituer un filet de sécurité en cas de difficulté grave

et des travaux sont aussi entrepris sur le point suivant :

- réexamen en commun des politiques relatives aux investissements étrangers.

La réaction des pays industrialisés à la nouvelle situation a été au début essentiellement défensive, mais elle se transforme progressivement en une stratégie nettement constructive. C'est ainsi que la voie a été ouverte à la recherche de solutions communes entre pays consommateurs et pays producteurs de pétrole. Ici, se posent deux questions étroitement interdépendantes :

- comment éviter un sur-ajustement important de l'offre et de la demande sur les marchés du pétrole et de l'énergie, ainsi que des fluctuations excessives des prix à moyen terme?

- comment trouver des débouchés sous forme d'investissements pour les capitaux pétroliers excédentaires conciliant le désir de sécurité et de rendement des pays producteurs avec les besoins qu'ont les pays consommateurs de financer le déficit de leurs balances de paiements et de promouvoir des investissements productifs?

Enfin, les pays de l'OCDE et ceux de l'OPEP devraient voir ce qu'il leur est possible de faire pour aider les pays en développement non producteurs de pétrole. Il s'agit non seulement de réduire leurs difficultés, mais également de les faire bénéficier de la redistribution des revenus et de l'accroissement de l'épargne auxquels on assiste aujourd'hui à l'échelon mondial.

Malgré les prévisions pessimistes, la coopération économique internationale a survécu aux tensions de la crise de 1974 et les gouvernements Membres de l'OCDE ont relevé le défi dans un esprit constructif et réaliste. Nous pouvons donc escompter des nouvelles initiatives et une amélioration continue de notre coopération en 1975 . 


\section{COOPERATION INTERNATIONALE: NOUVELLES INITIATIVES}

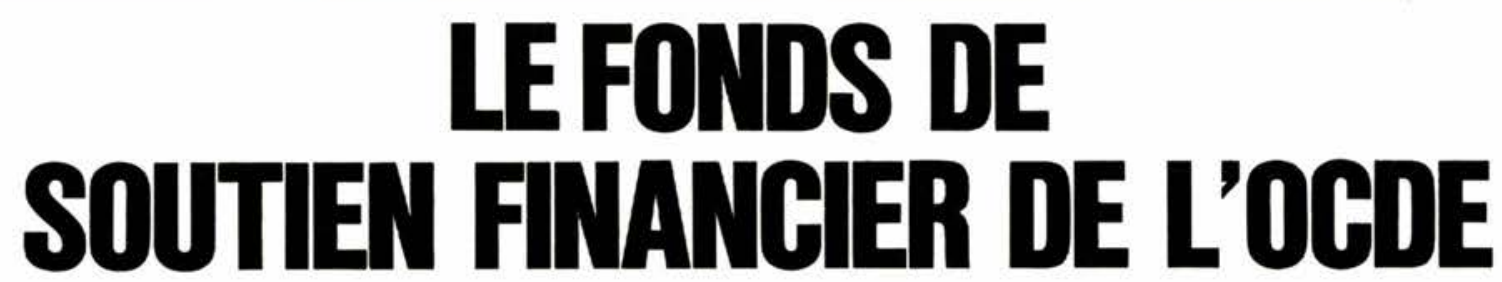

D es ministres et des hauts fonctionnaires de vingt-trois pays Membres de I'OCDE ont signé le 9 avril à Paris, au siège de l'Organisation, un accord sur le Fonds de soutien financier de I'OCDE d'un montant de 25 milliards de dollars.

Président de la réunion ministérielle, le ministre des Finances belge, Willy De Clercq, a présenté le nouvel accord :

"Le Fonds de soutien financier de l'OCDE est important à plusieurs égards et notamment parce qu'il est l'expression de la volonté des pays Membres de rechercher des solutions communes à des problèmes communs. I/s manifestent en effet ainsi leur coopération et leur solidarité face à. la situation économique actuelle qui est l'une des plus difficiles que le monde ait connues depuis la deuxième guerre mondiale.

Nous croyons sincèrement que cette volonté de coopération contribuera à favoriser le dialogue avec les pays producteurs de pétrole et les pays en développement non producteurs de pétrole car la solidarité qui vient de se manifester avec éclat n'est dirigée contre personne. II ne s'agit pas d'un instrument de confrontation mais au contraire d'un moyen d'encourager la solidarité internationale.

Une plus grande cohésion entre pays industrialisés est bénéfique non seulement à ces pays eux-mêmes mais au monde tout entier. Si cet accord nous permet de diminuer l'instabilité économique et d'éviter le cercle vicieux restrictions/récession, l'écono- mie mondiale dans sa totalité en profitera : les pays en développement aussi bien que les pays développés.

L'accord est essentiellement un mécanisme qui ne pourra être utilisé qu'après ceux qui existent déjà. Après la crise des années trente, de nombreux pays ont reconnu qu'il n'était pas acceptable de laisser s'effondrer des intermédiaires financiers souffrant de problèmes de liquidité. Aussi la plupart des pays ont-ils créé au niveau national un prêteur de dernier ressort. Nous avons aujourd'hui transposé certaines de ces idées au niveau international. Le fait même que ce fonds existe devrait renforcer la confiance et nous permettre d'espérer que, en fait, nous n'aurons jamais à nous en servir."

$$
\text { * }
$$

Dans sa réponse au ministre des Finances belge, le Secrétaire général de l'OCDE a souligné que la portée de l'accord est double : il est important en lui-même en raison du mécanisme financier qu'il met en place; il est également important comme une maille supplémentaire de la réaction commune que l'on constate depuis environ quinze mois à des problèmes économiques entièrement nouveaux.

L'accord a été préparé par un Groupe de travail ad hoc du Conseil de I'OCDE sous la présidence de Jacques van Ypersele de Strihou (Belgique). Le rapport que nous publions ci-après résume les principaux points de l'accord.

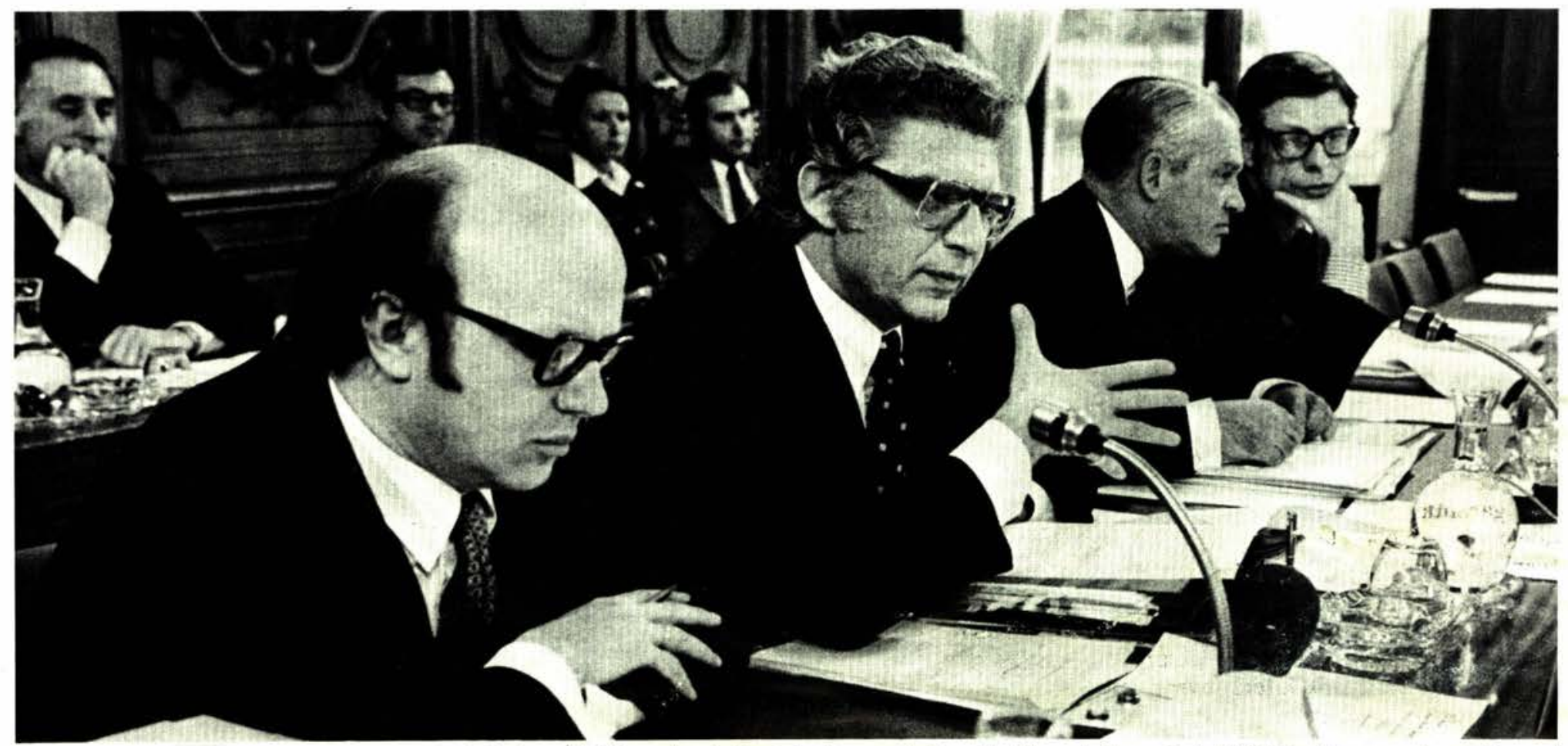

De gauche à droite : Jacques van Ypersele de Strihou (Belgique), président du Groupe de travail ad hoc du Conseil de l'OCDE créé pour préparer l'accord du Fonds de soutien financier; Willy De Clercq, ministre belge des Finances et président de la réunion; Emile van Lennep. Secrétaire général de l'OCDE; Stephen Marris, conseiller économique auprès du Secrétaire général. 


\section{COOPERATION INTERNATIONALE: NOUVELLES PRINCIPALES DISPOSTIIONS DE L'ACCORD PORTANT CREATION
D'UN FONDS DE SOUTIEN FINANGIER DE L'OCDE}

Participation

Le Fonds de Soutien Financier doit être institué dans le cadre de I'OCDE. II sera ouvert à la participation de tous les pays de I'OCDE. Les membres fondateurs pourront signer l'Accord entre le 9 avril et le 31 mai 1975.

\section{Les objectifs et la nature du Fonds}

Le Fonds a pour principaux objectifs d'encourager et d'aider ses membres :

- à éviter des mesures unilatérales qui restreindraient les échanges commerciaux internationaux ou stimuleraient artificiellement les exportations:

- à suivre des politiques économiques appropriées, intérieures et extérieures, notamment des politiques adaptées de balance des paiements et des politiques de coopération visant à favoriser l'accroissement de la production et les économies d'énergie.

Le Fonds fournira un cadre dans lequel ses membres renforceront leur coopération économique et s'assureront mutuellement une aide financière. Un élément essentiel est que les risques afférents aux prêts accordés par le Fonds seront partagés entre tous les membres en proportion de leurs quotes-parts et dans les limites de celles-ci, quel que soit le mode de financement des prêts.

Le Fonds a pour objet d'aider à surmonter les difficultés inhérentes à la situation économique actuelle. II possède le pouvoir, établi pour une période de deux ans à compter de l'entrée en vigueur de I'Accord, d'accorder des prêts, dans des cas exceptionnels, pour compléter les autres sources de crédit auxquelles les membres rencontrant de sérieuses difficultés économiques auront eu recours. II constituera ainsi en quelque sorte un "filet de sécurité " à utiliser en dernier ressort. Avant de faire appel au Fonds, un membre devra :

- avoir fait l'usage approprié le plus large de ses réserves:

- avoir fait de son mieux pour obtenir des capitaux à des conditions raisonnables en provenance d'autres sources;

- avoir fait l'usage approprié le plus large d'autres mécanismes de financement multilatéraux, tels que ceux du FMI et de la CEE (en ce qui concerne les membres de la CEE).

Cela ne signifie pas, toutefois, qu'avant de recourir au Fonds, un membre devra avoir épuisé ces autres ressources.

\section{Quotes-parts}

Les membres auront des quotes-parts qui détermineront : - leur part dans les risques afférents aux prêts,

- leurs droits de vote et,

- leur responsabilité financière maximale envers le Fonds, et qui serviront de base pour déterminer

- leur part dans le financement des prêts, et

- le montant qu'ils peuvent emprunter au Fonds.

Le montant total des quotes-parts est de 20 milliards de Droits de Tirage Spéciaux (DTS), soit environ 25 milliards de dollars des Etats-Unis. La répartition des quotes-parts (voir tabieau) est fondée sur une formule donnant un poids à peu près égal au PNB des pays et à leur commerce extérieur, avec certains ajustements (dáns le cas, notamment, des pays dont le volume du commerce extérieur est exceptionnement important par rapport à leur PNB, il a été tenu compte de ce facteur qui, sinon, aurait abouti à une quote-part trop élevée).
Prêts

\section{- Conditions à remplir par les emprunteurs}

Un pays qui demande un prêt devra apporter la preuve :

- qu'il rencontre de sérieuses difficultés financières extérieures :

- qu'il a fait l'usage approprié le plus large d'autres ressources (spécifiées ci-dessus);

- que ses politiques économiques sont compatibles avec les objectifs du Fonds et comprennent les mesures nécessaires pour redresser sa situation fiancière extérieure.

L'emprunteur s'engagera à mettre en œuvre les politiques requises pour redresser, sur une période de temps appropriée, sa situation financière extérieure et pour réaliser les objectifs du Fonds. Ses politiques économiques, ainsi que la réalisation des conditions auxquelles l'octroi du prêt est subordonné, seront régulièrement examinées.

\section{- Décision relative à l'octroi et au financement d'un prêt}

L'octroi d'un prêt fera l'objet d'une seule décision couvrant l'ensemble des points suivants :

- la réunion par l'emprunteur des conditions d'obtention d'un prêt ;

- les conditions relatives aux politiques économiques de l'emprunteur:

- le montant et la durée du prêt ;

- la méthode de financement du prêt;

- les éléments à partir desquels sont déterminés les taux d'intérêt, payables aux membres qui assurent un financement direct et applicables aux fonds prêtés à l'emprunteur.

Les modalités précises du financement et la date ou les dates de transfert des fonds seront spécifiées dans le texte définitif de l'accord de prêt entre le Fonds et l'emprunteur.

La décision devra être prise à la majorité des deux-tiers si, compte tenu du prêt, l'encours des emprunts du membre en cause ne dépasse pas sa quote-part, à la majorité de $90 \%$ si l'encours de ses emprunts dépasse sa quote-part sans excéder $200 \%$ de celle-ci, et à l'unanimité si l'encours de ses emprunts dépasse $200 \%$ de sa quote-part. Ces majorités doivent être réunies en ce qui concerne, d'une part, l'ensemble des membres du Fonds, à l'exception de l'emprunteur éventuel, et, d'autre part, les membres appelés à assurer le financement du prêt (1). Ces majorités doivent comprendre la moitié au moins des membres du Fonds.

\section{- Durée et taux d'intérêt}

Les prêts seront remboursables dans un délai n'excédant pas sept ans. Le taux d'intérêt payable sur les prêts sera déterminé en fonction des conditions prévalant au moment considéré, en tenant compte du taux d'intérêt payé par le Fonds sur les ressources destinées à financer le prêt en cause, et ne pourra être inférieur à ce dernier taux.

\section{- Remboursement anticipé des prêts}

Si la situation de balance des paiements d'un emprunteur s'est

(1) Des membres peuvent, pour des raisons de balance des paiements, être exemptés des appels adressés pour assurer un type de financement (voir ci-après). 
substantiellement améliorée, il pourra être requis, par une décision prise à la majorité des deux-tiers, compte non tenu de ses propres voix, de rembourser par anticipation tout ou partie de son prêt. Un emprunteur pourra aussi faire des remboursements anticipés de son propre gré, à condition que le remboursement anticipé du financement correspondant assuré au Fonds puisse être accepté par les prêteurs.

\section{Les deux principales méthodes de financement des prêts du Fonds}

Les prêts du Fonds pourront être financés selon deux principales méthodes :

- premièrement, par engagements individuels au titre desquels chaque membre auquel un appel a été adressé assure un financement direct (c'est-à-dire effectue un transfert de fonds), ou donne une garantie individuelle pour un emprunt du Fonds sur les marchés de capitaux (c'est-à-dire qu'il s'engage à transférer des ressources au Fonds pour couvrir le Fonds au cas où

\section{QUOTES-PARTS}

\begin{tabular}{|c|c|c|}
\hline Pays & $\begin{array}{c}\text { En pourcen- } \\
\text { tage du } \\
\text { total des } \\
\text { quotes-parts }\end{array}$ & $\begin{array}{c}\text { Montants } \\
\text { exprimés } \\
\text { en DTS } \\
\text { (millions) }\end{array}$ \\
\hline $\begin{array}{l}\text { République } \\
\text { Fédérale d'Allemagne }\end{array}$ & 12,5 & 2500 \\
\hline Australie & 1,5 & 300 \\
\hline Autriche & 1,0 & 200 \\
\hline Belgique & 2,4 & 480 \\
\hline Canada & 4,2 & 840 \\
\hline Danemark & 1,2 & 240 \\
\hline Espagne & 2,5 & 500 \\
\hline Etats-Unis & 27,8 & 5560 \\
\hline Finlande & 0,8 & 160 \\
\hline France & 8,5 & 1700 \\
\hline Grèce & 0,6 & 120 \\
\hline Irlande & 0,6 & 120 \\
\hline Islande & 0,1 & 20 \\
\hline Italie & 7,0 & 1400 \\
\hline Japon & 11,7 & 2340 \\
\hline Luxembourg & 0,1 & 20 \\
\hline Norvège & 1,0 & 200 \\
\hline Nouvelle-Zélande & 0,8 & 160 \\
\hline Pays-Bas & 3,0 & 600 \\
\hline Portugal & 0,6 & 120 \\
\hline Royaume-Uni & 8,0 & 1600 \\
\hline Suède & 1,5 & 300 \\
\hline Suisse & 2,0 & 400 \\
\hline Turquie & 0,6 & 120 \\
\hline Total & 100,0 & 20000 \\
\hline
\end{tabular}

le prêt qui est financé ne serait pas remboursé à la date d'échéance) :

- deuxièmement, par des emprunts du Fonds sur les marchés de capitaux, assortis d'une garantie collective de tous les membres (c'est-à-dire un engagement pris collectivement par tous les membres de transférer des ressources au Fonds pour couvrir le Fonds au cas où le prêt ne serait pas remboursé à la date d'échéance)

Les appels adressés pour assurer un financement seront proportionnels aux quotes-parts des membres auxquels l'appel est adressé, à moins qu'un membre n'accepte de fournir des ressources pour un montant dépassant cette proportion (mais qui ne devra pas excéder le montant non appelé de sa quotepart). Tous les transferts effectués au Fonds à la suite d'appels à assurer un financement devront l'être dans une monnaie effectivement convertible.

\section{Première méthode : engagements individuels}

Selon cette méthode, chaque membre peut, à son choix, fournir sa part, soit en procédant à un transfert de fonds immédiat, appelé financement direct, soit en donnant une garantie individuelle, sur la base de laquelle le Fonds pourra emprunter sur les marchés intérieurs ou internationaux de capitaux.

\section{- Non-participation aux appels à assurer un financement}

Selon cette méthode, l'emprunteur sera exclu des appels adressés pour assurer le financement, et des dispositions spéciales prévoient que d'autres membres pourront être exemptés des appels, en raison de la situation actuelle ou prévisible de leur balance des paiements. La non-participation à des appels sera décidée à la majorité des deux-tiers, avant la décision relative à l'octroi d'un prêt et à son financement dont il a été question ci-dessus. La majorité devra comprendre la moitié au moins des membres.

\section{- Financement direct}

Un membre qui assure un financement direct transférera des ressources au Fonds dans une monnaie effectivement convertible qu'il se sera procurée selon la méthode de son choix. II pourra, par exemple, faire des prélèvements sur ses réserves, ou bien sa banque centrale pourra présenter une demande de crédit à la Banque des Règlements Internationaux (BRI), ou encore il pourra emprunter à d'autres sources. Si sa balance des paiements devait ultérieurement se détériorer, un membre pourra mobiliser sa créance au titre d'un financement direct (voir ci-après).

\section{- Garanties individuelles}

Si un membre choisit de donner une garantie individuelle en réponse à un appel pour un financement par engagements individuels, le Fonds cherchera à se procurer les montants requis sur les marchés internationaux ou intérieurs de capitaux, en tenant dûment compte des conditions du marché et d'autres facteurs à prendre en considération. (Les conditions générales à remplir pour ces emprunts sont spécifiées ci-après.) Si le Fonds n'arrive pas à se procurer les ressources nécessaires dans un délai raisonnable et à des conditions relativement comparables à celles que peut obtenir un emprunteur de bon renom, ou à des conditions par ailleurs acceptables par le Fonds, le membre qui offre la garantie individuelle autorisera le Fonds à emprunter, après consultation entre le Fonds et ledit membre, dans la monnaie de ce membre (le montant en cause devant être convertible) et 
sur son marché intérieur de capitaux, y compris auprès d'institutions publiques, à concurrence du montant couvert par sa garantie.

En donnant une garantie individuelle, un membre s'engage à couvrir les obligations du Fonds envers des prêteurs. La garantie individuelle couvrira, en plus du montant emprunté par le Fonds sous cette garantie, une provision pour le paiement des intérêts et autres frais afférents à cet emprunt. Cette provision impliquera un prélèvement sur la quote-part du membre, s'ajoutant à sa participation au financement; et, pour des raisons d'équité, les quotes-parts de tous les autres membres participant au financement feront l'objet d'un prélèvement additionnel, représentant la même proportion de la part de chaque membre dans le financement (de sorte que leur responsabilité eu égard aux financements ultérieurs soit réduite dans les mêmes proportions).

\section{Deuxième méthode : emprunts par le Fonds sur la base d'une garantie collective}

Selon cette méthode de financement, le Fonds empruntera sur les marchés de capitaux sur la base d'une garantie collective donnée par tous les membres. S'il est décidé de financer un prêt de cette manière, aucun membre ne sera exempté de participer à la garantie collective.

La participation d'un membre à une garantie collective signifie qu'à concurrence de sa part dans cette garantie, ledit membre couvre les obligations du Fonds envers des prêteurs. Outre qu'il garantit qu'il fournira au Fonds, si nécessaire, un montant égal à sa part dans le montant total emprunté par le Fonds, ledit membre garantira deux autres montants : sa part dans une provision pour le paiement des intérêts et autres frais, et sa part de responsabilité couvrant les garanties des autres membres en cas de défaut. Cette responsabilité représentera un pourcentage uniforme, pouvant atteindre $50 \%$ au maximum, de la part de chaque membre dans le montant emprunté par le Fonds et dans la provision pour le paiement des intérêts et autres frais. A mesure que des remboursements de principal seront effectués par le Fonds sur ses emprunts, la provision et la responsabilité seront réduites proportionnellement.

\section{Souplesse des formules de financement du Fonds}

Le Fonds peut accorder à l'un quelconque de ces membres une aide financière relativement substantielle en cas de besoin - les emprunts dépassant la quote-part devant faire l'objet d'une décision prise à la majorité de $90 \%$ ou à l'unanimité mais n'étant pas soumis à une limite quantitative.

Les diverses formules de financement permettent à chaque membre de choisir, pour réunir les ressources qu'il a à fournir, la méthode qui convient le mieux à sa situation financière et à ses procédures légales intérieures. Ces formules ont aussi une souplesse suffisante pour permettre au Fonds d'adapter ses méthodes de financement à la situation économique du moment. Si quelques membres éprouvent des difficultés financières extérieures, alors que les autres sont en mesure de réunir des ressources suffisantes à des conditions raisonnables, un financement sous forme essentiellement d'engagements individuels sera peutêtre la meilleure solution. Si, au contraire, quelques pays ont une forte position financière et que les autres éprouvent des difficultés, il pourrait être préférable que le Fonds obtienne le financement en empruntant, sous une garantie collective, sur les marchés de capitaux des pays ayant une forte position financière (ou qu'il l'obtienne indirectement de ces pays en empruntant sur les marchés internationaux).
Le placement d'un emprunt important sur les marchés de capitaux demande du temps et il pourra être nécessaire d'attendre que les conditions s'y prêtent. Si, par conséquent, il y a lieu de fournir une aide financière substantielle sans délai, la meilleure formule pourrait être d'adresser, dans un premier temps, des appels pour assurer un financement par engagements individuels et, à un stade ultérieur, de remplacer ce financement par un emprunt sous garantie collective. L'Accord contient des dispositions qui permettent au Fonds de procéder de la sorte.

Les possibilités d'assurer, au stade initial, un financement par engagements individuels, seront considérablement renforcées par les facilités offertes par la Banque des Règlements Internationaux (BRI). La Banque pourra accorder des crédits aux Banques centrales des membres appelés à fournir le financement direct et, sous certaines conditions, elle pourra accorder des prêts au Fonds en liaison avec le financement fondé sur les garanties individuelles.

\section{Mobilisation de la créance d'un membre résultant d'un financement direct}

Si la situation de balance des paiements d'un membre qui a assuré un financement direct se détériore, il pourra mobiliser tout ou partie de sa créance sur le Fonds. A cet effet il pourra demander un prêt au Fonds, à condition qu'il ait d'abord cherché à obtenir qu'un ou plusieurs autres membres acceptent de reprendre sa créance ou à obtenir un financement par la voie d'un crédit accordé par la BRI à sa Banque Centrale. L'octroi d'un tel prêt devra faire l'objet d'une décision prise à la majorité des deuxtiers, confirmant que la demande du membre est justifiée par la situation de sa balance des paiements et prévoyant des dispositions pour assurer le financement du prêt. Cette majorité devra comprendre la moitié au moins des membres.

\section{Conditions générales relatives aux emprunts du Fonds sur les marchés de capitaux}

Les emprunts du Fonds seront effectués sur le territoire des membres. Ils pourront l'être sur les marchés intérieurs de capitaux, y compris auprès d'institutions publiques, ou sur les marchés internationaux de capitaux, ou auprès d'institutions internationales. Le Fonds tiendra dûment compte des conditions du marché et de tout autre facteur à prendre en considération. Tout projet d'emprunt du Fonds sur les marchés de capitaux internationaux sera examiné favorablement par le membre sur le territoire duquel l'emprunt doit être effectué. Avant d'emprunter sur le marché intérieur d'un membre, le Fonds devra avoir obtenu l'autorisation dudit membre et avant d'emprunter sur les marchés internationaux de capitaux, il devra avoir obtenu, si requête lui en a été faite, l'autorisation du membre dans la monnaie duquel l'emprunt doit être libellé. Sous réserve de ces conditions, les membres feront de leur mieux pour que les institutions financières situées sur leur territoire soient habilitées à acheter des titres émis par le Fonds.

\section{Organisation et gestion}

Le Fonds aura ses propres organes de décision et de gestion. Les décisions seront prises par le Comité de Direction, dans lequel tous les membres du Fonds seront représentés par de hauts fonctionnaires financiers. II y aura également un Conseil Consultatif composé de fonctionnaires financiers désignés par les membres et agissant en qualité d'experts. Le nombre des membres du Conseil Consultatif, qui ne devra pas dépasser la 
moitié du nombre des membres du Fonds, sera fixé par le Comité de Direction. Le Conseil Consultatif préparera les travaux du Comité de Direction avec le concours du Secrétariat. Le Secrétariat de I'OCDE assurera le secrétariat du Fonds.

Un représentant de la Commission des Communautés Européennes participera aux réunions du Comité de Direction et du Conseil Consultatif. Le Comité de Direction prendra des dispositions appropriées pour assurer la liaison avec le Fonds Monétaire International et la Banque des Règlements Internationaux et la participation de représentants de ces institutions aux réunions du Comité de Direction et du Conseil Consultatif. II est prévu que le Fonds passera avec la BRI un accord aux termes duquel la Banque jouera le rôle d'Agent du Fonds pour les tâches administratives et pour les dispositions techniques concernant les emprunts du Fonds sur les marchés de capitaux.

Tous les coûts afférents aux opérations du Fonds seront couverts au moyen des sommes reçues par lui en paiement d'intérêts ou d'autres charges, y compris les commissions de service, et dont il n'aura pas besoin pour effectuer des paiements aux prêteurs. Le Fonds aura une personnalité juridique distincte et jouira des privilèges et immunités nécessaires pour ses transactions.

\section{Libellé des créances et obligations du Fonds}

Les obligations du Fonds au titre d'un financement direct seront libellées soit en DTS, soit dans la monnaie transférée au Fonds par le membre assurant ledit financement, au choix de ce dernier. En cas de garanties individuelles et collectives, les obligations du Fonds et les garanties seront libellées soit en DTS, soit dans la monnaie ou les monnaies empruntées par le Fonds, selon la décision de ce dernier. Les prêts accordés par le Fonds seront libellés dans la même unité que les fractions correspondantes du financement.

\section{Partage des risques}

Dans le cas extrêmement improbable où un emprunteur serait dans l'impossibilité d'effectuer un paiement à la date d'échéance, le Fonds obtiendra le montant nécessaire pour s'acquitter de ses obligations envers des prêteurs résultant de ses emprunts sur les marchés de capitaux, en appelant les garants à fournir des fonds et en prélevant sur son compte de recettes et dépenses. II remplira ensuite ses obligations (découlant de financements directs ou de transferts'au titre de garanties) envers les membres ayant financé le prêt considéré, en adressant des appels à tous les membres, y compris les emprunteurs et ceux qui avaient été exemptés des appels à assurer le financement, le partage entre tous les membres des risques afférents à ses prêts étant une caractéristique essentielle du Fonds. Ce partage multilatéral des risques sera fondé sur les obligations et créances calculées comme si elles avaient été libellées en DTS. Les sommes correspondant aux différences entre les montants calculés de cette manière et les montants tels qu'ils sont libellés en monnaie seront reportées pour être remboursées à la suite des paiements ultérieurs de l'emprunteur, ou réglées à la liquidation à titre bilatéral entre l'emprunteur et les membres intéressés.

\section{Interprétation et amendement}

Toute question d'interprétation des dispositions de l'Accord soulevée entre un membre et le Fonds, ou entre membres du Fonds, sera soumise à un comité ad hoc de trois experts désignés par le Comité de Direction sur proposition de son Président. Sauf s'il en décide autrement par un vote à la majorité des voix (majorité qui doit comprendre la moitié au moins des membres), le Comité de Direction fera sienne l'opinion de la majorité des membres du comité ad hoc.

Des amendements à l'Accord peuvent être proposés par décision unanime des membres du Comité de Direction et, dans la mesure où l'exigent leurs procédures constitutionnelles, ils seront soumis à la ratification des pays Membres.

\section{Liquidation}

Le Fonds sera maintenu en existence jusqu'à ce qu'il se soit acquitté de toutes ses obligations envers des tiers et que le dernier remboursement de tout prêt accordé par lui soit venu à échéance. A cette date, le Fonds sera liquidé à moins que le Comité de Direction n'en décide autrement à une majorité de $70 \%$. Aux termes des dispositions relatives à la liquidation, tout élément d'actif et tout engagement restants du Fonds seront convertis en créances et dettes bilatérales.

\section{Entrée en vigueur de l'Accord}

Lorsque des pays représentant au moins $90 \%$ des quotes-parts auront déposé des instruments de ratification, l'Accord entrera en vigueur entre ces pays. En outre, si quinze pays au moins représentant au moins $60 \%$ des quotes-parts ont déposé un tel instrument, ils peuvent faire entrer l'Accord en vigueur entre eux.

\section{ENERGIE: ECONOMIES ET DEVELOPPEMENT DE SOURCES DE SUBSTITUTION}

'Agence internationale de l'énergie (1) a fait d'importants progrès sur plusieurs fronts pour mener à bien un programme de coopération à long terme destiné à réduire la dépendance des pays membres à l'égard du pétrole importé.

\section{Economies d'énergie}

Le Comité directeur de l'Agence a fixé, pour la fin de 1975, comme objectif une réduction de 2 millions de barils par jour sur l'ensemble des importations de pétrole opéré par les membres du groupe. Cela correspond à une diminution d'environ $10 \%$ par rapport à ce qu'elles auraient été sans, entre autres choses,

(1). Deux houvealix pays se sont joints à l'AIE : la NouvelleZélande qui est devenue membre le 21 mars et la Norvège qui participe aux travaux de l'Agence dans les conditions fixées par un accord daté du 7 février. Celui-ci spécifie qu'en cas d'urgence, impliquant une pénurie de pétrole sérieuse, le gouvernement norvégien doit, après en avoir ainsi décidé, contribuer à un programme de partage. 
.les mesures d'économies d'énergie qui sont déjà entrées en vigueur ou qui vont l'être au cours de l'année. Résultat : le niveau des importations en 1975 ne sera pas plus élevé que celui de 1973, à savoir d'environ 22 millions de barils par jour. Par rapport aux projections faites avant la hausse du prix du pétrole, il s'agit d'une diminution de quelque 6 millions de barils par jour.

Cet objectif est fondé sur un rassemblement d'estimations nationales. La même méthode ne sera pas nécessairement utilisée pour établir les objectifs d'économies d'énergie pour 1976 et 1977, tâche à laquelle s'emploient actuellement les experts de I'Agence.

Le renchérissement de l'énergie a incité la plupart des gouver-
Bien des pays donnent d'autre part des subventions ou autorisent des déductions fiscales pour les industries qui font des investissements destinés à économiser l'énergie. Pour réduire spécifiquement les importations de pétrole, certains pays adaptent leurs centrales électriques de manière à pouvoir les alimenter au charbon. La production combinée d'électricité et de chaleur fait souvent partie des projets à long terme.

\section{Développement de sources d'énergie de substitution}

Le principe adopté par le Comité directeur dans ce domaine prévoit trois dispositions de coopération interdépendantes :

- encouragement et garantie des investissements dans les

\section{PERSPECTIVES ÉNERGÉTIQUES pour les membres de l'Agence internationale de l'énergie de I'OCDE}

\begin{tabular}{l|c|c|c}
\hline & \multicolumn{1}{|c|}{1973} & $\begin{array}{c}1975 \\
\text { (estimation) } \\
\text { millions de barrils par jour }\end{array}$ & $\begin{array}{c}\text { variation } \\
\%\end{array}$ \\
\hline $\begin{array}{l}\text { Besoins totaux } \\
\text { d'énergie primaire } \\
\begin{array}{l}\text { Consommation } \\
\text { de pétrole }\end{array}\end{array}$ & 65,5 & 66,9 & $+2,1$ \\
$\begin{array}{l}\text { Importations } \\
\text { de pétrole }\end{array}$ & 35,0 & 34,6 & $-1,1$ \\
\hline
\end{tabular}

- Sauf la Nouvelle-Zélande et la Norvège.

nements à trouver des moyens susceptibles de faire baisser la consommation. Les décisions que vient de prendre l'Agence devraient encourager ceux qui en sont membres à intensifier leurs efforts. Les voies qu'ils empruntent pour y parvenir sont variées, allant de campagnes de propagande et d'information aux mesures autoritaires en passant par de simples recommandations.

L'augmentation du prix du pétrole a partout été accompagnée par une hausse des autres formes d'énergie et, dans certains pays, par la suppression ou la réduction de subventions ou par l'augmentation des taxes. Certains pays, comme l'Irlande, par exemple, ont repensé leurs systèmes de tarification, de manière à décourager les utilisateurs de consommer davantage à certaines heures. Un pays, l'Espagne, a pris une décision intéressante : toute consommation de fuel supérieure à $80 \%$ (pour le chauffage domestique) ou à $90 \%$ (pour l'industrie) du niveau de 1973 est sujette à une surtaxe de $25 \%$.

Les normes de température et d'éclairage sont en général limitées au secteur public. Elles sont cependant accompagnées par des campagnes d'information destinées à inciter les consommateurs privés à suivre l'exemple donné et de se contenter de températures plus basses. Dans ce contexte, des subventions ou des possibilités de déductions fiscales pour des améliorations apportées à l'isolation thermique sont très fréquentes.

Dans le secteur des transports, en dehors de l'effet dissuasif de a hausse des prix do l'essence, c'est l'arme de la limitation de la vitesse gui es' a plus souvent utilisée pour freiner la consommation. Ceris as pays ont par ailleurs introduit, même avant la crise ds iénergie, un c müdulation des taxes sur les automobiles en foncion de la taille (taxe annuelle ou TVA sur les voitures neuves). Mais ces dispositions sont encore loin d'être la règle.

\section{LE COMITE DE L'INVESTISSEMENT}

D our renforcer la coopération dans les domaines liés à l'investissement international et aux activités des entreprises multinationales un nouveau comité a été créé au sein de I'OCDE. II a pour objet de faire progresser les travaux dans ces deux domaines d'une manière généralement équilibrée. Deux types de sujets seront examinés :

\section{- Comment traiter les questions soulevées par les entreprises multinationales?}

Le Comité va plus spécifiquement étudier les moyens de promouvoir l'échange de renseignements et d'améliorer et d'harmoniser les statistiques nationales concernant ces firmes. II essaiera également de développer des règles de conduite uniformes applicables aux entreprises et des procédures intergouvernementales d'examen des plaintes éventuelles.

\section{- Questions concernant l'investissement internatio- nal}

Le Code de libération des mouvements de capitaux a été élaboré par I'OCDE dans les années soixante comme un moyen de libérer de tels flux de capitaux à une époque où de nombreuses restrictions s'y opposaient. Le Comité s'interrogera pour savoir s'il est possible de compléter ce Code par des principes assurant des traitements nationaux plus équitables d'entreprises sous contrôle étranger.

Un gouvernement peut se sentir obligé, dans certaines circonstances, de stimuler ou de décourager les investissements internationaux qu'il s'agisse d'investissements faits par ses propres ressortissants ou par des étrangers sur son territoire. Le problème est d'éviter que de telles mesures ne faussent les relations économiques internationales ou ne nuisent à d'autres économies nationales.

On assistera peut-être également au développement de nouveaux schémas d'investissements internationaux à cause de l'important afflux, en provenance de l'extérieur, vers les pays de l'OCDE. C'est pourquoi il pourra devenir nécessaire de prendre des mesures pour reconcilier des exigences nationales spécifiques avec le principe de la libération des mouvements de capitaux.

\section{米}

Lors de la première réunion de travail du nouveau Comité, le Secrétaire général de l'OCDE, Emile van Lennep, a attiré l'attention sur quelques-uns des principaux domaines où les problèmes se font sentir. 
sources d'énergie de substitution conventionnelles (fossiles, hydro-électrique et nucléaire). Cela implique la fixation d'un niveau de prix commun de protection au-dessous duquel le pétrole importé ne pourra être vendu sur les marchés nationaux.

Chaque pays choisira ses moyens propres pour s'assurer que le prix du pétrole importé ne descend pas au-dessous de ce niveau minimum qui doit encore être fixé.

- établissement d'un cadre général de coopération dont l'objectif est de fournir une aide, projet par projet, au développement des énergies de substitution

- mise en œuvre de projets de recherche en trois domaines

- récupération de la chaleur résiduelle

- utilisation des déchets industriels et municipaux

— production d'hydrogène à partir de l'eau.
Les membres de l'Agence se sont par ailleurs mis d'accord sur l'intérêt prioritaire que représentent trois autres programmes de R \& D : la technologie du charbon, la sécurité des installations nucléaires et la gestion des déchets radioactifs. Les membres envisagent de poursuivre très rapidement la coopération dans ces trois domaines et également dans ceux de la fusion thermonucléaire, des économies d'énergie et de l'énergie solaire.

Après avoir conclu cet accord de principe, le Comité directeur doit prendre la décision de mise en application, conformément aux dispositions du Programme international de l'énergie. Le système qui sera alors adopté tiendra compte d'un côté d'éventuels ajustements d'ordre technique jugés nécessaires par les groupes de travail, de l'autre de l'évolution des relations entre consommateurs et producteurs de pétrole.

\section{NTERNATIONAL ET DES ENTREPRISES MULTINATIONALES DE L'OCDE}

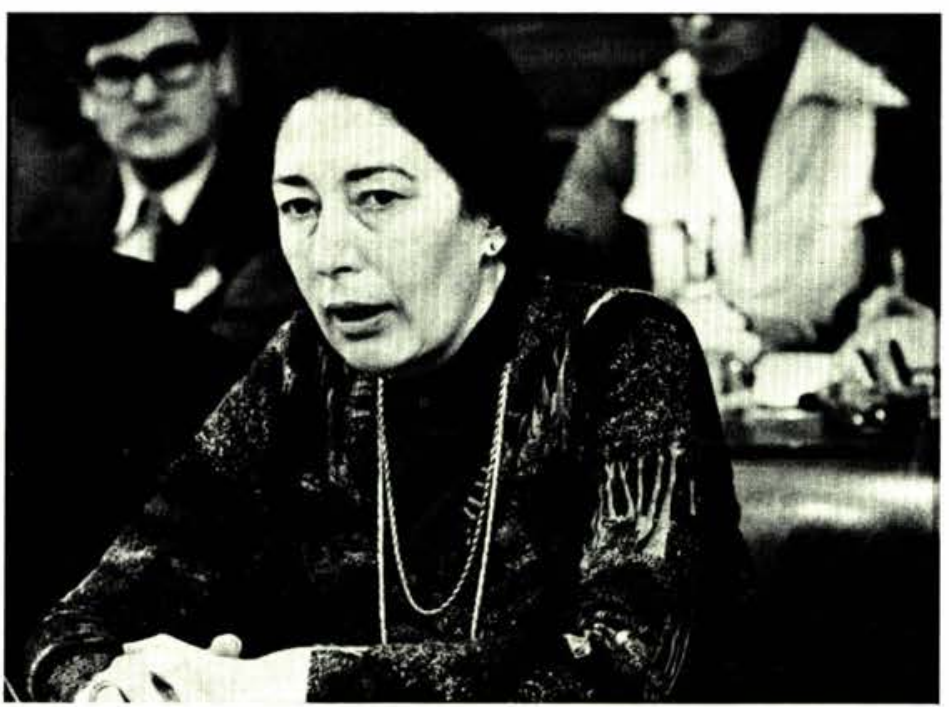

Le président du nouveau Comité : Helga Steeg, directeur au ministère de l'Économie, Allemagne.

Les entreprises multinationales ont fait l'objet, ces dernières années, de nombreux commentaires mais la discussion a souvent été passionnelle et gênée par un manque de renseignements qualitatifs et quantitatifs ou par une absence d'accord sur la vraie nature politique du problème.

Certains regrettent l'avènement d'entreprises multinationales et l'engagement croissant du monde des affaires à l'étranger : ils considèrent que cet état de fait est de nature à porter atteinte à certains éléments de la souveraineté nationale. D'autres ont salué les entreprises multinationales comme susceptibles de contribuer à l'établissement d'un type de relations économiques internationales caractérisé par une distribution des ressources optimale.

II ne faut certainement pas perdre de vue la contribution positive faite par les entreprises multinationales au bien-être des pays où elles se sont implantées et dans ceux où elles ont leur siège. Cependant, l'augmentation rapide depuis une dizaine d'années du nombre, de la taille, et de l'envergure de ces firmes et également l'antinomie qui peut exister entre leurs structures transnationales et le caractère national des gouvernements ont créé des inquiétudes.

Comment traiter ces problèmes? Le besoin d'établir un meilleur échange de renseignements quantitatifs et qualitatifs est tout d'abord très net. Cet échange devrait cependant assez rapidement se traduire par des recommandations d'agir.
Pour réduire les tensions qui existent entre les entreprises multinationales et la souveraineté nationale l'on peut envisager deux approches. Premièrement, les entreprises multinationales peuvent se mettre d'accord elles-mêmes sans une quelconque intervention gouvernementale sur un certain nombre de principes de conduite et s'employer à les faire respecter. Deuxièmement, les gouvernements peuvent établir des règles de conduite applicables aux entreprises, nécessairement sur une base régionale, des principes directeurs qui pourraient servir de base pour l'action gouvernementale et également, comme il convient, des procédures de consultation intergouvernementales. Celles-ci constitueraient des étapes d'un processus continu destiné à harmoniser les lois et les procédures administratives nationales. Sans écarter l'utilité de la première approche, le Conseil de I'OCDE a recommandé au nouveau Comité d'adopter la seconde : commencer par préparer des propositions d'action destinées à développer des règles de conduite applicables aux entreprises et des procédures intergouvernementales pour examiner les plaintes éventuelles. A long terme, cependant, l'objectif sera de renforcer la coopération par l'harmonisation de lois et de procédures nationales et éventuellement même par l'établissement de règles internationales équitables - si possible dans un contexte plus large que la seule zone OCDE. Car, si l'on ne fait pas de progrès rapides par le renforcement de la coopération intergouvernementale vers l'adaptation des structures politiques à la réalité moderne, les gouvernements pourraient devenir incapables de prendre les mesures nécessaires à la sauvegarde de l'intérêt et du bien-être publics. De l'autre cơté, les entreprises multinationales pourraient être de plus en plus harassées par des obstacles et des restrictions inutiles qui pourraient sérieusement réduire leur potentiel et, par conséquent, les empêcher de faire une contribution optimale au bienêtre des nations.

II y a par conséquent dans ce domaine un besoin manifeste de coopération qui doit déboucher sur l'action. Action qui, cependant, ne doit pas compromettre le niveau de libération déjà atteint par les pays de l'OCDE dans le domaine des investissements internationaux. C'est pourquoi le deuxième grand domaine dont le Comité aura à s'occuper concerne l'investissement international. Ici, d'après son mandat, le Comité doit d'abord s'employer à organiser des consultations au sujet de la limitation des effets nocifs sur les économies de pays Membres, effets pouvant être la conséquence, dans certains pays, d'une politique de stimulation et dans d'autres d'une politique de découragement des investissements. Deuxièmement, le Conuté doit considérer la possibilité de mettre en ceuvre le prircige du traitement national des entreprises sous contróle étranger. ? 


\section{FLUX FINANCIERS VERS LE TIERS-MONDE}

\section{LES APPORTS DE DIVERSES SOURCES AUT PAYS EN DEVELOPPENENT: CHA NGEWENTS RECENTS}

Quelle a été l'évolution de l'aide au développement en 1974? Que peut-on savoir dès maintenant de l'avenir? Quelle place occupent - et occuperont - les pays exportateurs de pétrole dans le groupe des pays donneurs? (1) Ce genre de questions a amené le Secrétariat de l'OCDE à essayer de faire des estimations chiffrées que résume l'article ci-dessous. Le rapport du président du Comité d'aide au développement (CAD) - examen 1974, Coopération pour le développement, a également servi de base.

\section{Augmentation des iramsferls de ressomirces:...}

L'aide publique au développement (APD) fournie par tous les pays (aide bilatérale et dons et souscriptions au capital des institutions multilatérales aussi bien par les pays du CAD que par ceux de l'OPEP et les pays communistes) se serait, selon les estimations, sensiblement accrue en 1974 par rapport à 1973 : elle serait passée, en termes monétaires, de 11 à 15 milliards de dollars environ. Si l'on y rajoute les " autres apports du secteur public " on atteint le chiffre de 20 milliards de dollars (2). Les apports privés des pays du CAD ont probablement dépassé, en 1974, 13 milliards de dollars nets : plus de 7 milliards pour les investissements directs privés, quelque 4,5 milliards pour les crédits à l'exportation et d'autres prêts et environ 1,5 milliard pour les dons des organismes bénévoles. Cela ne comprend pas les engagements de prêts aux pays en développement en eurodevises qui, à eux seuls, ont dépassé 9 milliards de dollars.

\section{... el des besoins:}

Bien qu'une partie de l'augmentation en termes monétaires des apports de ressources aux pays en développement ait été absorbée par l'inflation, on peut admettre qu'il y a eu un accroissement réel. Malheureusement, il n'a pas réussi à suivre l'évolution des besoins des pays bénéficiaires qui, eux, ont augmenté beaucoup plus. D'après les estimations, la facture pétrolière de ces pays se serait accrue, à elle seule, de quelque 10 milliards de dollars (tableau 1A).

Le domaine alimentaire, pris séparément, révèle un même déséquilibre entre besoins et aide. La FAO estime ainsi que le coût des importations commerciales de céréales (c'est-à-dire en dehors de l'aide alimentaire) s'est élevé entre $1972 / 73$ et 1973/74 d'environ 6 milliards de dollars. On peut estimer que, pour seulement maintenir le pouvoir d'achat des apports financiers de

(1) Un document élaboré à ce sujet est disponible à la Direction de l'aide au développement de l'OCDE.

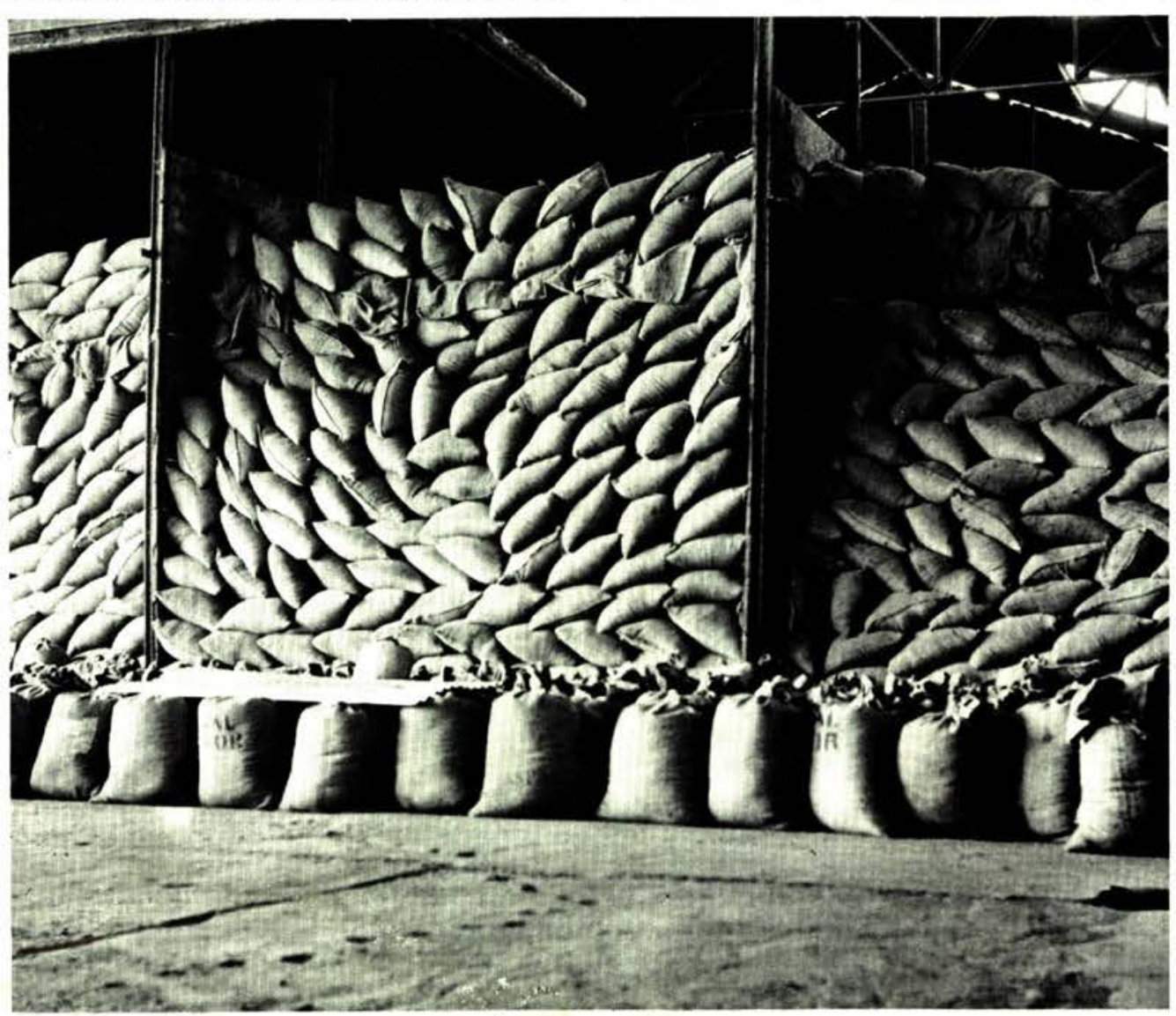

La hausse des prix des céréales importées a frappé les pays en développement en même temps que le renchérissement du pétrole.
(2) Ces chiffres ne comprennent pas les emprunts nets en eurodollars obtenus dans les pays du CAD ou par leur intermédiaire qui sont estimés, pour 1973, à 10 milliards de dollars environ, ni les contributions au " mécanisme pétrolier " du FMI.

Il convient de souligner que les chiffres utilisés dans l'article ci-dessous sont en partie des estimations, indiquant seulement des ordres de grandeur. 
1. AUGMENTATION DU COUT DES IMPORTATIONS

(a) MAJORATION DE LA FACTURE PÉTROLIĖRE EN 1971

(en pourcentage du PNB de 1971)

\begin{tabular}{llllll}
\hline Corée (Rép. de) & 9,0 & Liban & 4,6 & Nicaragua & 3,5 \\
Afghanistan & 8,5 & Sri Lanka & 4,8 & Turquie & 3,3 \\
Thaïlande & 5,4 & Philippines & 4,5 & Mauritanie & 3,3 \\
Jamaïque & 5,3 & Vietnam (Rép. du) & 4,1 & Guinée & 3,2 \\
Liberia & 5,1 & Soudan & 3,8 & Kenya & 3,1 \\
Uruguay & 4,9 & Taïwan & 3,7 & & \\
\hline
\end{tabular}

(b) COUT SUPPLÉMENTAIRE DES IMPORTATIONS DE CÉRÉALES EN 1973 ET 1974

(par rapport à la moyenne 1970-1972)

\begin{tabular}{|c|c|c|c|c|}
\hline \multicolumn{2}{|l|}{ Pays } & \multirow{2}{*}{$\begin{array}{c}\begin{array}{c}\text { Coût en } \\
\text { millions } \\
\text { de dollars }\end{array} \\
+5176\end{array}$} & \multirow{2}{*}{$\begin{array}{c}\begin{array}{c}\text { Pourcentage } \\
\text { des }\end{array} \\
\text { importations } \\
\text { totales en } \\
\text { 1970-1972 }\end{array}$} & \multirow{2}{*}{$\begin{array}{c}\text { Pourcentage } \\
\text { du PNB } 1971 \\
-\end{array}$} \\
\hline Pays en développement & 73 & & & \\
\hline & 74 & +8376 & 13 & - \\
\hline \multirow[t]{2}{*}{ Bangladesh } & 73 & +337 & - & 7 \\
\hline & 74 & +413 & 一 & 8 \\
\hline \multirow[t]{2}{*}{$\overline{\text { Sri Lanka }}$} & 73 & +85 & 21 & 7 \\
\hline & 74 & +111 & 27 & 9 \\
\hline \multirow[t]{2}{*}{$\overline{\text { Inde }}$} & 73 & +255 & 11 & 0 \\
\hline & 74 & +667 & 28 & 1 \\
\hline \multirow[t]{2}{*}{ Pakistan } & 73 & +105 & 13 & 1 \\
\hline & 74 & +303 & 36 & 4 \\
\hline \multirow[t]{2}{*}{ Egypte } & 73 & +369 & 44 & 5 \\
\hline & 74 & +603 & 73 & 8 \\
\hline \multirow{2}{*}{ Philippines } & 73 & +84 & 7 & 1 \\
\hline & 74 & +167 & 13 & 2 \\
\hline \multirow[t]{2}{*}{ Sénégal } & 73 & +79 & 32 & 8 \\
\hline & 74 & +70 & 28 & 7 \\
\hline \multirow[t]{2}{*}{ Corée (Rép. de) } & 73 & +430 & 19 & 5 \\
\hline & 74 & +564 & 25 & 6 \\
\hline \multirow[t]{2}{*}{$\overline{\text { Brésil }}$} & 73 & +221 & 6 & 1 \\
\hline & 74 & +125 & 3 & 0 \\
\hline \multirow[t]{2}{*}{$\overline{\text { Mexique }}$} & 73 & +179 & 7 & 1 \\
\hline & 74 & +283 & 11 & 1 \\
\hline \multirow[t]{2}{*}{$\overline{\text { Chili }}$} & 73 & +142 & 15 & 2 \\
\hline & 74 & +323 & 33 & 4 \\
\hline
\end{tabular}

Source : Banque mondiale et Secrétariat de l'OCDE.

1973 , il aurait fallu les augmenter de quelque 3 milliards de dollars. Et cela en supposant que le prix des importations n'ait pas augmenté de plus de 10 à $15 \%$. Ces chiffres ne tiennent pas compte des variations intervenues dans la balance commerciale normale des pays en développement (pris en tant que groupe) à la suite des variations de prix relatives qui ont été enregistrées en 1974 pour les produits autres que le pétrole et les céréales (tableau 1 B).

\section{Entrée en scine de I'DPEP}

L'entrée en scène des pays de l'OPEP constitue le plus important changement intervenu dans la composition du groupe des pays donneurs. Entrée en force : les versements d'APD de ces pays ont probablemènt quintuplé en 1974 par rapport à 1973 pour atteindre quelque 2,5 milliards de dollars.
La montée de cette aide a produit des modifications en ce qui concerne la place relative appartenant aux deux autres grands groupes de pays donneurs : les pays membres du CAD et les pays communistes. Ces derniers sont passés de la seconde à la troisième place après le CAD et l'OPEP. Même en valeur absolue, leurs apports, en 1974, n'ont pas changé (tableau 2). En ce qui concerne les pays du CAD, leurs versements d'aide ont augmenté en termes monétaires de quelque 2 milliards de dollars en 1974 et ils restent de loin la source d'aide la plus importante. Toutefois, l'importance relative de leur aide dans l'aide totale a tout naturellement diminué à la suite de l'augmentation de l'aide accordée par les pays producteurs de pétrole. C'est ainsi qu'il est probable que la part du CAD dans les versements de l'APD est passée entre 1973 et 1974 de 85 à $76 \%$ environ (tableau 2).

Les critères qu'ont les trois grands groupes de pays donneurs (CAD, OPEP, pays communistes) pour apporter leur aide sont apparemment très différents, ce qui entraîne, avec le changement survenu dans la composition du groupe donneur dans son ensemble, un déplacement de la répartition géographique de l'aide.

Les pays du CAD répartissent traditionnellement leur aide entre un grand nombre de pays dont une quarantaine reçoivent plus de 10 dollars par habitant. Les trois principaux bénéficiaires (Indonésie, Inde, République du Vietnam) ont reçu en 1973 moins de $20 \%$ du total.

Par contre, l'aide apportée par les pays communistes est depuis toujours très concentrée notamment sur Cuba et la République démocratique du Vietnam (qui ensemble ont reçu, en 1973, à peu près la moitié du total). Cet état de choses n'empêche d'ailleurs pas un pays comme la Chine, dont l'aide est très libérale par rapport à celle fournie par les autres pays communistes, de secourir près de 50 pays, surtout en Afrique.

Quant aux pays de l'OPEP, la concentration géographique de l'aide qu'ils dispensent est un phénomène dont on ne doit pas négliger l'importance étant donné l'accroissement absolu et relatif de cette aide. Malgré la diversification des engagements que l'on observe actuellement, il est probable qu'en 1974 les quatre plus importants bénéficiaires - l'Egypte, l'Inde, le Pakistan et la Syrie - ont reçu $70 \%$ des versements d'aide bilatérale des pays de l'OPEP. On constate cependant (tableau 3), en dépit de la répartition particulière de l'aide accordée par les pays producteurs de pétrole, qu'en 1974 plus de quatre dixièmes des engagements bilatéraux (environ 2,7 milliards de dollars) ont été destinés à des pays faisant partie du groupe 


\section{APPORTS DES PRINCIPAUX GROUPES DE DONNEURS, 1970-1974*}

(en millions de dollars)

\begin{tabular}{l|r|r|r|r|r}
\hline & 1970 & 1971 & 1972 & 1973 & 1974 \\
\hline Apport public total & & & & & \\
CAD & 8006 & 9054 & 10253 & 11995 & $(14000)$ \\
Pays communistes & 1150 & 1150 & 1000 & 1400 & $(1400)$ \\
Pays de l'OPEP & 410 & 560 & 525 & 850 & $(4800)(\mathrm{a})$ \\
Autres pays (b) & 46 & 16 & 34 & 40 & $(50)$ \\
\cline { 2 - 6 } Total & $\mathbf{9 6 1 2}$ & $\mathbf{1 0 7 8 0}$ & $\mathbf{1 1 ~ 8 1 2}$ & $\mathbf{1 4 2 8 5}$ & $\mathbf{( 2 0 2 5 0 )}$ \\
CAD en \% du total & 83 & 84 & 87 & 84 & $(69)$ \\
\hline dont : APD & & & & & \\
CAD & 6845 & 7776 & 8672 & 9408 & $(11400)(\mathrm{c})$ \\
Pays communistes & $(1000)$ & $(1000)$ & $(850)$ & $(1100)$ & $(1100)$ \\
Pays de l'OPEP & 379 & 473 & 418 & 531 & $(2500)$ \\
Autres pays (b) & 27 & 13 & 21 & 40 & $(50)$ \\
Total & $\mathbf{8 2 5 1}$ & $\mathbf{9 2 6 2}$ & $\mathbf{9 9 6 1}$ & $\mathbf{1 1 0 7 9}$ & $(\mathbf{1 5 0 5 0 )}$ \\
CAD en \% du total & 83 & 84 & 87 & 85 & $(76)$ \\
\hline
\end{tabular}

* Les chiffres entre parenthèses sont des estimations du Secrétariat qui revêtent un caractère hautement conjecturel.

(a) Ne sont pas comprises les contributions au " mécanisme pétrolier " du FMI, d'un montant de 3,2 milliards de dollars.

(b) Finlande, Irlande, Luxembourg et Afrique du Sud. Depuis janvier 1975, la Finlande est membre du CAD.

(c) Le Portugal non compris.

des pays «les plus gravement touchés » (3), dont après l'Inde et le Pakistan principalement le Soudan, le Bangladesh et la Somalie.

\section{Engagemenls pour l'avenir.}

Les données concernant les engagements d'aide - plus " sûres " que les estimations des versements pour 1974 en ce qui concerne les pays de l'OPEP - sont d'une manière générale particulièrement intéressantes dans la mesure où, tournées vers l'avenir, elles dessinent une évolution. Evolution qui d'après les chiffres disponibles serait assez favorable. C'est ainsi qu'en 1974 les engagements au titre de l'aide des pays membres de l'OPEP ont fortement augmenté : ils ont atteint 8 milliards de dollars, dont plus de 6,1 milliards pour les engagements bilatéraux et 1,8 milliards pour les engagements multilatéraux. Ni le 2,1 milliard de dollars mis à la disposition de la Banque mondiale, ni les 3,2 milliards de dollars offerts au FMI dans le cadre du "mécanisme pétrolier » (mécanisme qui n'est pas uniquement destiné aux pays en développement) ne sont compris dans les chiffres ci-dessus.

En ce qui concerne les engagements bilatéraux, les principaux donneurs sont l'Iran (2,5 milliards de dollars), l'Arabie saoudite $(1,5)$ suivis par la Fédération des Emirats arabes $(0,7)$, le Koweit $(0,6)$, la Libye $(0,5)$,
l'Irak $(0,3)$ et Qatar $(0,1)$. Les engagements multilatéraux souscrits en 1974 l'ont été en faveur de la Banque islamique de développement $(0,7$ milliard de dollars $)$, de la Banque arabe pour l'Afrique $(0,2)$, du Fonds spécial arabe pour l'Afrique $(0,2)$, du Compte spécial pour les opérations d'urgence de l'ONU $(0,2)$ et de plusieurs autres institutions.

Les engagements d'aide des pays membres du CAD pourraient au cours de toute l'année 1974 être de l'ordre de 14 à 15 milliards de dollars. Par rapport à 1973 cette somme représente une augmentation nominale d'environ $10 \%$ qui devrait assurer à peu près le maintien du niveau de l'aide en valeur réelle. Ce résultat n'est pas négligeable si l'on considère la difficile situation économique et financière qu'ont à affronter la plupart des pays donneurs.

C'est l'importance relative de ces engagements d'aide associée à l'entrée en jeu d'un nouveau groupe de pays donneurs, l'OPEP, qui donnent une lueur d'espoir à la situation actuelle - souvent dramatique des populations du tiers et du quart monde.

(3) Liste établie par les Nations Unies des 33 pays les plus gravement touchés par la hausse des prix à l'importation : Cameroun, République centrafricaine, Tchad, Dahomey, Ethiopie, Guinée, Kenya, Lesotho, République malgache, Mali, Mauritanie,

\section{BÉNÉFICIAIRES D'ENGAGEMENTS D'AIDE DES PAYS DE L'OPEP EN 1974}

Aide bilatérale assortie de conditions libérales

\begin{tabular}{|c|c|c|}
\hline & $\begin{array}{c}\text { Millions } \\
\text { de } \\
\text { dollars }\end{array}$ & $\begin{array}{c}\% \\
\text { du total }\end{array}$ \\
\hline Afghanistan & 85 & 1,4 \\
\hline Argentine & 200 & 3,3 \\
\hline Bahrein & 79 & 1,3 \\
\hline Bangladesh* & 199 & 3,2 \\
\hline Dahomey & 4 & 0,1 \\
\hline Egypte & 1820 & 29,6 \\
\hline Ethiopie* & 1 & n.d. \\
\hline Gambie & 1 & n.d. \\
\hline Guinée* & 16 & 0,3 \\
\hline Guinée équatoriale & 1 & n.d. \\
\hline Guyane* & 15 & 0,2 \\
\hline Honduras* & 5 & 0,1 \\
\hline Inde* & 873 & 14,2 \\
\hline Jordanie & 139 & 2,3 \\
\hline Lesotho* & 1 & n.d. \\
\hline Liban & 75 & 1,2 \\
\hline \multicolumn{3}{|l|}{ République } \\
\hline malgache* & 114 & 1,9 \\
\hline Mali* & 1 & n.d. \\
\hline Malte & 5 & 0,1 \\
\hline Maroc & 90 & 1,5 \\
\hline Mauritanie* & 62 & 1,0 \\
\hline Niger* & 1 & n.d. \\
\hline Oman & 3 & 0,1 \\
\hline Ouganda & 12 & 0,2 \\
\hline Pakistan* & 867 & 14,1 \\
\hline Sahel* & 6 & 0,1 \\
\hline Sénégal* & 11 & 0,2 \\
\hline Somalie* & 194 & 3,2 \\
\hline Soudan* & 205 & 3,3 \\
\hline Sri Lanka* & 32 & 0,5 \\
\hline Syrie & 757 & 12,3 \\
\hline Tchad* & 8 & 0,1 \\
\hline Thaïlande & 40 & 0,7 \\
\hline Tunisie & 82 & 1,3 \\
\hline Yémen (Rép. arabe)* & 73 & 1,2 \\
\hline Yémen (RDP)* & 33 & 0,5 \\
\hline Zaïre & 26 & 0,4 \\
\hline Zambie & 2 & n.d. \\
\hline TOTAL & $6138(1)$ & 100,0 \\
\hline \multicolumn{3}{|l|}{ dont les plus } \\
\hline gravement touchés & 2721 & 44,3 \\
\hline
\end{tabular}

Les chiffres sont sujets à révision.

* Pays les plus gravement touchés.

(1) Ne comprend pas un prêt régional de l'Arabie Saoudite.

Niger, Ruanda, Sierra Leone, Somalie, Soudan, Tanzanie, Haute Volta, Bangladesh, Inde, République khmère, Laos, Pakistan, Sri Lanka, République arabe du Yémen, République populaire du Yémen, Haîti, Salvador, Ghana, Guyanne, Honduras, Côted'Ivoire, Sénégal. 

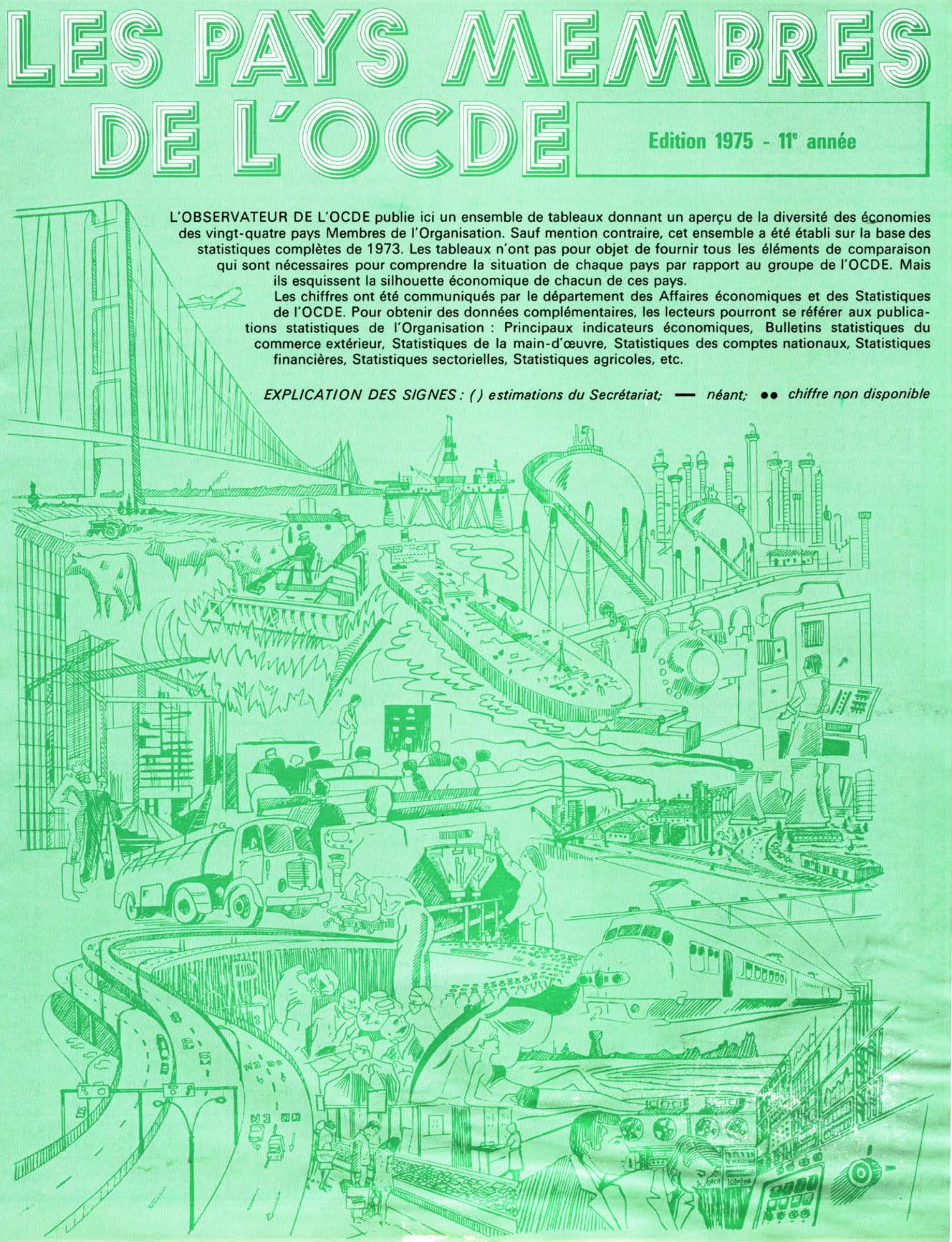
En raison de récentes révisions, les chiffres relatifs à la population et à l'emploi peuvent différer assez sensiblement de ceux publiés lors de la précédente édition.

\section{ALLEMAGNE}

AUSTRALIE

AUTRICHE

BELGIQUE

CANADA

DANEMARK

ESPAGNE

ÉTATS-UNIS

FINLANDE

FRANCE

\section{GRÈCE}

IRLANDE

ISLANDE

ITALIE

JAPON

LUXEMBOURG

NORVĖGE

NOUV.-ZÉLANDE

PAYS-BAS

PORTUGAL

ROYAUME-UNI

SUĖDE

SUISSE

TUROUIE
SUPERFICIE SUPERFICIE

TOTALE

en milliers de $\mathrm{km}^{2}$ en milliers de $\mathrm{km}^{\mathbf{3}}$

AGRICOLE

SUPERFICIE

CULTIVEE

y compris les herbages

temporaires

en milliers de $\mathrm{km}^{2}$

248,5

7686,8

83,8

30,5

9976,1

43,1

504,8

9363,4

337,0

549,1

132,0

70,3

103,0

301,2

372,3

2,6

323,9

268,7

36,7

91,6

244,0

450,0

41,3

780,6 
TAUX

D'ACCROIS-

SEMENT

TOTAL

$\%$ annuel moyen 1963-1973

0,8

1,9

0,5

0,5

1,6

0,7

1,1

1,1

0,3

0,9

0,6

0,7

1,4

0,7

1,1

0,8

0,8

1,6

1,2

0,5

0,4

0,7

1,1

2,5
TAUX BRUTS

DE NATALITE

$\%$

10,3

18,9

13,0

13,2

15,7

14,3

19,2

14,9

12,2

16,4

15,4

22,3

21,7

16,1

19,3

10,9

15,4

20,5

14,5

20,1

13,9

13,5

13,7

$(39,6)$
EMPLOI CIVIL TOTAL

en milliers de personnes dont :

AGRICULTURE, SYLVICULTURE

ET PÊCHE

26202

5640

3039

3818

8759

2385

12844

84409

2153

20953

(3 320)

1042

(88)

18310

52330

154

1654

1137

4564

(3 109)

24553

3879

3097

13810

3,9

33,9

7,5

INDUSTRIE

AUTRES

$\%$

43,0

49,5

35,5

57,3

40,1

43,8

16,1

43,3

52,8

6,5

31,3

62,2

33,8

56,7

9,5

26,5

38,0

35,5

$(31,7)$

$(64,2)$

4,1

17,1

35,7

47,1

39,3

48,5

12,2

$(34,1)$

$(25,7)$

$(40,2)$

30,7

44,2

25,1

$(15,9)$

$(37,5)$

$(46,6)$

44,0

38,6

17,4

13,4

37,2

49,4

48,6

42,4

9,0

54,7

53,2

34,7

57,1

36,2

$(33,8)$

$(37,4)$

$(28,8)$

3,0

42,3

54,7

36,8

56,1

7,1

$(7,3)$

$(46,2)$

$(46,5)$

63,4 


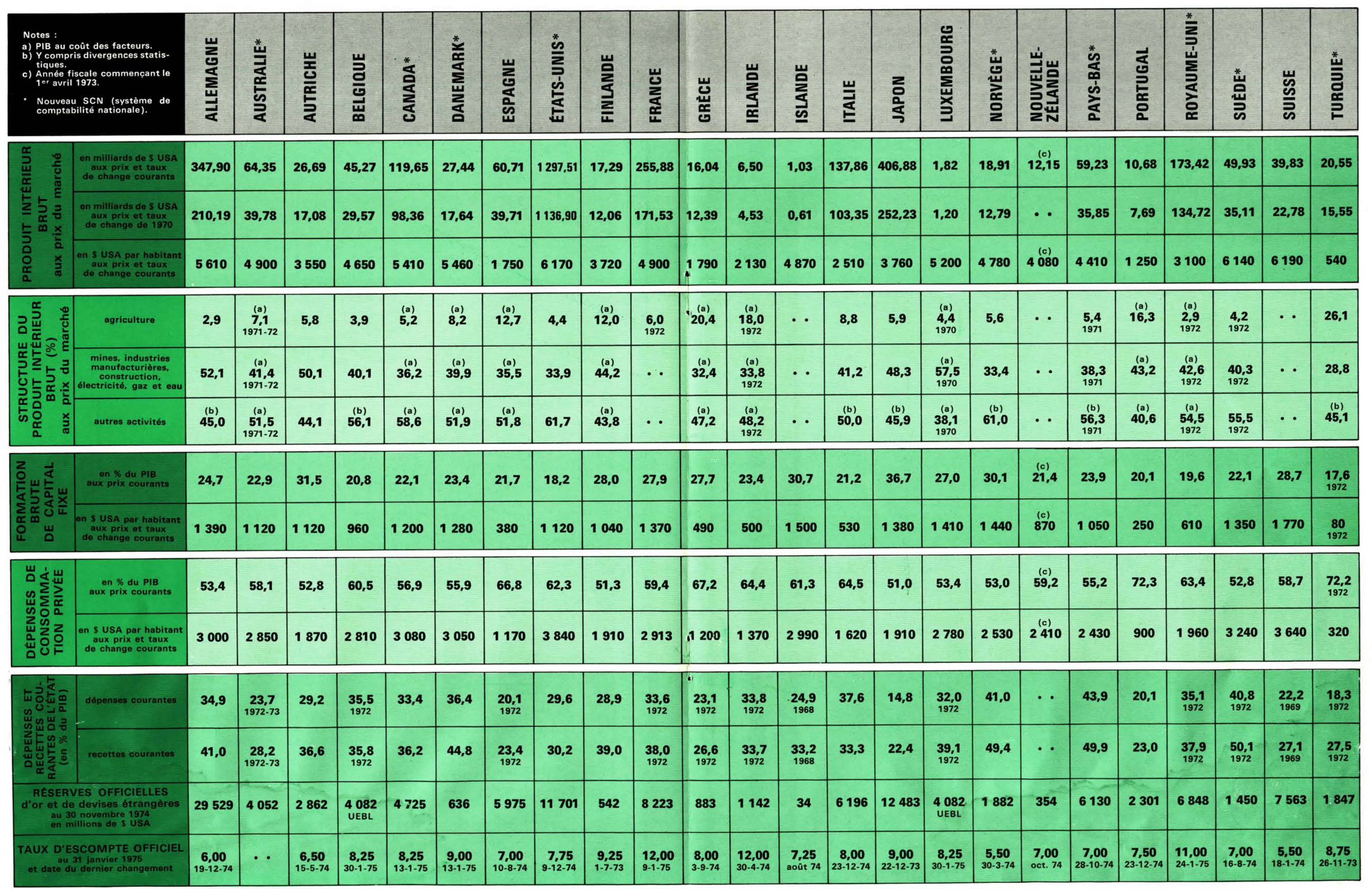


UEBL : Union Economique

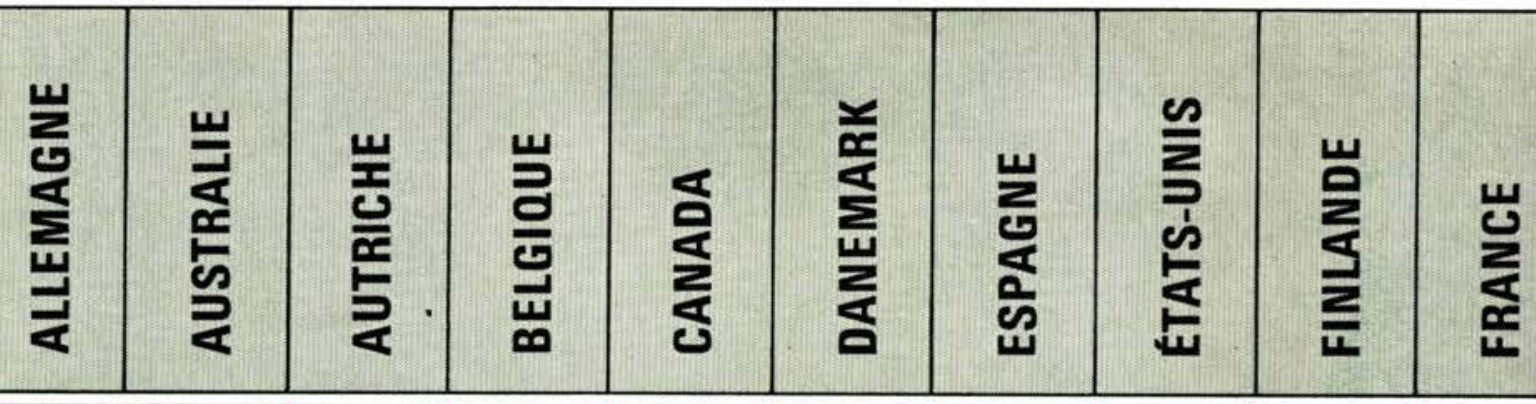

\begin{tabular}{|c|c|c|c|c|c|c|c|c|c|c|}
\hline unité monétaire & $\begin{array}{c}\text { Deutsche } \\
\text { Mark }\end{array}$ & $\begin{array}{c}\text { Dollar } \\
\text { australien }\end{array}$ & Schilling & $\begin{array}{l}\text { Franc } \\
\text { belge }\end{array}$ & $\begin{array}{c}\text { Dollar } \\
\text { canadien }\end{array}$ & Krone & Peseta & Dollar & $\begin{array}{c}\text { Mark } \\
\text { finlandais }\end{array}$ & $\begin{array}{c}\text { Franc } \\
\text { français }\end{array}$ \\
\hline $\begin{array}{l}\text { nombre } \\
\text { d'unités monétaires } \\
\text { par } \$ \text { USA } \\
\text { aux taux du marché } \\
\text { 31 décembre } 1974\end{array}$ & 2,410 & 0,754 & 17,130 & $\begin{array}{c}36,120 \\
\text { UEBL }\end{array}$ & 0,991 & 5,650 & 56,110 & 1,000 & 3,560 & 4,445 \\
\hline
\end{tabular}

\begin{tabular}{|c|c|c|c|c|c|c|c|c|c|c|}
\hline $\begin{array}{l}\text { totales (CAF) } \\
\text { en millions de } S \text { USA }\end{array}$ & 54496 & 6892 & 6770 & $\begin{array}{c}21935 \\
\text { UEBL }\end{array}$ & 23306 & 7704 & 9628 & 69121 & 4341 & 37380 \\
\hline $\begin{array}{l}\text { en provenance des } \\
\text { autres pays de I'OCDE } \\
\text { en millions de S USA }\end{array}$ & 42026 & 5665 & 5637 & $\begin{array}{c}18616 \\
\text { UEBL }\end{array}$ & 20865 & 6634 & 6868 & 47596 & 3308 & 28318 \\
\hline $\begin{array}{l}\text { en provenance du } \\
\text { reste du monde en } \\
\text { millions de S USA } \\
\text { (non spécifiés exclus) }\end{array}$ & 12425 & 1160 & 1133 & $\begin{array}{c}3322 \\
\text { UEBL }\end{array}$ & 2438 & 1071 & 2752 & 20544 & 1033 & 9048 \\
\hline $\begin{array}{l}\text { totales en } \% \text { du PIB } \\
\text { aux prix courants }\end{array}$ & 15,7 & 10,7 & 25,4 & $\begin{array}{l}46,6 \\
\text { UEBL }\end{array}$ & 19,5 & 28,1 & 15,9 & 5,3 & 25,1 & 14,6 \\
\hline $\begin{array}{l}\text { accroissement du vo- } \\
\text { lume des importa- } \\
\text { tions totales de } 1968 \\
\text { à } 1973 \text { en } \% \text { par an }\end{array}$ & 11,9 & 4,6 & 12,1 & $\begin{array}{l}11,8 \\
\text { UEBL }\end{array}$ & 9,3 & 9,2 & 10,4 & 7,2 & 11,5 & 12,6 \\
\hline
\end{tabular}

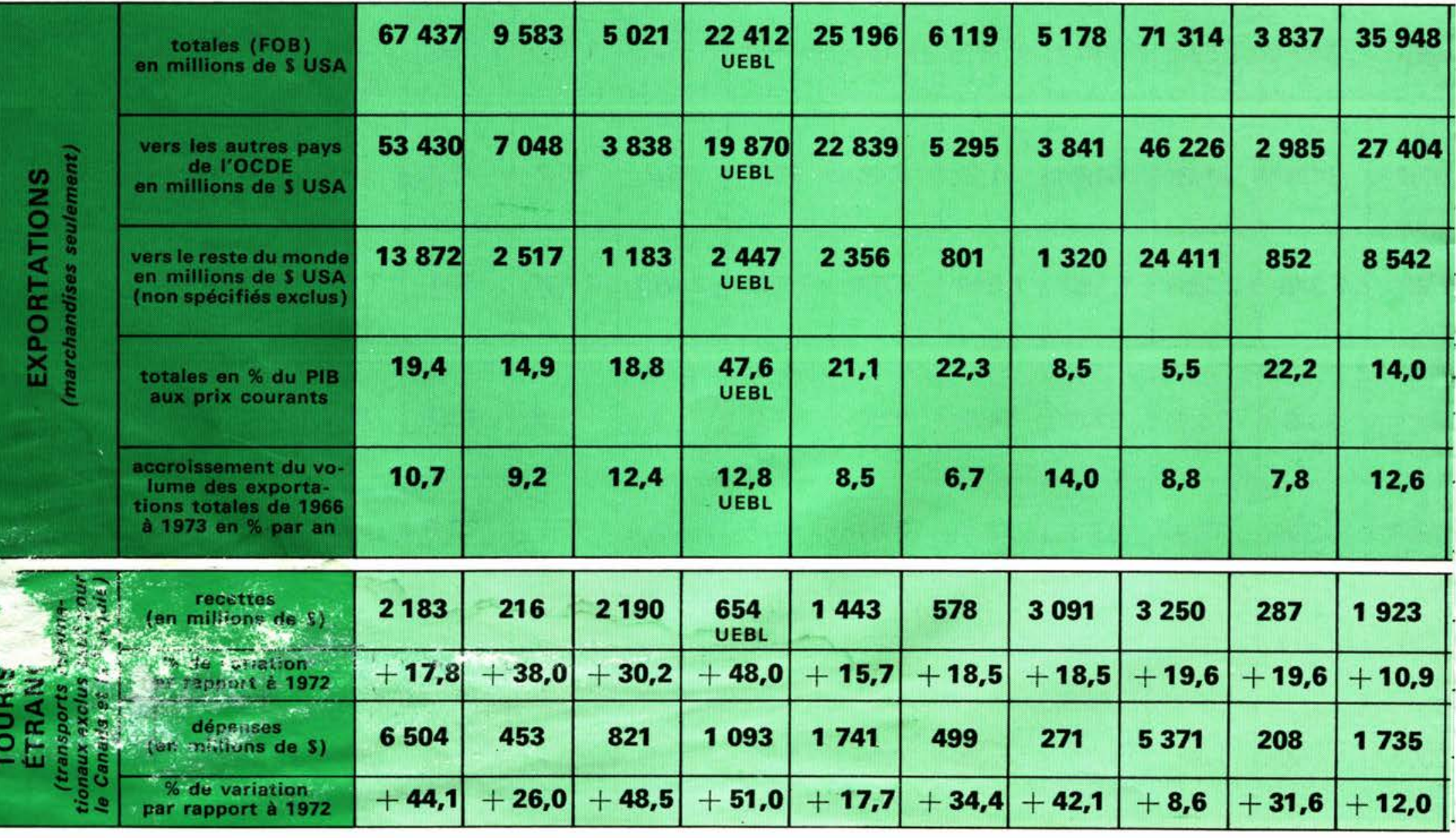




\begin{tabular}{|c|c|c|c|c|c|c|c|c|c|c|c|c|c|}
\hline 岃 & $\underset{\underline{\Sigma}}{\text { 岂 }}$ & $\frac{\text { 岂 }}{\frac{\Omega}{2}}$ & $\underline{\underline{E}}$ & $\frac{2}{2}$ & 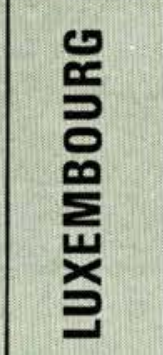 & 岂 & 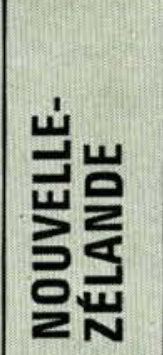 & $\frac{\infty}{\infty}$ & 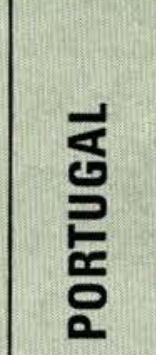 & 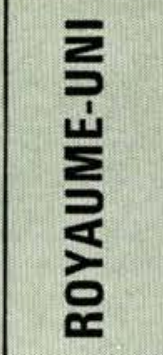 & $\begin{array}{l}\text { 岂 } \\
\text { 岂 }\end{array}$ & $\frac{w}{\tilde{\infty}}$ & $\underset{⿱ ㇒}{\stackrel{u}{2}}$ \\
\hline Drachma & Pound & Krona & Lira & Yen & $\begin{array}{c}\text { Franc } \\
\text { luxem- } \\
\text { bourgeois }\end{array}$ & Krone & $\begin{array}{c}\text { Dollar } \\
\text { néo- } \\
\text { zélandais }\end{array}$ & Guilder & Escudo & Pound & Krona & $\begin{array}{l}\text { Franc } \\
\text { suisse }\end{array}$ & Lira \\
\hline 30,000 & 0,426 & 118,700 & 649,430 & 300,950 & $\begin{array}{c}36,120 \\
\text { UEBL }\end{array}$ & 5,220 & 0,752 & 2,507 & 24,710 & 0,426 & 4,081 & 2,550 & 14,000 \\
\hline 3473 & 2789 & 356 & 27815 & 38313 & $\begin{array}{c}21935 \\
\text { UEBL }\end{array}$ & 6219 & $\begin{array}{c}1531 \\
1972\end{array}$ & 24364 & 2864 & 38749 & 10585 & 11621 & 2098 \\
\hline 2671 & 2479 & 314 & 19345 & 19477 & $\begin{array}{c}18616 \\
\text { UEBL }\end{array}$ & 5419 & - & 18836 & 2215 & 27641 & 8977 & 10409 & 1636 \\
\hline 802 & 270 & 41 & 8464 & 18836 & $\begin{array}{c}3322 \\
\text { UEBL }\end{array}$ & 800 & - & 4387 & 634 & 11049 & 1608 & 1212 & 462 \\
\hline 21,7 & 42,9 & 34,6 & 20,2 & 9,4 & $\begin{array}{l}46,6 \\
\text { UEBL }\end{array}$ & 32,9 & $\begin{array}{l}20,0 \\
1972\end{array}$ & 41,1 & 26,8 & 22,3 & 21,2 & 29,2 & 10,2 \\
\hline 11,3 & 9,5 & - & 11,5 & 15,1 & $\begin{array}{l}11,8 \\
\text { UEBL }\end{array}$ & 7,8 & - & 10,9 & - & 7,4 & 5,6 & 9,4 & - \\
\hline 1454 & 2129 & 289 & 22239 & 36930 & ${ }_{\text {UEBL }}^{22412}$ & 4680 & $\begin{array}{c}1765 \\
1972\end{array}$ & 23954 & 1750 & 30452 & 12114 & 9525 & 1318 \\
\hline 1050 & 1978 & 259 & 17034 & 18610 & $\begin{array}{c}19870 \\
\text { UEBL }\end{array}$ & 3827 & - & 20918 & 1383 & 21921 & 10252 & 7335 & 949 \\
\hline 403 & 126 & 30 & 4980 & 18320 & $\begin{array}{c}2447 \\
\text { UEBL }\end{array}$ & 853 & - & 2753 & 356 & 8423 & 1862 & 2190 & 369 \\
\hline 9,1 & 32,8 & 28,1 & 16,1 & 9,1 & $\begin{array}{l}47,6 \\
\text { UEBL }\end{array}$ & 24,7 & $\begin{array}{r}23,1 \\
1972\end{array}$ & 40,4 & 16,4 & 17,6 & 24,3 & 23,9 & 6,4 \\
\hline 16,8 & 7,2 & - & 8,7 & 12,8 & $\begin{array}{l}12,8 \\
\text { UEBL }\end{array}$ & 8,2 & - & 13,7 & - & 7,6 & 9,2 & 7,8 & - \\
\hline 515 & 193 & 13 & 2373 & 209 & $\begin{array}{l}654 \\
\text { UEBL }\end{array}$ & 242 & 99 & 973 & 491 & 1678 & 219 & 1389 & 19 \\
\hline$+31,1$ & $+22,8$ & $+54,9$ & $+9,1$ & $+4,0$ & $+48,0$ & $+16,7$ & $+60,2$ & $+32,0$ & $+17,7$ & $+23,7$ & $|721,0|$ & I t 30,8 & 465.4 \\
\hline 73 & 145 & 13 & 1459 & 1252 & 1093 & 282 & 183 & 1193 & 222 & 1683 & 718 & 789 & 93 \\
\hline$+10,3$ & $+27,5$ & $+57,8$ & $+39,0$ & $+61,8$ & $+51,0$ & $+32,8$ & $+61,4$ & $+37,8$ & $+36,0$ & $+28,5$ & $+5,7$ & $+34,5$ & $+56,8$ \\
\hline
\end{tabular}


20,4

16,7

23,7

17,0

16,8

13,5

15,1

17,6

10,1

12,9

27,8

ITALIE

IAPON LUXEM-

\begin{tabular}{l|l|l|} 
BOURG NORVEGE & NOUVELLE- \\
ZELANDE
\end{tabular}

PAYS-8AS PORTUGAL $\begin{gathered}\text { ROYAUME: } \\ \text { UNI }\end{gathered}$

SUĖDE

SUISSE

TURQUIE

1972

25,7

11,7

13,5

11,3

16,2

11,6

44,8

17,5

9,6

12,8

153,0

TAUX D'ACCÉS A

L'ENSEIGNEMENT SUPÉRIEUR

\% du groupe d'âge correspondant

\begin{tabular}{|c|c|c|c|c|c|c|c|c|c|}
\hline ALLEMAGN & Australie & AUTRICHE & BELgiaue & CANADA & DANEMARK & ESPAGNE & ETATS-UNIS & FINLANDE & FRANCE \\
\hline $\begin{array}{c}15,8 \\
1970\end{array}$ & $\begin{array}{r}28,5 \\
1972\end{array}$ & $\begin{array}{r}15,6 \\
1972\end{array}$ & $\begin{array}{c}(28,5) \\
1970\end{array}$ & $\begin{array}{l}49,8 \\
1972\end{array}$ & $\begin{array}{l}34,3 \\
1972\end{array}$ & $\begin{array}{l}27,1 \\
1972\end{array}$ & $\begin{array}{l}43,8 \\
1972\end{array}$ & 21,5 & $\begin{array}{l}30,0 \\
1971\end{array}$ \\
\hline JAPON & $\begin{array}{l}\text { LUXEM- } \\
\text { BOURG }\end{array}$ & NORVEGE & $\begin{array}{l}\text { NOUVELLE- } \\
\text { ZELANDEE }\end{array}$ & PAYS-BAS & PORTUGAL & $\begin{array}{c}\text { ROYAUME- } \\
\text { UNI }\end{array}$ & SUEDEE & SUISSE & TURQUIE \\
\hline $\begin{array}{l}23,8 \\
1970\end{array}$ & - • & $\begin{array}{l}27,5 \\
1970\end{array}$ & -. & $\underset{1971}{20,5}$ & $\begin{array}{l}6,6 \\
1970\end{array}$ & $\begin{array}{l}21,3 \\
1971\end{array}$ & $(31,1)$ & & -. \\
\hline
\end{tabular}

LOGEMENTS ACHEVÉS

ALLemagne Australie AUTRICHe Belgioue

mans

1000 habitant:

\begin{tabular}{c|c}
10,7 & 11,1 \\
\hline
\end{tabular}

6,4

5,4
Mis en chant.

10,6

10,0

9,6

11,3

10,8

10,5

\begin{tabular}{c|c|c|}
\hline $\begin{array}{c}\text { LUXEM- } \\
\text { BOURG }\end{array}$ & NORVEGE & $\begin{array}{c}\text { NOUVELLE- } \\
\text { ZELANDE }\end{array}$ \\
\hline
\end{tabular}

14,0

6,9

9,0

\begin{tabular}{ll}
4,7 & 16,8 \\
\hline
\end{tabular}

5,3
1970

11,1

9,3

3,4

BoYaume

6,1

12,8

11,5

2,8
PROTÉINES ANIMALES

grammes par habitant et par jour 1972

\begin{tabular}{|l|l|l|l|}
\hline GRECE & IRLANDE & IsLANDE & ITALIE \\
\hline
\end{tabular}

\section{5}

1967

63

-

45

\begin{tabular}{|l|l|l|}
\hline ALLemagne & Australie & Autriche \\
\hline
\end{tabular}

Belgiaue

GANADA

DANEM

UEBL

66

66

58

71

55

JAPON LUXEMBOURG

31

UEBL

57

74

56

34

56

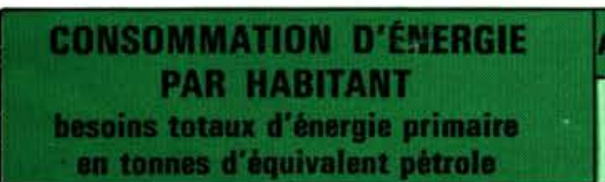

ALLEMAGNE AUSTRALE A A

\begin{tabular}{|l|l|l|l|l|l|l|l|l|l|}
\hline 4,75 & 4,62 & 2,85 & 5,38 & 8,25 & 4,24 & 1,64 & 9,06 & 3,82 & 3,54 \\
\hline
\end{tabular}

\begin{tabular}{|c|c|c|c|c|c|c|c|c|c|c|c|c|c|}
\hline 1,52 & 2,19 & 4,51 & 2,57 & 3,21 & 12,88 & 4,27 & - & 6,01 & 0,87 & 4,35 & 4,75 & 3,17 & 0,44 \\
\hline
\end{tabular}

\begin{tabular}{|c|c|c|c|c|c|c|c|c|c|c|c|c|c|}
\hline \multirow{2}{*}{\multicolumn{4}{|c|}{$\begin{array}{c}\text { TÉLÉPHONES } \\
\text { nombre pour } 1000 \text { habitants } \\
1972\end{array}$}} & \multirow{2}{*}{ ALLEMAGNE } & \multirow{2}{*}{\begin{tabular}{|c|} 
AUSTRALIE \\
340
\end{tabular}} & \multirow{2}{*}{\begin{tabular}{|c|} 
AUTRICHE \\
226
\end{tabular}} & \multirow{2}{*}{$\begin{array}{l}\text { BELGIQUE } \\
240\end{array}$} & \multirow{2}{*}{$\frac{\text { CANADA }}{499}$} & \multirow{2}{*}{\begin{tabular}{|c|} 
DANEMARK \\
377 \\
\end{tabular}} & \multirow{2}{*}{\begin{tabular}{|c|} 
ESPAGNE \\
164 \\
\end{tabular}} & \multirow{2}{*}{\begin{tabular}{|c|} 
EtATS-UNIS \\
628
\end{tabular}} & \multirow{2}{*}{\begin{tabular}{|c|} 
FINLANDE \\
295 \\
\end{tabular}} & \multirow{2}{*}{$\frac{\text { FRANCE }}{199}$} \\
\hline & & & & & & & & & & & & & \\
\hline GRECE & IRLANDE & ISLANDE & ItALLE & JAPON & $\begin{array}{l}\text { LUXEM- } \\
\text { BOURG }\end{array}$ & NORVĖGE & $\begin{array}{l}\text { Nouv } \\
\text { ZELL }\end{array}$ & PAYS-BAS & PORTUGAL & $\begin{array}{c}\text { ROYAUME- } \\
\text { UNI }\end{array}$ & SUĖDE & SUISSE & TURQUIE \\
\hline 160 & 114 & 370 & 206 & & & & 45 & 299 & & & & & 19 \\
\hline & nel & & & EMAGNE & AUSTRALIE & AUTRICHE & Belgiaue & INADA & DANEMARK & ESPAGNE & ETATS-UNIS & FINLANDE & FRANCE \\
\hline & E T & Sion & & 293 & 7 & ? & 5 & & 282 & 5 & a & 6 & 237 \\
\hline & & & IFA & JAPON & $\begin{array}{l}\text { LUXEM- } \\
\text { BOURG }\end{array}$ & NORVEGE & $\begin{array}{l}\text { RGuVELLE- } \\
\text { SELANDE }\end{array}$ & PAYS-BAS & PORTUGAL. & $\begin{array}{l}\text { ROYAUME- } \\
\text { UNI }\end{array}$ & SUEDE & SUISSE & TURQUIE \\
\hline$=0$ & 173 & 220 & 202 & 5 & $\begin{array}{l}220 \\
1971\end{array}$ & 241 & 250 & $\begin{array}{l}2.33 \\
1271\end{array}$ & 6 & b & 333 & 9 & 4 \\
\hline
\end{tabular}

L'OBSERVATEUR DE L'OCDE No 74, MARS-AVRIL 1975 


\section{FLUX FINANCIERS VERS LE TIERS-MONDE}

\section{APPORTS DE CAPITAUX PRIVES VERS \\ LES PAYS EN DEVELOPPEMENT: LE SCHEMA CHANGE}

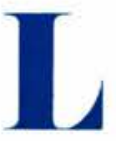

ES pays en développement ont eu à faire face en 1974 à des besoins financiers plus considérables que jamais. Étant donné que les plus démunis d'entre eux ont un droit prioritaire sur le volume limité des fonds publics en provenance des pays du CAD, ceux qui ont un revenu moyen ou relativement élevé devront à l'avenir faire de plus en plus appel à des capitaux privés ou à des capitaux assortis des conditions normales du marché pour financer leur développement économique.

\section{Les apports des pays du CAD}

Les capitaux fournis aux conditions du marché par les membres du CAD aux pays en développement ont continué d'augmenter en 1974 : ils ont atteint un montant net de quelque 14 millards de dollars dont la moitié environ en investissements privés directs. Parmi les projets d'investissement importants qui ont été décidés ou réalisés récemment dans des pays en développement non producteurs de pétrole, on peut citer :

- l'expansion de la capacité de fonderies d'aluminium au Ghana grâce aux États-Unis et au Japon. Par ailleurs, un consortium japonais construit actuellement au Brésil l'une des plus grandes fonderies d'aluminium du monde : les investissements totaux atteindront d'après les estimations quelque 3 milliards de dollars. - l'exploitation de gisements de cuivre au Panama par des entreprises canadiennes, britanniques et japonaises et au Pérou par des firmes américaines dans ce qui devrait devenir l'une des plus grandes mines de cuivre du monde (coût : 600 millions de dollars) - une usine d'engrais au Pendjab, qui sera financée conjointement par le Pakistan, une entreprise américaine et la Société financière internationale (SFI)

- toute une série d'investissements, financés conjointement par la Belgique et la Corée du Sud, dans l'équipement, la sidérurgie, la pétrochimie et la construction de locomotives de ce dernier pays (coût total d'ici à 1980 : quelque 10 milliards de dollars).

Des événements récents indiquent cependant qu'il y a une détérioration du climat des investissements dans certains pays en développement. Cette évolution pourrait avoir un effet négatif sur les investissements directs dans ces pays.

\section{La contribution des pays de l'OPEP}

L'importance des recettes pétrolières amassées par les pays de l'OPEP entraîne obligatoirement la question suivante : est-il possible - et dans l'affirmative comment? - de recycler ces fonds, en partie au moins, au profit des pays en développement pauvres en capital, plutôt que de les consacrer intégralement aux besoins financiers des pays de l'OCDE et au financement des plans de développement nationaux des pays de l'OPEP eux-mêmes?

Certains pays en développement à revenu moyen ou relativement élevé non producteurs de pétrole - par exemple le Brésil, la Corée la Malaisie, le Mexique, les Philippines, le Pérou et Taïwan - ont pu, et pourront sans doute encore, attirer des apports financiers considérables. Il s'agit en grande partie d'emprunts en euromonnaies, réalisés par l'intermédiaire des systèmes bancaires occidentaux. Mais récemment un syndicat de banques exclusivement arabe a accordé directement un prêt au Brésil et l'on peut attendre d'autres opérations de cette nature à mesure que les pays de l'OPEP développeront leurs institutions financières. Par ailleurs les nombreux fonds et institutions bancaires de développement qui, comme la Banque islamique de développement, ont été créés dans le monde arabe pour fournir des moyens de financement à long terme, pourraient, bien qu'essentiellement orientés vers les pays musulmans, financer en partie les investissements à long terme de pays en développement à revenu moyen ou relativement élevé.

Jusqu'à présent, les investissements directs, projetés ou réalisés, des pays de l'OPEP dans les pays en développement non producteurs de pétrole ont été en grande partie des opérations " en aval » - raffineries, réseaux de distribution, industries utilisant du pétrole - dont le financement a été assuré pour l'essentiel par les pays producteurs. Exemples : une opération commune entre I'Iran et l'Inde pour la production d'engrais azotés; une autre entre l'Arabie Saoudite et le Japon pour financer, en Corée, la construction d'entrepôts et d'un terminal de pétrole brut; des prises de participation de la Libye dans des raffineries en Yougoslavie, au Tchad et à Chypre.

Les investissements directs projetés par les pays de l'OPEP ne sont cependant pas tous "en aval ». C'est ainsi que quatre pays arabes se seraient associés pour financer l'exploitation de gisements de bauxite en Guinée, et la Libye aurait l'intention de développer au Zaïre, avec la Banque mondiale et la Banque européenne d'investissement, la production de cuivre et de cobalt.

Le Brésil a négocié avec le Koweït un accord global comprenant des prêts, des investissements directs et des projets financés en commun par les deux pays (coût total : environ un milliard de dollars). La Turquie a l'intention d'ouvrir ses universités aux étudiants saoudiens et d'envoyer des techniciens en Arabie Saoudite. Ce dernier pays et la Libye envisagent de créer ensemble. au Liberia, une société holding pour la fabrication de produits de caoutchouc, de papier et de sucre. Une commission saoudienne est actuellement mise sur pied : elle est destinée à assurer la réalisation en Inde de diverses opérations associant les deux pays, dont probablement des usines d'engrais et de produits phamaceutiques.

On a également constaté l'existence de certains flux de capit:a." en sens inverse, allant des pays er liverons. + les de l'OPEP. Le Pakistan se propose ainsi d'arpo. à la construction d'une aciérie à Abou Dhaioi ei i ai de réaliser en Arabie Saoudite une raffinerie, une usiric de néthan. et une usine d'engrais en association avec le pays d'accueil. 


\section{Un schẻma triangulaire}

Dans la plupart des cas, les investissements faits par des pays de l'OPEP exigent un apport de technologie occidentale, même si cette contribution doit être de plus en plus dissociée de prises de participation financières. La disponibilité croissante de capitaux de I'OPEP donne ainsi naissance à de nouveaux types d'" arrangements triangulaires", dans lesquels les entreprises des pays membres du CAD fournissent la compétence, les pays de l'OPEP les capitaux et les pays en développement non producteurs de pétrole les terrains et la main-d'œuvre.

Les opérations en cours de réalisation dans les pays de l'OPEP eux-mêmes offrent par ailleurs déjà un modèle de ce nouveau schéma dans la mesure où l'importance des participations financières d'entreprises des pays du CAD tend à diminuer par rapport aux concours que ces entreprises apportent sur les plans de la technique et de la gestion. Il reste que, bien souvent, les pays de l'OPEP exigent comme preuve de bonne foi une prise de participation, sans que cela implique nécessairement un contrôle étranger équivalent.

De même, les pays du CAD commencent à fournir aux pays non producteurs de pétrole des services techniques et des services de gestion parfois combinés avec des prises de participation financières.

Ces arrangements triangulaires peuvent revêtir de nombreuses formes : des pays de l'OPEP peuvent, par exemple, acheter des actions d'entreprises des pays membres du CAD - sociétésmères ou filiales - et se servir de ces actions pour peser sur le type et le montant des investissements que font les sociétés-mères dans les pays en développement non producteurs de pétrole. L'acquisition par l'Iran d'une importante participation dans la société Krupp, et celle du Koweït dans la société Lonrho, sont sans doute de ce type.

De façon un peu plus directe, les pays de l'OPEP peuvent aussi utiliser leurs capitaux pour prendre dans des pays en développement des participations majoritaires dans certaines entreprises. En pareil cas, la participation financière directe des entreprises de pays du CAD est en général limitée, leur rôle essentiel consistant en une contribution dans les domaines de la gestion et de la technologie (et éventuellement des marques commerciales).

C'est cette direction que semble prendre la firme British Leyland, qui, avec une participation saoudienne de 50 millions de livres, se propose de créer dans une zone franche en Égypte une usine de montage de véhicules qui approvisionnerait les marchés arabes en Land-Rovers. L'Arabie Saoudite financerait la majeure partie des dépenses en devises, tandis que la British Leyland apporterait son savoir-faire technique, et l'Égypte de la main-d'œuvre qualifiée.

De la même façon, la société Pilkington, fabricant de verre britannique, est entrée en pourparlers avec le Koweït et l'Égypte pour la construction d'une usine dont la production de verre serait destinée à approvisionner aussi bien l'Égypte que d'autres pays arabes. Ces négociations traduisent la détermination du Koweït de consacrer systématiquement une partie de ses ressources financières à investir à l'étranger - principalement dans le monde arabe - en liaison avec des apports de technologie occidentale. Par ailleurs il est possible que la participation d'institutions financières internationales, comme la Société financière internationale, incite les pays de l'OPEP à s'associer à des arrangements triangulaires. C'est le cas, par exemple, d'une opération qui serait réalisée pour la construction en Jordanie d'une usine d'engrais chimiques. Le capital serait souscrit par ane entreprise américaine, la SFI, la Jordanie et d'autres investisseurs, arabes pour la plupart.

\section{Les possibilitès d'action des pays de l'OCDE}

Étant donné que la concurrence pour obtenir des capitaux - et aussi de la compétence technique - sur les marchés internationaux est très vive, il peut devenir nécessaire de prendre des mesures spécifiques destinées à faciliter l'accès aux capitaux privés des pays non producteurs de pétrole. Les membres du CAD ont encouragé, dans le passé, les apports de capitaux privés vers les pays en développement en recourant à certaines mesures particulières d'incitation auxquelles l'on pourrait encore donner plus d'ampleur :

\section{- Les garanties d'investissements}

Les systèmes de garantie des investissements pourraient être élargis de manière à couvrir des opérations qui sont financées par des firmes des pays du CAD avec prises de participation de pays producteurs de pétrole. On pourrait également envisager une coopération entre ces derniers pays et des organismes de garantie des investissements des membres du CAD.

\section{- Les sociétés publiques de financement du développement}

La participation de ces sociétés au financement d'opérations conjointes avec les pays producteurs de pétrole pourrait être encouragée de même que leur collaboration avec les institutions des pays de l'OPEP qui ont des activités semblables.

\section{- La coopération technique}

Il serait souhaitable de favoriser, en combinaison avec des capitaux provenant des pays producteurs de pétrole, le transfert de ressources techniques des pays de l'OCDE. Ces derniers pourraient apporter leur concours dans des domaines tels que la recherche de possibilités d'investissements et les études techno-économiques. Ils pourraient également contribuer à encourager des transferts de compétence sur les plans de la gestion et de la technique.

\section{- L'accès aux marchés financiers internationaux et aux marchés de l'OCDE}

De nombreux pays en développement cherchent à accéder aux marchés financiers des pays de l'OCDE ainsi qu'aux marchés financiers internationaux, à cause principalement de la durée relativement longue et du caractère non lié des prêts que l'on peut y obtenir. C'est pourquoi il serait sans doute intéressant en particulier pour les Membres de l'OCDE qui bénéficient d'entrées de capitaux en provenance des pays de l'OPEP, ou qui ont des balances de paiements excédentaires - d'examiner plus en détail des mesures susceptibles d'aplanir les obstacles actuels. Ils pourraient envisager, par exemple, de lever des restrictions administratives et des entraves légales et, éventuellement, de développer l'utilisation de places privilégiées sur les «listes d'attente ", lorsque celles-ci existent.

\section{- Amélioration des marchés financiers intérieurs des pays en développement}

Dans les circonstances actuelles, il serait particulièrement important d'améliorer le fonctionnement de ces marchés, car certains pays en développement seraient ainsi mieux placés pour se procurer auprès des pays de l'OPEP des capitaux non assortis de conditions libérales. Les pays membres du CAD pourraient aider les pays en développement à améliorer leurs marchés financiers intérieurs, notamment en leur fournissant une assistance en matière de technique bancaire et éventuellement en offrant une partie du capital nécessaire à la création d'établissements financiers locaux ou de banques financées conjointement. 


\section{FLUX FINANCIERS VERS LE TIERS - MONDE}

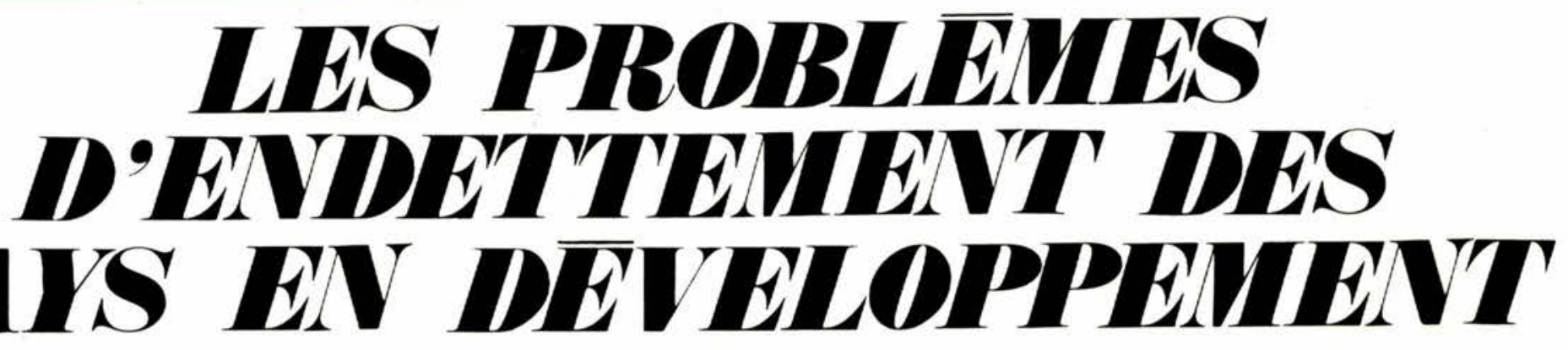

Si les pays en développement sont obligés de recourir de plus en plus à des apports de capitaux aux conditions du marché, leurs problèmes d'endettement - déjà préoccupants - en seront sans doute aggravés.

Cette question et d'autres aspects du problème d'endettement sont étudiés dans l'article qui suit par

Edgar Kröller, chef de la Division des politiques financières de la Direction de l'aide au développement de l'OCDE (1).

$\Omega^{u}$ u cours des dernières années, un nombre croissant de pays en développement ont connu des crises d'endettement qui appelaient des opérations d'allégement de leurs dettes : par exemple l'Argentine, le Bangladesh, le Brésil, le Chili, le Ghana, I'Inde, I'Indonésie, le Pakistan, le Pérou et la Turquie. Des renégociations multilatérales au sujet de la dette de ces pays ont eu lieu dans des " clubs de créditeurs " ou organes semblables. Pour satisfaire le désir du pays débiteur de partager ses expériences avec d'autres pays en développement avant d'entamer, avec les créditeurs, les vraies négociations, le Groupe de la CNUCED sur l'endettement vient d'aboutir à une conclusion importante. Afin de faciliter l'examen envisagé, il est proposé qu'un pays débiteur, agissant par l'intermédiaire et avec le concours de la CNUCED ou de toute autre institution internationale appropriée, convoque une réunion ad hoc à laquelle il inviterait les principaux pays créanciers intéressés et également, en qualité d'observateurs, les institutions internationales concernées. La réunion pourrait rédiger un rapport, à soumettre pour examen au pays débiteur et aux créditeurs, sur des mesures économiques internes, des perspectives d'apports de capitaux nouveaux, d'exportation et d'autres éléments de la balance des paiements. Il ne devrait pas, toutefois, faire de recommandations concernant le volume, les conditions et les modalités d'accords ultérieurs éventuels portant réaménagement de la dette.

Les crises d'endettement entraînent des bouleversements économiques dans les pays en développement et troublent les relations entre créanciers et débiteurs. Ceux qui fournissent les ressources et ceux qui en bénéficient doivent donc garantir un transfert international de celles-ci propre à éviter aux pays en développement des difficultés dues à leur endettement.

Ce problème se voit accorder une importance accrue dans la situation actuelle, marquée par le ralentissement de la croissance économique des pays industrialisés, le renchérissement du pétrole, des produits de base, des denrées alimentaires et des engrais ainsi que par la montée de l'inflation et des taux d'intérêt, c'est-à-dire par un climat général d'incertitude sur la scène monétaire et commerciale internationale. Tandis que pour certains pays en développement le bilan des récents événements a été au total positif, il a été, pour d'autres, négatif. Parmi les perdants on compte un certain nombre de pays très pauvres dont les perspectives de développement étaient déjà trop faibles. Beaucoup de ces pays ne pourront désormais maintenir ne serait-ce qu'un taux minimal de croissance économique sans de substantiels transferts supplémentaires de capitaux et sans des efforts internes pour s'adapter aux modifications structurelles de la situation. Comme les apports de ressources extérieures nécessaires peuvent en partie seulement être fournis à des conditions libérales, ils devront consister dans une large mesure en concours aux conditions du marché, ce qui alourdira dans les années à venir les charges du service de la dette des pays en développement.

Des problèmes de dette se manifestent en général au niveau de la balance des paiements par une crise de liquidités. Bien que d'apparences semblables, ces problèmes peuvent avoir des causes très diverses. Il convient de distinguer entre les problèmes fondamentaux qui se produisent parce que le coût du financement extérieur excède les avantages procurés à l'économie du débiteur, les problèmes plus techniques de reconduction (dus, par exemple, à des "pointes d'accumulation" des paiements du service de la dette) et les problèmes à court terme (dus, par exemple, à une mauvaise moisson).

\section{Considerations: fondamentales:}

\section{- Croissance et endettement}

Pourquoi et comment un pays entre-t-il dans une situation d'endettement? Dans quelle mesure les capitaux extérieurs sont-ils profitables au développement économique? Où se situent les limites au-delà desquelles une dette devient un fardeau? Quel rôle les "dispensateurs " de ressources et ceux qui en bénéficient ont-ils respectivement à jouer pour favoriser une gestion adéquate de l'économie et de la dette? Ce sont là des questions essentielles pour qui veut tâcher d'analyser le phénomène de l'endettement. La relation qui existe entre la croissance économique et la dette extérieure peut à cet égard constituer un point de départ.

En l'absence de tout apport de capitaux étrangers, on peut admettre que le taux d'accroissement du PNB d'un pays est fonction de la proportion des ressources intérieures qu'il peut mobiliser pour l'investissement (le taux d'épargne) et de l'efficacité dont il peut faire preuve pour traduire cet investissement en croissance. Or, comme la plupart des pays en développement jugent nécessaire d'accroître leur production à un rythme plus rapide, ils cherchent à compléter leur épargne nationale par l'épargne étrangère (les apports de capitaux). Dans la mesure où les apports de capitaux étrangers revêtent la forme de prêts, et non de dons, et où ils représentent des sommes supérieures à celles qui sont remboursées, une dette extérieure est créée qui entraîne pour le débiteur des charges financières correspondant au paiement des intérêts ê à l'amortissement.

L'endettement n'a rien en soi de critiquable : un pays endetté es! celui qui a reçu des ressources étrangères, sous d'autres formes que des dons, pour financer son développement. l.e résultat

(1) Pour une anolyse plus détaillie, voir: "Les problèmes d'endettement des pays en développement ", Direction de l'aide au développement, OCDE et chapitre X du Rapport du Président du Comité d'aide au développement qui vient d'étre publié sous le titre "Coopération pour le développement - Examen 1974». 


\section{FLUX FINANCIERS VERS LE TIERS·MONDE}

- gain ou appauvrissement - qu'ont pour le pays emprunteur les apports de capitaux étrangers dépend de deux choses : le coût des emprunts extérieurs est-il inférieur ou supérieur à la rentabilité de son programme d'investissement? Ces emprunts extérieurs complètent-ils son épargne intérieure ou la remplacent-ils? Comme le service de la dette extérieure doit être assuré dans une monnaie que le débiteur doit se procurer par ses exportations, les coûts et avantages de l'endettement doivent être mesurés par des prix qui traduisent le véritable coût, en devises rares, des facteurs de production et des produits en cause. De surcroît, la comparaison des coûts et avantages doit s'effectuer au niveau de la marge et non de la moyenne : il faut que le taux de rendement de l'investissement marginal, par exemple du projet le moins rentable, soit supérieur au coût du prêt le plus onéreux pour que le pays intéressé ne se trouve pas dans une situation plus défavorable qu'en l'absence de ce prêt et de l'investissement marginal.

\section{- Dette et service de la dette}

A première vue, il semble que l'endettement des pays en développement ait à présent atteint des niveaux impressionnants. A la fin de 1972, l'encours de leur dette (montants versés et non versés) dépassait 100 milliards de dollars, qui, ajoutés à la cinquantaine de milliards représentés par les investissements privés étrangers, constituaient le montant total de leur passif en devises.

Les chiffres indiquant le volume global de la dette en cours n'offrent cependant qu'un intérêt limité pour l'analyse économique. La composition de la dette qui détermine le service de la dette, variable pertinente pour en mesurer le coût économique, diffère, en effet, considérablement selon les pays.

Même en ce qui concerne le service de la dette, il est utile de garder la distinction entre remboursements et paiements d'intérêts. Les paiements dus au titre du remboursement peuvent dans la plupart des cas être reconduits au moyen de nouveaux emprunts, car donneurs et bénéficiaires considèrent le transfert de ressources des pays riches vers les pays pauvres comme un aspect de la coopération internationale qui se poursuivra pendant encore longtemps. Cela signifie que l'encours total de la dette de l'ensemble des pays en développement continuera probablement d'augmenter dans l'avenir prévisible. Certes, les créanciers comptent que chacun de leurs prêts, pris individuellement, leur sera remboursé; et certains pays en développement peuvent même effectuer un remboursement net sur l'ensemble de leur dette. Mais si, considérés en tant que groupe, les pays en développement effectuaient un remboursement net de leur dette, il n'y aurait plus l'apport net positif d'aide (en dehors des dons) et d'autres ressources financières que les donneurs se sont engagés à leur fournir dans le cadre de la stratégie pour la "deuxième décennie du développement».

\section{- Aide et endettement}

Quelle est la relation qui existe entre l'aide et l'endettement? On prétend souvent que les conditions financières de l'aide sont l'une des causes majeures des difficultés que les pays en développement ont connues du fait de leur endettement. C'est là un argument spécieux et qui détourne l'attention du véritable problème : l'Aide publique au développement (APD) représente le tiers environ de l'encours de la dette extérieure de ces pays, mais le cinquième seulement du montant total du service de cette dette. De plus, les conditions dont est assortie l'APD sont déjà très libérales (2) et il n'est pas sûr qu'elles puissent encore être sensiblement adoucies - malgré les efforts poursuivis dans ce sens par les membres du CAD.

La majeure partie du service de la dette étant constituée par les crédits à l'exportation et les crédits des banques commerciales,

(2) En 1973 deux tiers des engagements d'APD consistaient en dons; les prêts avaient en moyenne un taux d'intérêt de $2,5 \%$, une échéance de 33 ans et un délai de franchise de 9 ans.

\section{ENCOURS DE LA DETTE DES PAYS EN VOIE DE DÉVELOPPEMENT,}

MONTANTS VERSÉS A LA FIN DE 1972 ET MONTANT DU SERVICE DE LA DETTE EN 1972

La différence dans le degré de libéralité des conditions dont sont assorties les diverses composantes de la dette apparait lorsqu'on rapproche leur part dans l'encours de la dette à celle dans le service de la dette. Ainsi à la finde 1972, la dette libérale résultant des prêts d'APD accordés par les pays du CAD se chiffrait à 28 milliards de dollars. Elle représentait $37 \%$ du total de la dette afférente aux montants versés, mais ne comptait que pour $20 \%$ dans le montant total du service de la dette. Par contre, la dette au titre des créditsfournisseurs et autres crédits aux conditions du marché représentait environ la moitié de la dette en cours, mais plus des deux tiers du service de la dette.

\begin{tabular}{|c|c|c|c|c|c|c|c|c|}
\hline \multirow[b]{2}{*}{ Créanciers } & \multicolumn{2}{|c|}{$\begin{array}{c}\text { En cours } \\
\text { de la dette }\end{array}$} & \multicolumn{2}{|c|}{$\begin{array}{c}\text { Service } \\
\text { de la dette }\end{array}$} & \multicolumn{2}{|c|}{$\begin{array}{l}\text { Paiements } \\
\text { d'intérêts }\end{array}$} & \multicolumn{2}{|c|}{$\begin{array}{l}\text { Remboursements } \\
\text { de principal }\end{array}$} \\
\hline & $\begin{array}{l}\text { Milliards } \\
\quad \text { de } \\
\text { dollars }\end{array}$ & $\%$ & $\begin{array}{l}\text { Milliards } \\
\text { de } \\
\text { dollars }\end{array}$ & $\%$ & $\begin{array}{l}\text { Milliards } \\
\quad \text { de } \\
\text { dollars }\end{array}$ & $\begin{array}{c}\text { En pour- } \\
\text { centage } \\
\text { de la } \\
\text { dette } \\
\text { en cours }\end{array}$ & $\begin{array}{l}\text { Milliards } \\
\text { de } \\
\text { dollars }\end{array}$ & $\begin{array}{l}\text { En pour- } \\
\text { centage } \\
\text { de la } \\
\text { dette } \\
\text { en cours }\end{array}$ \\
\hline 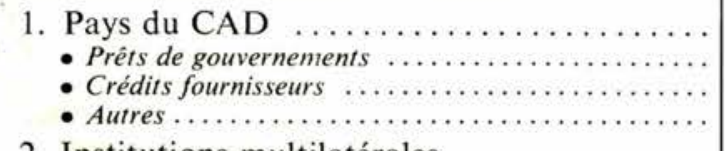 & $\begin{array}{ll}51 & 949 \\
30 & 625 \\
10 & 077 \\
11 & 247\end{array}$ & $\begin{array}{l}69 \\
41 \\
13 \\
15\end{array}$ & $\begin{array}{lll}6 & 415 \\
2 & 151 \\
2 & 404 \\
1 & 860\end{array}$ & $\begin{array}{l}71 \\
24 \\
27 \\
20\end{array}$ & $\begin{array}{r}1815 \\
777 \\
524 \\
514\end{array}$ & $\begin{array}{l}3,5 \\
2,5 \\
5,2 \\
4,6\end{array}$ & $\begin{array}{lll}4 & 6 C 0 \\
1 & 374 \\
1 & 880 \\
1 & 346\end{array}$ & $\begin{array}{r}8,9 \\
4,5 \\
18,7 \\
12,0\end{array}$ \\
\hline 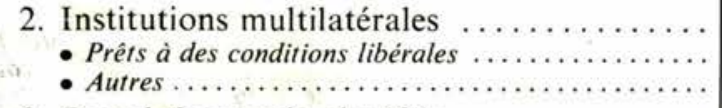 & 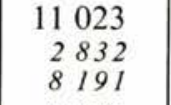 & $\begin{array}{r}15 \\
4 \\
11\end{array}$ & $\begin{array}{r}1055 \\
24 \\
1031\end{array}$ & $\begin{array}{r}12 \\
0 \\
11\end{array}$ & $\begin{array}{r}499 \\
21 \\
478\end{array}$ & $\begin{array}{l}4,5 \\
0,7 \\
5,8\end{array}$ & $\begin{array}{r}556 \\
3 \\
553\end{array}$ & $\begin{array}{l}5,0 \\
0,1 \\
6,8\end{array}$ \\
\hline 3. Pays à économie planifiée.............. & 5553 & 7 & 520 & 6 & 68 & 1,2 & 452 & 8,1 \\
\hline 4. Pays en développement $\ldots \ldots \ldots \ldots \ldots \ldots$ & 2398 & 3 & 308 & 3 & 72 & 3,0 & 236 & 9,8 \\
\hline 5. Autres $\ldots \ldots \ldots \ldots \ldots \ldots \ldots \ldots \ldots \ldots \ldots \ldots$ & 4123 & 6 & 707 & 8 & 165 & 4,0 & 542 & 13,1 \\
\hline $\begin{array}{l}\text { Dette totile }, \ldots \ldots \ldots \ldots \ldots \ldots \ldots \\
\text { Bow référence }\end{array}$ & 75046 & 100 & 9005 & 100 & 2619 & 3,5 & 6386 & 8,5 \\
\hline Dét e envers les pays du@CAD au titre de l'APD & 27.988 & 37 & 1800 & 20 & 600 & 2,1 & $12 \mathrm{CO}$ & 4,2 \\
\hline
\end{tabular}


une saine gestion de la dette exige qu'on surveille de manière particulièrement étroite ces deux catégories d'emprunts. Beaucoup de pays en développement ont, sans nul doute, eu délibérément recours à des emprunts aux conditions du marché pour maintenir leur rythme de développement ou pour le porter au-dessus du taux permis par l'aide assortie de conditions libérales. Une augmentation des apports de cette dernière forme d'aide diminuerait sans doute la tentation qu'ont les pays en développement de se procurer des capitaux étrangers à des conditions et pour des montants qui leur permettent difficilement d'assurer le service de leur dette. Mais les besoins de capitaux de ces pays sont tels qu'il faudrait de très fortes augmentations des apports d'aide, des exportations et de l'épargne pour qu'ils puissent sortir de l'impasse où ils ont à choisir entre la réalisation d'un taux de croissance satisfaisant et l'absence de problèmes d'endettement.

En outre, tout surcroît d'aide à des conditions libérales devrait être réservé aux pays en développement les plus défavorisés, ceux, par exemple, dont le revenu par habitant est inférieur à 375 dollars - ce qui correspond à peu près au niveau permettant de bénéficier des fonds de l'International Development Agency (IDA). Les sommes dues par ces pays ne représentent, au demeurant, que le quart du total de l'encours de la dette au titre des crédits aux conditions du marché. Ainsi, un supplément d'aide laisserait, pour ainsi dire, intacts les trois quarts de la charge de la dette et notamment celle des pays de la tranche des revenus les plus élevés qui sont les plus gros débiteurs. Il est vrai, cependant, que si le bénéfice en était réservé aux pays en développement les plus pauvres et s'il était utilisé à des fins productives, il leur permettrait d'augmenter substantiellement leur potentiel de croissance et de diminuer leurs problèmes de service de la dette.

\section{La siluation achuelle (3)}

La dette totale des pays en développement à l'égard de l'ensemble de leurs créanciers (membres du CAD, autres pays et institutions d'aide multilatérale) s'élevait à 75 milliards de dollars à la fin de 1972, dernière année pour laquelle des chiffres valables sont disponibles (tableau 1). Ce chiffre correspond aux montants versés. Si l'on y ajoute les montants ayant fait l'objet d'engagements mais qui ne sont pas encore versés, il passe à 103 milliards de dollars environ. Calculée sur la base des engagements, la valeur actualisée de la dette (à un taux d'actualisation de $10 \%$ ) est de 63 milliards de dollars. C'est là le montant que les pays débiteurs devraient actuellement verser pour se libérer de leur dette en une seule fois, dans l'hypothèse où leurs créanciers accepteraient de recevoir maintenant une somme inférieure à celle qu'ils allaient recevoir sur plusieurs années. Cela puisqu'ils pourraient, en l'investissant à $10 \%$, en tirer un revenu égal au service de la dette initialement dû. Il est évident que ces chiffres globaux ne signifient pas grand-chose lorsqu'il s'agit d'évaluer l'incidence sur les différents pays. La moitié de l'encours total de la dette est imputable à neuf pays seulement : Inde, Brésil, Iran, Indonésie, Mexique, Pakistan, Israël, Corée du Sud et Argentine; le reste est imputable pour moitié à onze autres pays : Chili, Turquie, Yougoslavie, Algérie, Colombie, Espagne, Égypte, Grèce, Pérou, Venezuela et Taïwan. Pour chacun de ces pays, l'encours total de la 'dette dépassait 1,5 milliard de dollars (y compris les montants non versés).

Faute de pouvoir procéder à une évaluation par pays, il est intéressant de voir comment la dette se répartit entre les pays classés par groupes de revenus. La dette tend à être concentrée sur les pays relativement les plus favorisés : en 1972, les pays ayant un revenu par habitant inférieur à 200 dollars représentaient $51 \%$ de la population totale des pays en développement, mais ne comptaient que pour $23 \%$ dans leur dette totale. De plus, la dette contractée à des conditions relativement rigoureuses souvent la source de problèmes d'endettement - est encore plus fortement concentrée sur les pays en développement les plus riches.
C'est ce qui apparaît à l'évidence lorsqu'on examine la répartition du montant actualisé de la dette. Dans le montant total de la dette actualisée, la part des pays en développement les plus pauvres (ayant moins de 200 dollars de revenu par habitant) est de $17 \%$ seulement.

Cette répartition géographique n'a rien de surprenant et elle est, somme toute, conforme à ce qui est souhaitable. De plus, elle a son importance lorsqu'il s'agit d'examiner les mesures à prendre pour éviter les crises d'endettement, ou pour y faire face.

Un accroissement des apports de fonds à des conditions libérales pour renflouer un débiteur qui se situe dans une tranche de revenu relativement élevée ne constitue pas forcément la solution appropriée, car cela peut revenir à détourner des ressources d'APD limitées de pays plus pauvres qui ne connaissent peut-être pas de problèmes d'endettement simplement parce qu'ils sont dans l'incapacité d'emprunter aux conditions du marché.

\section{Les problemes diendellement dans le contexte des ivènements économiques récents}

\section{- L'effet de l'inflation}

La tendance à l'accélération de l'inflation a eu certaines répercussions importantes sur les relations entre pays créanciers et pays débiteurs. Dans la mesure où le taux d'intérêt fixé pour un prêt ne tient pas pleinement compte du taux d'inflation (ce qui est le cas pour les prêts d'APD, les crédits à l'exportation, et sans doute même pour les prêts en euromonnaies), l'inflation réduit la charge du débiteur, car ce dernier s'acquitte du service de sa dette avec de l'argent qui a moins de valeur qu'au moment où il a contracté son emprunt. Mais l'incidence de l'inflation est, bien entendu, plus compliquée : elle dépend de ses répercussions sur les prix des exportations et des importations des pays en développement, c'est-à-dire sur leurs termes de l'échange. Alors que l'inflation se traduit en général immédiatement par une hausse des prix des exportations et des importations, le service de la dette constitue une charge qui est fixée de façon contractuelle pour une longue période.

\section{- L'incidence de la hausse des prix des produits de base et en particulier du pétrole}

Les conséquences économiques de la hausse des prix du pétrole et d'autres produits de base ont accentué les disparités qui existaient déjà dans la répartition géographique de la dette des pays en développement. Du point de vue de la situation de la balance des paiements, cette hausse s'est soldée par un gain pour les uns et par une perte pour les autres. Dans le camp des perdants se trouvent des pays dont les perspectives de développement n'étaient déjà que trop fragiles avant la crise.

\section{- Les gagnants}

Les pays qui ont tiré avantage de la hausse des prix du pétrole sont naturellement les pays exportateurs de cette source d'énergic.

(3) Il existe deux grandes sources statistiques sur la dette : Io le Système de notification par les débiteurs (SND), mis en place par la BIRD, qui permet dé rassembler des renseignements sur la dette publique et la dette garantie pai l'État des presque 100 pays en développement qui ont reçu des prêts du Gronpe de la Banque Mondiale; $2^{\circ}$ le Système élargi de notification (SEN) établi conjointement par l'OCDE et la BIRD, qui permet de collecter des informations sur la dette due au secteur public des pays du CAD ou officiellement garantie dans ces derniers. Les deux systèmes se recouvrent en partie, mais une certaine part de la dette leur échappe encore, notamment toute la dette à échéance de moins d'un an, la dette privée non garantie et certains crédits militaires. D'autre part, pour les pays qui ne sont pas couveris nar le Sivi, on . posséde aucu renseignement sur leur dette à l'égard de pays yui no sont nas nie.,bre. the. La p part des nrêts en euromonnaies ne s... pas compris vans a $3,1 \mathrm{t}$. combinant les renseiznements obtenus au moyen de ces der'x sistemes, u.. nésnmoins arriver _ pour les 140 pays et territoires cn causc .. - tite e\%... aui se rapproche de la vérité autant que possible, en '"état actue' des ́orinau. 
Mais là encore une distinction s'impose. Dans ce groupe, ce sont seulement les pays à revenu élevé et certains pays à revenu moyen qui n'ont pas désormais à affronter de problème de dette et qui peuvent même contribuer à alléger la charge qu'ont à supporter les pays perdants. A cet égard, ils ont diverses possibilités. Certains pays pétroliers pourraient, par exemple, effectuer des remboursements anticipés de leur dette, ce qui procurerait à leurs créanciers un supplément de ressources à acheminer vers les pays défavorisés. En outre, les pays disposant d'excédents pétroliers n'ont plus, comme par le passé, recours au marché des eurodevises; ils laissent ainsi davantage de ressources disponibles pour les pays dont les besoins de capitaux ont au contraire augmenté.

Les pays pétroliers ne sont naturellement pas tous dans une situation aussi favorable. Ceux dont le revenu par habitant est encore faible, et dont les besoins de développement restent considérables, peuvent utiliser pour leur propre économie la majeure partie de leurs recettes pétrolières immédiates; toutefois il est peu probable que ces pays (par exemple l'Indonésie et le Nigeria) aient des problèmes d'endettement sérieux.

\section{- Les perdants}

Pour les pays dont les dépenses d'importation ont augmenté à cause de l'enchérissement des produits de base - et en particulier du pétrole - sans qu'ils bénéficient en contrepartie de gains dans leurs exportations, la hausse des prix de ces produits peut avoir, du point de vue de leur dette, un double effet : 1) un effet immédiat et indirect s'exerçant par le biais de la balance des paiements; 2) un effet retardé et direct, résultant des emprunts extérieurs supplémentaires qu'ils peuvent éventuellement être obligés de contracter.

Dans l'immédiat, la hausse des coûts du pétrole et d'autres produits de base laisse inchangé le montant de la dette et du service de la dette des pays en développement. Cependant, ceux-ci doivent ajuster d'une certaine façon leur balance des paiements pour faire face à l'alourdissement de leurs dépenses d'importation, sous peine de voir la réduction de leurs disponibilités en devises freiner le rythme de leur croissance. Ce processus d'ajustement peut revêtir diverses formes. D'abord, ces pays peuvent être en mesure d'intensifier leurs efforts intérieurs pour accroître leurs exportations (et leur épargne) et supprimer de leurs importations les produits qui ne leur sont pas essentiels. En second lieu, ils peuvent utiliser leurs réserves et les moyens de financement à court terme disponibles, par exemple les facilités de crédit du FMI, pour amortir le choc. Mais une fois épuisées les possibilités offertes par ces deux lignes de défense, ils peuvent encore avoir des besoins de devises incompressibles, car il leur faut financer un volume d'importations minimal ainsi que les intérêts et l'amortissement de leur dette, fixés de façon contractuelle.

Les ressources dont ils ont besoin peuvent leur être fournies grâce à un accroissement des entrées de capitaux étrangers ou à un allégement de la dette. Les deux ont essentiellement le même effet sur l'économie : l'un et l'autre assurent aux pays en cause les ressources extérieures nécessaires. Cependant, l'allégement de la dette a l'avantage de leur fournir des devises librement utilisables. Mais cette solution a aussi l'inconvénient d'exiger de longues négociations et elle implique en général, entre les créanciers, un accord de partage des charges qui soit d'une certaine façon fondé sur le montant de la dette ou du service de la dette que le débiteur en cause doit à chacun d'entre eux.

Le second effet de l'enchérissement du pétrole et d'autres produits de base sur la dette des pays en développement intervient lorsque cus pays cont coligés, pour équilibrer leur balance des paiements, de rechercher des ressources extérieures supplémentaires, en particulier sous forme de concours aux conditions du marché. Cet apport de ressources crée une nouvelle dette et de nouvelles charges au titre du service de la dette. Il peut fort bien arriver que, pour sauvegarder le rythme de son développement, un pays soit tenté de contracter des emprunts extérieurs pour des montants et à des conditions qui ne lui permettent pas d'en assurer sans danger le service.

Parmi les pays définis par les Nations Unies comme ayant été les plus gravement touchés par la hausse des prix du pétrole, des matières premières, des produits alimentaires et des engrais, on en compte plusieurs qui, avant même les récents événements économiques, éprouvaient déjà de graves difficultés à assurer le service de leur dette. En témoigne la nécessité où ils se sont trouvés d'en obtenir un allégement. Il est évident que cette charge supplémentaire aggrave encore la situation de leur balance des paiements. Il est par conséquent particulièrement nécessaire que les donneurs d'aide prennent des mesures supplémentaires en faveur de ce groupe de pays. A la différence de certains pays en développement plus favorisés, ils ne peuvent recourir à des emprunts supplémentaires aux conditions du marché pour compenser la hausse des prix du pétrole : ni leur réputation de solvabilité ni leur capacité d'assurer le service de leur dette ne le leur permettent.

\section{Les actions posssibles:}

Les récents événements économiques ont donné une importance accrue à un certain nombre de mesures destinées à éviter des difficultés d'endettement. Toutes les parties intéressées reconnaissent pleinement que c'est aux pays en développement eux-mêmes et non pas aux fournisseurs de capitaux qu'incombe la responsabilité première de la gestion de leur dette. D'un autre côté, la coopération pour le développement entre pays riches et pays pauvres veut que les donneurs fassent tout leur possible pour aider les pays défavorisés à suivre sans embûches la voie difficile qui consiste à accélérer au maximum leur développement, tout en évitant un effondrement de leur situation en matière de paiements extérieurs. La nécessité d'une telle coopération est devenue particulièrement aiguë dans les circonstances actuelles, où la situation des paiements extérieurs de plusieurs pays en développement est mise en danger par des événements qui échappent à leur contrôle, tels qu'une rapide détérioration de leurs termes de l'échange. Certaines dispositions pratiques pourraient cependant être prises dans ce domaine aussi bien par ceux qui fournissent des ressources que par ceux qui en bénéficient.

\section{- Politiques des pays débiteurs}

En toute circonstance, le moyen essentiel pour les pays en développement d'éviter des problèmes d'endettement consiste à gérer efficacement leurs ressources, aussi bien intérieures qu'extérieures, de manière à promouvoir la croissance économique et le développement. Cela suppose une large gamme de mesures dans différents domaines : budgétaire et monétaire, taux de change, promotion des exportations et choix des projets dans le cadre d'un programme global de développement.

Les pays en développement ont particulièrement intérêt à :

- s'assurer un montant d'épargne et de recettes d'exportation leur permettant de faire face à leurs obligations envers l'étranger

- faire attention à ce que les entrées de capitaux étrangers constituent une augmentation nette de leurs propres ressources d'investissement et ne viennent pas se substituer à un effort national d'épargne

- ne pas recourir à des apports aux conditions du marché au-delà du montant correspondant à celui qu'ils peuvent rémunérer sans danger

- gérer sainement leurs réserves, pour créer un moyen de défense contre les pressions à court terme qui peuvent s'exercer sur leur balance des paiements. 


\section{^ FLUX FINANCIERS...}

\section{- Politiques d'aide}

Compte tenu des contraintes imposées par le montant total limité de l'aide, celle-ci a pour premier objectif de promouvoir la croissance économique des pays en développement. Comme l'aide constitue la source de financement extérieur la moins chère, tout accroissement de son volume soutient ces pays dans leur effort de développement sans les exposer à des difficultés d'endettement.

En général, toutefois, dans le cas des pays les plus défavorisés, c'est plutôt leur pauvreté que leur endettement qui justifie une augmentation de l'aide en leur faveur.

Les ressources fournies au titre de l'APD recouvrent des opérations qui offrent des degrés de libéralité variables, allant du don pur et simple au prêt comportant un élément de libéralité de $25 \%$. Comme ce sont les pays en développement les plus pauvres qui ont le plus besoin d'accélérer leur croissance économique, c'est à eux que devrait aller la fraction la plus libérale de l'aide, afin qu'ils soient moins tentés de compléter les fonds d'aide qui leur sont accordés à des conditions libérales par des crédits aux conditions du marché, plus rigoureuses.

$\mathrm{Si}$ des problèmes d'endettement surgissent néanmoins, des mesures appropriées pour y remédier doivent être recherchées. Le fait que les débiteurs peuvent se trouver à des stades de développement très différents entraîne des répercussions évidentes sur le type de mesures qu'il convient de prendre dans chaque cas particulier.

Dans le cas des pays en développement les plus pauvres, une augmentation des apports à des conditions libérales sous des formes appropriées, y compris, si nécessaire, sous celle d'allégements de dettes, constituera une mesure souhaitable pour leur éviter des problèmes d'endettement.

Il est douteux, en revanche, qu'un accroissement des apports à des conditions libérales soit justifié lorsque le débiteur en difficulté compte parmi les pays en développement jouissant d'une relative richesse qui, étant donné leurs possibilités d'attirer des capitaux aux conditions du marché, supportent l'essentiel de la charge totale du service de la dette des pays en développement.

L'utilisation des fonds limités d'APD pour alléger la dette des pays en développement les plus favorisés peut aboutir à détourner ces fonds de pays qui, du fait de leur pauvreté intrinsèque, ont un droit prioritaire à des concours assortis de conditions libérales.

\section{- Politiques en matière de crédits à l'exportation}

Outre l'aide, les crédits à l'exportation constituent d'importants apports de ressources pour le tiers monde, bien que leur objectif principal soit de promouvoir les exportations. En ce qui concerne les conditions des crédits à l'exportation, les possibilités d'atténuer leur incidence sur l'endettement des emprunteurs sont limitées. Dans la plupart des pays, ces crédits bénéficient déjà d'une bonification d'intérêt (qui porte préjudice aux exportations des pays en développement), et les organismes qui accordent des crédits de ce genre souhaitent vivement éviter de se livrer entre eux à des surenchères. Étant donné la concurrence qui existe entre les vendeurs sur les marchés internationaux, les pays créanciers peuvent difficilement limiter de leur propre chef le volume de leurs prêts commerciaux. Ils pourraient cependant aider les pays en développement dans la gestion de leur dette, qui exige une mise à jour permanente de la totalité de leurs emprunts, en subordonnant l'octroi ou la garantie des crédits à l'exportation à l'approbation préalable des autorités financières centrales des pays bénéficiaires, dans le cas de projets du secteur public, et à une notification ou déclaration préalable auprès de ces autorités, dans le cas de projets du secteur privé. Lancée par une étude du FMI, cette idée trouve aujourd'hui un large écho dans de nombreux pays, y compris dans les pays en développement. Beaucoup des pays qui accordent des crédits à l'exportation ont déjà fait de l'application de mesures de ce genre une condition réglementaire pour que les garanties soient valables.

\section{Le rồle alu} MARCHE DES EUROCREDITS

Alors que l'on envisageait ou que l'on recherchait de nouveaux mécanismes internationaux pour financer les déficits de paiements courants survenus à la suite du renchérissement $d u$ pétrole, une grande partie $d u$ recyclage des capitaux en provenance des pays à balance de paiements excédentaire vers les pays à balance déficitaire était effectuée en 1974 par les euromarchés. Ce recyclage s'est fait pour une bonne part sous forme de prêts à moyen terme par l'intermédiaire de consortiums bancaires internationaux, c'est-à-dire sous forme d'eurocrédits.

Depuis le début de 1974, la Direction des affaires financières et fiscales de l'OCDE recueille régulièrement des informations sur l'activité et l'évolution de ce marché (1). Ces statistiques font partie de la documentation de base établie pour les experts gouvernementaux qui, dans le cadre du Comité des marchés financiers de l'OCDE, examinent la situation du marché international et des marchés nationaux de capitaux.

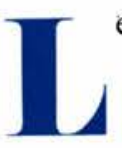

e volume des eurocrédits, qui s'était établi aux environs de 10 milliards de dollars en 1971 et en 1972, est passé à 24 milliards de dollars en 1973 et à 30 milliards en 1974. En même temps, les gouvernements, aussi bien ceux des pays de l'OCDE que ceux des pays du tiers-monde, avaient de plus en plus recours au marché des eurocrédits pour faire face aux importants déficits des paiements courants provoqués par la hausse du prix du pétrole. Il était pratiquement impossible d'obtenir des prêts à plus long terme, car, en raison du haut niveau des taux d'intérêt à court terme, souvent plus élevés que ceux à long terme, les capitaux à investir s'étaient plus volontiers tournés vers le court terme que vers les euro-obligations à long terme.

Au cours du troisième trimestre 1974, le volume des eurocrédits a fortement diminué, en raison des incertitudes et des difficultés qu'ont rencontrées les établissements financiers opérant sur le marché des eurodevises. Plusieurs prêts à des pays en développement et à des sociétés privées ont été annulés et le montant des prêts accordés à des particuliers a été réduit en même temps que les conditions devenaient plus rigoureuses. En septembre et en octobre, l'expansion a repris à un rythme modéré.

Les sources auxquelles les eurobanques font appel pour accorder prêts et crédits sont difficiles à identifier, mais on s'accorde en général pour penser qu'à l'heure actuelle un rôle essentiel incombe à des établissements financiers arabes et à des banques multinationales à forte participation arabe. De toute évidence, le marché des eurocrédits ne saurait à lui seul résoudre le problème du recyclage des excédents en provenance des pays de l'OPEP vers les pays importateurs de pétrole qui en ont besoin pour financer le déficit de leur balance des paiements courants. Mais, dans l'éventail des solutions, ce marché a son importance. Depuis le début de 1975 , les taux d'intérêt à court terme ont fortement baissé à mesure que les pays, pour combattre le chomage, ont desserré les restrictions de crédit. Les taux d'intérêt à long terme sont maintenant de nouveau plus élevés que cux à court terme et l'euromarché des obligations à moye: et à long terme s'est réanimé.

(1) La liste complète de ces prêts est publiée tous les deux mois dans les "Statistiques financières de L'OCDE », tableau IIB2. 


\section{POURQUOI LES FUSIONS DOIVENT ÊTRE CONTROLEES PAR LES POUVOIRS PUBLICS}

Au cours des dix dernières années, les fusions se sont multipliées de façon presque continue dans les pays Membres de l'OCDE - du moins dans ceux pour lesquels des données statistiques sont disponibles - et elles ont souvent préoccupé les pouvoirs publics. L'expérience révèle de plus en plus que les très grandes entreprises résultant de fusions ne sont pas toujours parvenues à l'efficacitéaccrue sur laquelle on comptait pour contrebalancer leurs effets défavorables sur la concurrence. Cette évolution a incité de nombreux gouvernements à envisager d'instituer un contrôle des fusions ou de renforcer celui qui existe déjà. Elle a d'autre part conduit le Comité d'experts de l'OCDE sur les pratiques commerciales restrictives à établir un rapport au bénéfice à la fois des pays Membres qui disposent déjà d'un contrôle des fusions et de ceux qui envisagent d'adopter une nouvelle législation à ce sujet.

Ce rapport, dont les conclusions sont en partie reproduites dans le présent article, vient d'être publié (1). Il prend particulièrement en considération les aspects économiques des fusions et leurs incidences sur la politique gouvernementale. Il fait d'autre part un certain nombre de suggestions concernant la politique que les gouvernements pourraient mener dans ce domaine, suggestions sur lesquelles le Conseil de l'OCDE a récemment attiré l'attention des pays Membres.

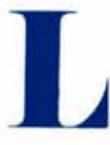

e rapport de l'OCDE décrit quatre facteurs principaux qui exercent une influence sur l'évolution des fusions (2) :

- l'encouragement à fusionner émanant d'organismes gouvernementaux ou non gouvernementaux

- l'intégration de plus en plus poussée des marchés nationaux due au rythme élevé et constant de l'expansion du commerce international

- l'importance accrue des entreprises multinationales dans le commerce national et international

- le rythme accéléré de l'évolution des techniques qui rend la diversification plus intéressante par la sécurité qu'elle procure. Ces quatre facteurs ont des répercussions importantes sur la structure des économies nationales. L'expansion du commerce mondial consolide les forces financières et techniques qui tendent à favoriser la croissance des grosses entreprises, car l'un des obstacles qui s'oppose à celle-ci - les dimensions absolues du marché — disparaît. Faisant contrepoids à ces tendances, !'augmentation des importations et la croissance des sociétés multinationales ont probablement rendu plus vive la concurrence sur les marchés nationaux et internationaux en donnant à des entreprises nouvelles et à des produits nouveaux la possibilité d'y pénétrer. Il est difficile, en l'absence d'analyses fouillées, de se prononcer sur l'orientation générale et la puissance de ces forces, mais on peut supposer, à bon droit semble-t-il, qu'elles ont vraisemblement pour effet d'accroître le degré de la concentration sur les marchés nationaux et internationaux. Ceci pose la question du contrôle par les pouvoirs publics.

\section{Les problèmes qui se posent}

L'augmentation de la concentration et ses effets posent d'importants problèmes économiques :

- quels sont les niveaux actuels de la concentration globale et de la concentration du marché et quel est le taux d'accroissement de cette concentration?

- quelle est l'importance relative des fusions, par opposition à la croissance interne sement de la concentration? des entreprises, comme cause de l'accrois-
- comment identifier, évaluer et comparer les effets favorables et défavorables des fusions?

- quels sont les principes définissant le type de mécanisme qui peut être utilisé pour exercer un contrôle sur les fusions?

\section{Niveau et accroissement de la concentration}

Les préoccupations que suscite l'accroissement de la concentration sont dues en partie aux effets que celle-ci peut avoir sur les résultats et les structures économiques et, partant, sur la réalisation des objectifs économiques nationaux. L'expérience nous montre que de médiocres résultats économiques sont souvent la conséquence directe d'un degré élevé de concentration. Ces résultats peuvent se traduire par des prix et des bénéfices très élevés, ou encore par des coûts élevés dus à de trop importants frais inhérents à la différenciation des produits et à la commercialisation, par un rendement technique insuffisant, par une absence d'innovation technique et enfin par une faible compétitivité sur le plan international.

Du fait de l'importance relative différente dans chaque économie nationale des facteurs qui compensent ou qui freinent l'exercice de la puissance économique, on ne peut pas généraliser et indiquer le niveau de concentration à partir duquel se produisent des effets préjudiciables. Mais, s'il appartient aux autorités nationales de définir exactement ce qu'on doit considérer comme "degré élevé de concentration", il n'est guère contestable que la fusion en est une des principales causes; elle peut par conséquent être une importante source potentielle de préjudice économique.

(1) Fusions et politique de concurrence; rapport du Comité d'experts sur les pratiques commerciales restrictives, OCDE 1974. II constitue la suite d'un rapport antérieur fait par le Comité, La puissance économique et la loi, publié en 1970.

(2) On distingue souvent la "fusion" de la "prise de contrôle ", la "fusion" définissant le processus d'union volontaire entre deux ou plusieurs sociétés, et la "prise de contrôle " caractérisant celle qui s'opère par l'achat d'actions d'une société sans l'accord de ses administrateurs. Toutefois, le terme de "fusion" tel qu'il est utilisé dans le présent article et dans le rapport de l'OCDE s'applique à toute acquisition du contrôle, quel que soit le moyen utilisé; elle comprend par conséquent les deux processus. 


\section{La fusion par opposition à la croissance interne}

Bien qu'indispensable, le fait de mesurer la concentration ne constitue qu'un point de départ pour l'examen des problèmes qui se posent. Il convient d'établir une distinction très nette entre la croissance interne, qui peut se produire lorsqu'une entreprise, consciente de l'évolution de la demande des consommateurs, s'adapte pour la satisfaire plus rationnellement à des coûts réels moindres, et la croissance externe résultant d'une fusion qui peut simplement se traduire par une croissance de l'entreprise, sans amélioration correspondante pour les consommateurs, ni réduction des coûts réels. La croissance interne de l'entreprise, lorsqu'elle est la conséquence d'une baisse des coûts et/ou d'une adaptation plus rationnelle à la demande des consommateurs, donnera des marchés plus concurrentiels, tout au moins pendant la phase de croissance, ce qui se traduira, pour la collectivité, par des avantages économiques réels. La croissance externe peut aussi apporter les mêmes avantages, mais elle peut aussi se traduire seulement par un accroissement du pouvoir économique s'accompagnant d'effets préjudiciables du point de vue des résultats économiques, sociaux et politiques.

Peut-être convient-il toutefois d'apporter quelques nuances à cette distinction. Si une fusion déterminée est susceptible de créer des avantages sensibles en matière d'efficacité, la rapidité avec laquelle ces avantages sont obtenus - par comparaison avec la croissance interne - doit être mise en balance avec les conséquences immédiates qu'entraîne une fusion du point de vue de la puissance économique. Une fusion, qui se traduit par des gains d'efficacité obtenus beaucoup plus rapidement que ceux qui résultent d'une croissance interne, peut être préférable pour la collectivité. Il importe, toutefois, d'examiner si bon nombre d'améliorations sur le plan de l'efficacité ne pourraient pas être obtenues sans recourir à une fusion, ou au moyen de fusions qui ne soulèveraient pas de problème dans le domaine de la concurrence.

\section{Avantages et inconvẻnients - un bilan}

Une distinction doit être faite entre les conglomérats, ou fusions diversifiées, qui accroissent la concentration globale, et les fusions horizontales ou verticales qui ont aussi pour effet d'accroître la concentration du marché. Les effets de ces deux types de fusion peuvent être différents et pourraient conduire à des choix politiques différents.

L'un des problèmes que pose la fusion horizontale et verticale est celui de la rela- tion d'interdépendance entre l'accroissement du potentiel d'efficacité et le renforcement de la puissance économique qui risque d'ouvrir la voie à des abus sur le plan de la concurrence. Du fait des économies d'échelle qu'elles permettent de faire dans les domaines de la production, des ventes, de la gestion, du financement, de la recherche et du développement, grâce aussi à la répartition des activités entre plusieurs usines et à d'autres facteurs, ces fusions pourraient favoriser un accroissement de l'efficacité. De plus, la fusion peut avoir une incidence sensible sur les perspectives de croissance et en particulier sur le commerce extérieur. Toutefois, il est à craindre qu'à un degré plus élevé la concentration, et par conséquent la puissance économique qu'elle confère, entraîne certains abus d'ordre monopolistique ou oligopolistique, tels que la perception de profits supérieurs à la normale qui diminueront le bien-être économique global et auront peut-être une incidence défavorable sur la répartition des revenus.

Les résultats économiques des entreprises qui ont fusionné peuvent aussi devenir moins bons, provoquant ainsi un abaissement du bien-être économique. Toute fusion horizontale, à l'exception peut-être de celle qui unit une entreprise viable à une entreprise en déconfiture, a inévitablement un effet défavorable : elle supprime un concurrent et réduit le nombre de forces indépendantes qui s'exercent sur le marché. $\mathrm{Si}$ la fusion déclenche d'autres groupements défensifs entre des entreprises, sans que ceux-ci se traduisent par un meilleur rendement, il faut également prendre en considération les effets dynamiques sur les structures d'une branche d'industrie. Pour analyser les mesures à prendre, il convient donc d'étudier d'abord les effets de chaque fusion, horizontale ou verticale, en fonction, bien entendu, des dispositions législatives en vigueur ou de la pratique judiciaire ou administrative acquise dans des affaires antérieures.

Les problèmes à étudier sont quelque peu différents dans le cas d'un conglomérat ou d'une fusion diversifiée, qui n'implique aucun accroissement de concentration sur un marché. Toutefois, la taille peut par elle-même avoir deux types d'inconvénients économiques : si elle dépasse celle qui permet une exploitation efficace en fonction des techniques existantes de production et de gestion, la fusion peut entraîner une baisse globale des résultats. Elle peut aussi donner à l'entreprise la possibilité d'adopter sur le marché certains types de comportement qui peuvent avoir des conséquences défavorables pour la concurrence. La taille de l'entreprise peut lui valoir une puissance financière globale renforcée qui lui permet, d'une part, de participer à des accords de subventions réciproques sur les marchés où elle opère, de conclure des accords de réciprocité avec d'autres grosses entreprises et des conglomérats et de renforcer la position dominante de l'entreprise acquise; d'autre part, cette taille peut également lui donner la possibilité de modifier les structures du marché en lui permettant d'absorber assez facilement des concurrents éventuels.

En revanche, le conglomérat ou la fusion diversifiée peut être une forme légitime de croissance pour l'entreprise s'il est fondé sur une spécialisation des connaissances, des techniques et des compétences dont le transfert sur d'autres marchés peut se faire pour un coût économique réel faible ou nul, ou bien s'il facilite la fourniture de capitaux en vue d'une modernisation. Dans ces cas, l'entrée de l'entreprise sur un nouveau marché peut bouleverser les structures et les comportements de façon telle que l'intensité ou les formes de la concurrence se modifient et accroissent le bien-être économique. Avant de porter sur un conglomérat un jugement global on doit, par conséquent, semble-t-il, l'étudier sous l'angle de ses effets sur chaque marché.

Il y a cependant de nombreuses fusions qui, du fait de leurs dimensions ou de leur incidence économique, ne sont pas susceptibles de retenir l'attention des pouvoirs publics lorsque ceux-ci se préoccupent du problème de la diminution de la concurrence. Il est possible même que bon nombre d'entre elles favorisent celle-ci. Où tracer la ligne de démarcation, selon la taille et le type des fusions, dépend des conditions régnant dans chaque pays.

\section{Les mècanismes de contrôle}

Bien qu'en pratique les systèmes de contrôle des fusions en vigueur dans les pays Membres de l'OCDE présentent de nombreux éléments communs, on peut distinguer deux méthodes différentes, quoique liées, pour résoudre les problèmes que pose un accroissement de la puissance économique. La première met l'accent sur la valeur absolue de la concurrence en tant que régulateur de l'activité économique; elle est appliquée, par exemple, aux EtatsUnis où l'on ne peut invoquer l'argument que les avantages possibles d'une fusion compensent les inconvénients qui résultent d'une concentration accrue. La seconde méthode, utilisée notamment au RoyaumeUni, considère l'encouragement d'une concurrence effective comme un objectif parmi de nombreux autres concernant par exemple l'emploi, la répartition géographique des implantations industrielles et l'équilibre des paiements.

Tous les systèmes de contrôle des fusions ont une caractéristique commune : ils s'efforcent de réduire la marge d'incertitude quant au caractère acceptable d'une fusion envisagée ou réalisée. On a constaté qu'une notification préalable, officieile ou officieuse, est un moyen extrêmement efficace pour limiter cette incertitude, 
quoiqu'il existe aussi dans certains pays un système de notification a posteriori.

Quel que soit le système de contrôle, il ne concerne en général que les fusions, en nombre relativement peu élevé, qui posent des problèmes graves de limitation de concurrence. Peut-être n'est-il pas possible de définir des directives précises qui soient d'une application générale; certains pays établissent des limites exprimées en parts du marché, d'autres tiennent compte en plus de la taille de l'entreprise évaluée, par exemple, en fonction de ses actifs ou de son chiffre d'affaires.

Déterminer les éléments dont il convient de tenir compte en présence d'une fusion est la question la plus épineuse. Les problèmes soulevés par l'accroissement du degré de concentration qui résulte d'une fusion ne comportent peut-être pas de solution idéale; celles qui ont été essayées n'ont réussi que partiellement à stopper les principales fusions. II n'en est pas moins vrai qu'un certain nombre de fusions impliquent effectivement des coûts sociaux et ne font que conférer des avantages à des particuliers grâce à un accroissement de puissance économique. Qu'il n'existe pas de solution idéale et dont l'application puisse être généralisée, ne constitue pas une raison pour que l'on n'essaye pas d'adopter des réglementations en vue de réduire ces coûts sociaux.

\section{Fusions internationales}

Les données exposées dans le rapport de l'OCDE indiquent que les fusions internationales peuvent être un élément important de l'ensemble des activités de fusion; on ne peut donc les négliger. Les fusions internationales constituent une forme d'investissement direct et, de ce fait, elles posent des problèmes d'efficacité et de concurrence qui sont fondamentalement les mêmes que ceux qui se posent dans le cas des fusions nationales. Certains faits donnent à penser que ce type de fusion peut résulter du désir d'exploiter un avantage particulier, que ce soit l'efficacité ou la différenciation des produits : c'est pourquoi elles revêtent plutôt la forme d'une fusion horizontale que verticale ou diversifiée. Il est évident que ces fusions ne peuvent pas renforcer la concentration dans les pays d'accueil, mais si l'on envisage le marché mondial du produit considéré, elles ont bien cet effet. Ce phénomène peut donc avoir a long terme des conséquences préjudiciables.

A court terme, en revanche, le rapport làisse penser que les fusions internationales fonciées sur une différence d'efficacité peuvent ascroitre la concurrence sur le marché du pays d'accueil, car l'entreprise étrangère nouvelle-venue souhaitera exploiter cet avantage; elle n'aura pas non plus été contaminée par aucun des comportements non compétitifs en usage sur ce marché. Pour ces raisons il n'est pas possible de formuler de conclusions générales sur les effets des fusions internationales : à l'instar de nombreuses fusions nationales il faut les examiner cas par cas.

Jusqu'à présent, les fusions internationales qui ont soulevé des problèmes de politiques de concurrence semblent avoir été relativement peu nombreuses, mais il est probable que l'expansion régulière des investissements internationaux et l'intégration des marchés mondiaux vont susciter dans l'avenir un bien plus grand nombre d'affaires semblables.

\section{Sugigestions en vue d'une action ultérieure}

Le rapport conclut qu'il n'existe pas nécessairement une politique unique à l'égard des fusions qui puisse être recommandée aux gouvernements qui envisagent d'adopter une législation relative aux fusions ou de modifier la législation en vigueur dans ce domaine. Il faut tenir compte des grandes différences d'ordre économique, social et juridique qui existent entre les pays. Sans doute certaines fusions peuvent-elles avoir des conséquences graves sur les plans économique, social et même politique, mais l'importance relative des fusions en tant que moyen de croissance des entreprises étant différente selon les pays, on peut s'attendre aussi à ce que le préjudice qu'elles infligent à l'économie varie quant à son étendue et à ses conséquences générales. De plus, il y a souvent bien des moyens pour éviter ou compenser des résultats économiques déficients et, là aussi, on peut s'attendre à ce que les remèdes soient différents suivant les pays. Il convient donc d'étudier chaque fusion en fonction de ses conséquences propres.

N'oublions pas, cependant, que des forces économiques puissantes sont en jeu. Ce fait met en évidence la nécessité, pour la plupart des pays développés, de reconnaître que la question des fusions et de leur contrôle mérite examen. Le rapport suggère aux pays Membres, s'ils ne l'ont déjà fait, d'envisager l'adoption d'un système efficace de contrôle des fusions qui reposerait sur les cinq principes suivants : - une procédure d'enregistrement des fusions, dans tous les cas où elle paraît nécessaire

- un système destiné à faciliter l'obtention de renseignements sur les principales opérations de fusion, par exemple en exigeant leur notification préalable

- des critères quantitatifs minima, en deçà desquels les fusions ne seraient pas soumises à contrôle

- des critères objectifs, ou des présomptions, permettant d'évaluer les fusions

- des délais raisonnables dans lesquels il serait décidé, dès leur origine, soit de permettre, soit de contester, certaines opérations de fusion.

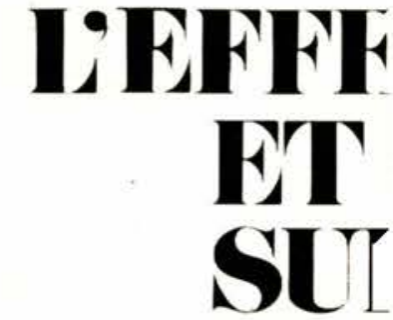

De nombreux pays Membres de $l$ sur les revenus disponibles des $f a$ entre les régimes en vigueur dan. et quantifier les données sur les de renseignements comparables er un salaire moyen, "l'ouvrier moy, les limites de cette première tenta

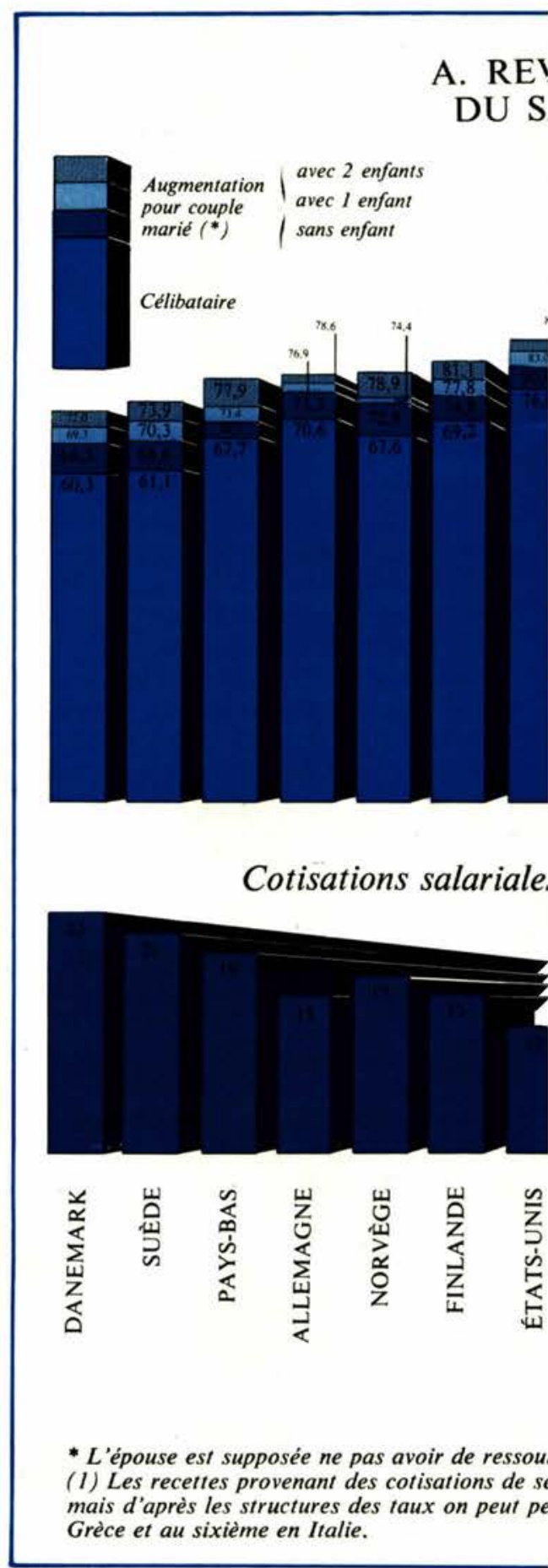


recettes ne peuvent éviter que les contributions incombant aux ouvriers qui gagnent des salaires moyens soient élevées. Cela est vrai même si ces pays imposent très lourdement les groupes à revenus plus élevés (2).

\section{Nide à la famille}

Les politiques que suivent les pays à l'égard de la famille peuvent répondre à des objectifs très différents. C'est ainsi, par exemple, qu'un pays peut chercher à moduler son système de fiscalité et de prestations sociales de manière à tenir compte de l'inégalité des besoins qui existe entre familles de composition (nombre, âge, etc.) fort différente. Les impôts et les prestations sociales peuvent également faire partie d'une politique démographique ou encore servir à encourager le maintien des structures familiales traditionnelles.

Lorsqu'il s'agit d'assurer une égalité entre familles ayant le même revenu mais pas la même composition, les systèmes fiscaux essaient de le faire $1^{\circ}$ en autorisant des abattements qui tiennent compte des différences entre les familles et $2^{\circ}$ en exonérant d'impôts la partie du revenu qui équivaut à un "revenu de subsistance " (revenu minimum indispensable). Ce système repose sur le principe de la «capacité de payer " : qui a un revenu de subsistance est exonéré d'impôt.

Le tableau 1 indique la manière dont le régime d'imposition et de transferts sociaux d'un pays donné traite les familles de composition différente : l'importance (en pourcentage du revenu disponible) des abattements fiscaux et des prestations en espèces dont bénéficie un ouvrier lorsqu'il se marie, lorsqu'il a un premier, puis un deuxième enfant.

Les différences que l'on observe à cet égard ne peuvent être considérées comme reflétant, seules, l'importance que les pays attachent aux divers objectifs mentionnés plus haut. En effet, un système d'impositions et de prestations en apparence moins favorable à la famille peut être compensé par d'autres avantages qui sortent du cadre de cette étude : dispositions spéciales en matière de logement, repas gratuits à l'école, etc. Les chiffres présentés n'en sont pas moins intéressants. Ils montrent, par exemple, que, dans la moitié à peu près des pays, le revenu disponible augmente d'environ le même montant avec le second qu'avec le premier enfant, et qu'il augmente davantage dans l'autre moitié. Tableau 1 montre également que la France, qui passe généralement pour avoir mené une politique active d'encouragement à la natalité, est fidèle à sa réputation : elle est en fait l'un des pays où l'écart est le plus important entre le revenu disponible d'un célibataire et celui d'un couple marie tvec deux enfants.

On note d'autre part avec intérêt que, pour ce qui est de l'augmentation du
1. QUE DEVIENT LE REVENU DISPONIBLE DE L'OUVRIER LORSQU'IL SE MARIE ET LORSQU'IL A DES ENFANTS? Indice du revenu disponible* (ouvrier célibataire $=100$ )

\begin{tabular}{l|c|c|c}
\hline & Marié & $\begin{array}{l}1 \text { en- } \\
\text { fant }\end{array}$ & $\begin{array}{c}2 \text { en- } \\
\text { fants }\end{array}$ \\
\hline Allemagne & 107 & 109 & 111 \\
Australie & 103 & 105 & 108 \\
Autriche & 107 & 116 & 126 \\
Belgique & 107 & 107 & 120 \\
Canada & 106 & 108 & 111 \\
Danemark & 110 & 115 & 119 \\
Espagne & 103 & 105 & 108 \\
Etats-Unis & 105 & 108 & 111 \\
Finlande & 108 & 112 & 117 \\
France & 104 & 109 & 124 \\
Grèce & 101 & 101 & 102 \\
Irlande & 105 & 110 & 116 \\
Italie & 104 & 109 & 114 \\
Japon & 103 & 104 & 106 \\
Luxembourg & 108 & 115 & 123 \\
Norvège & 108 & 110 & 117 \\
Nouvelle-Zélande & 103 & 108 & 113 \\
Pays-Bas & 102 & 108 & 115 \\
Portugal & 100 & 101 & 102 \\
Royaume-Uni & 104 & 109 & 115 \\
Suède & 109 & 115 & 121 \\
Suisse & 102 & 105 & 108 \\
\hline
\end{tabular}

* Changement cumulatif par rapport au revenu d'un célibataire.

\section{L'IMPORTANCE DES PRESTATIONS EN ESPECCES} (allocations familiales, etc.) (en pourcentage du total des avantages fiscaux et sociaux reçus)

\begin{tabular}{lrlr} 
Danemark & 100 & Finlande & 80 \\
Norvège & 100 & Autriche & 65 \\
Suède & 100 & Luxembourg & 64 \\
Espagne & 100 & Canada & 55 \\
Portugal & 100 & Australie & 40 \\
Italie & 95 & Royaume-Uni & 20 \\
Nouvelle- & & Irlande & 19 \\
$\quad$ Zélande & 93 & Grèce & 0 \\
Belgique & 90 & États-Unis & 0 \\
Pays-Bas & 85 & Allemagne & 0 \\
France & 83 & Japon & 0 \\
Suisse & 81 & & \\
\hline
\end{tabular}

revenu disponible résultant du mariage, les pays se classent à peu près dans le même ordre que sur le graphique $A$, tandis que cela n'est pas du tout vrai pour l'accroissement dû à deux enfants. La raison principale de ce phénomène est que le mariage donne en général droit à des abattements fiscaux - et plus le taux d'imposition marginal est élevé, plus est importante la valeur de l'abattement tandis que les avantages accordés pour les enfants prennent souvent la forme de transferts.

La question a été beaucoup débattue de savoir s`il est préférable d'aider les familles par le truchement de prestations en espèces ou par des avantages fiscaux, et dans ce dernier cas, par des abattements fiscaux ou des crédits d'impôt. Ce qui distingue essentiellement ces deux dernières méthodes tient au fait que la valeur de l'abattement est fonction du taux marginal d'impôt sur le revenu du contribuable. Ceci implique que les groupes à revenu élevé gagnent comparativement plus lorsque l'on accorde des abattements et qu'ils perdent comparativement plus lorsqu'ils sont supprimés (par exemple lorsqu'un enfant cesse d'être à charge). Par contre, les crédits d'impôts ne varient normalement pas en fonction du revenu; mais les personnes qui ont un revenu au-dessous du niveau imposable (ou qui sont passibles d'un impôt inférieur au crédit d'impôt) ne touchent rien : leur crédit reste inutilisé (3). En revanche, le versement de prestations en espèces ne dépend pas de la situation fiscale du bénéficiaire. Cela dit, étant donné que les ayants droit aux prestations en espèces peuvent avoir à en faire la demande pour les obtenir, il se peut qu'ils soient moins nombreux à bénéficier effectivement de ces transferts que si ceux-ci leur étaient accordés automatiquement par l'intermédiaire du système fiscal. En règle générale, il semble d'autre part que ce soient les hommes qui reçoivent des avantages fiscaux et les femmes qui touchent les prestations en espèces.

Les choix des gouvernements (pour autant que l'on puisse parler de choix délibérés) entre ces diverses formes d'aide à la famille peuvent, en partie, dépendre d'un certain nombre de facteurs : coûts d'administration des différents systèmes (ces coûts peuvent eux-mêmes varier suivant le type du système d'impôt sur le revenu en vigueur); conception de l'équité (certains considèrent l'abattement fiscal, d'autres le crédit d'impôt comme le système le plus équitable); le désir de révéler ou de cacher le coût de ces aides (le coût des prestations en espèces est plus transparent que celui des avantages fiscaux).

Dans la pratique, les avantages accordés aux couples mariés revêtent la forme, dans presque tous les pays, d'un abattement fiscal. En Italie, cependant, s’y rajoute une prestation en espèces, qui est beaucoup plus importante que l'abattement, et en Belgique et en Suède, on applique à la place un crédit d'impôt. Beaucoup plus variés, les avantages accordès pour les enfants peuvent prendre la forme d'allégements fiscaux (ordinairement des abattements, mais aussi des crédits d'impôt dans le cas de la Belgique et de la Finlande) ou de prestations en espèces, ou des deux à la fois. Le tableau 2 illustre les importantes différences qui séparent les pays à cet égard, en indiquant

(2) Par conséquent dans les pays où les ouvriers conservent un faible pourcentage de leur salaire brut, le produit de l'impôt sur le revenu des personnes physiques et des cotisations salariales à la sécurité sociale tend à représenter une part importante du PNB.

(3) En 1972, année pour laquelle les données sont disponibles, la formule du crédit d'impót était en usage en Autriche, en Belgique et en Finlande. 
les pourcentages qu'y représentent les prestations en espèces dans l'aide totale fournie au titre des programmes compris dans l'étude.

\section{Limpôt sur le revenu des personnes physiques et les rotisations salariales à la sé(curitẻ sociale(4)}

Les résultats de l'étude de l'OCDE mettent en lumière une double relation entre ces deux types de prélèvements. Premièrement, dans la plupart des pays où les taux marginaux d'impôt sur le revenu à la charge de "l'ouvrier moyen" sont élevés, les taux marginaux des cotisations à la sécurité sociale sont faibles. L'inverse est également vrai. En corollaire, dans la plupart des pays où le rapport entre le produit de l'impôt sur le revenu et le PNB est élevé le rapport entre les recettes au titre de la sécurité sociale et le PNB est faible, et inversement.

On constate également que, dans tous les pays, le taux marginal de l'impôt sur le revenu est supérieur au taux moyen, tandis que le taux marginal des cotisations à la sécurité sociale est égal ou inférieur au taux moyen. En d'autres termes, l'impôt sur le revenu est toujours plus progressif que les cotisations salariales à la sécurité sociale.

\section{Les taux d'imposition marginaux et la répartition du revenu}

Les obligations sociales croissantes des gouvernements ont accru leurs besoins financiers, et les taux d'imposition marginaux se sont élevés en conséquence. Cette évolution préoccupe aussi bien les dirigeants que les contribuables euxmêmes.

Le tableau 3 indique l'incidence d'une augmentation du salaire brut - de $10 \%$ en l'occurrence - sur les impôts que doivent payer respectivement un ouvrier célibataire et un ouvrier avec deux enfants (5). Là encore on relève d'importantes différences entre les pays : les taux marginaux représentent en moyenne $55 \%$ et $50 \%$ pour les pays nordiques, alors qu'à l'autre bout de l'échelle, pour les pays les moins industrialisés de l'OCDE, ils sont en moyenne de 14 et $13 \%$.

Les pays où les taux d'imposition marginaux sont les plus élevés sont aussi ceux où le produit cumulé de l'impôt sur le revenu et des cotisations à la sécurité sociale est le plus élevé par rapport au PNB.

En comparant la situation de "l'ouvrier moyen " à celle d'une personne qui gagne $10 \%$ de plus, on peut avoir une idée des effets du système fiscal sur la répartition des revenus. C'est ainsi, par exemple, que dans les pays scandinaves l'ouvrier qui gagne $10 \%$ de plus, brut,
3. COMBIEN UN OUVRIER PAIE-T-IL D'IMPOTS LORSQUE SON SALAIRE (\% de l'augmentation du salaire payé au titre de l'impôt sur le revenu et des cotisations à la sécurité sociale* ou « taux marginaux d'imposition »)

\begin{tabular}{l|c|c}
\hline & $\begin{array}{c}\text { Céli- } \\
\text { bataire }\end{array}$ & $\begin{array}{c}\text { Marié avec } \\
\text { 2 enfants }\end{array}$ \\
\hline Allemagne & 38 & 26 \\
Australie & 35 & 33 \\
Autriche & 35 & 23 \\
Belgique & 29 & 24 \\
Canada** & 29 & 27 \\
Danemark & 61 & 54 \\
Espagne & 13 & 13 \\
Etats-Unis & 34 & 28 \\
Finlande & 45 & 38 \\
France & 21 & 14 \\
Grèce & 15 & 13 \\
Irlande** & 26 & 26 \\
Italie & 24 & 23 \\
Japon & 21 & 18 \\
Luxembourg & 39 & 24 \\
Norvège & 47 & 42 \\
Nouvelle-Zélande & 32 & 31 \\
Pays-Bas & 43 & 35 \\
Royaume-Uni & 35 & 34 \\
Suède & 62 & 62 \\
Suisse & 28 & 23 \\
\hline
\end{tabular}

* Les transferts liés au revenu ne sont pas compris. Les taux marginaux d'imposition sont par conséquent égaux aux taux d'imposition/ prestation.

** Le plafond des cotisations à la sécurité sociale est fixé à un niveau de salaire inférieur à celui de "l'ouvrier moyen". S'ACCROIT DE $10 \%$ ? augmente son revenu disponible réel seulement de 4 à $6 \%$. Le système fiscal est par conséquent utilisé ici comme un instrument de redistribution des revenus : il diminue les inégalités entre salaires bruts même à des niveaux autour de la " moyenne".

\section{Travaux futurs}

Cette étude n'est - on l'a dit - que la première ébauche d'une nouvelle forme de comparaison internationale : elle a besoin d'être perfectionnée. Il s'agit d'abord de remettre ces chiffres à jour, sur la situation de "l'ouvrier moyen" pour ce qui est de l'impôt et des prestations sociales. En second lieu, le salaire des épouses sera pris en considération. $\mathrm{Si}$ possible aussi, la comparaison internationale sera élargie à des contribuables situés dans d'autres tranches de revenu que celles de l'ouvrier gagnant un salaire moyen. Enfin, l'on espère faire entrer dans le champ d'étude quelques-unes des plus importantes prestations en espèces liées au revenu et aux dépenses.

(4) Les cotisations salariales à la sécurité sociale ressemblent à l'impôt sur le revenu des personnes physiques, en ce sens que les deux sont obligatoires et que le montant payé est sans rapport direct avec les prestations reçues. Il se peut, cependant, que les cotisations soient plus acceptables pour le contribuable que l'impôt sur le revenu, parce qu'il peut les considérer comme une assurance dont il bénéficiera à titre individuel.

(5) Les transferts liés au revenu ne sont pas comconséquent égaux aux taux d'imposition/prestation. afin de voir quel a été l'effet de l'inflation pris. Les taux marginaux d'imposition sont par

\section{Qui est "l'ouvrier moyen" dans l'étude de l'OCDE? Quels sont les impôts et les prestations discutés?}

Deux raisons ont incité l'OCDE à choisir, pour une comparaison internationale, un ouvrier travaillant dans l'industrie manufacturière qui gagne un salaire moyen : $\bullet$ des données comparables existent à son sujet dans un certain nombre de pays de l'OCDE - c'est un contribuable représentatif (*).

Il est également intéressant de savoir comment évolue dans les différents pays la situation de l'ouvrier lorsque son revenu augmente. D'autres données indiquent par conséquent le montant des impôts qu'il paye et des avantages dont il bénéficie lorsque son revenu brut s'accroit de $10 \%$.

Tout citoyen effectue diverses sortes de versements à l'État et aux administrations locales et $i l$ en reçoit diverses formes d'aide, en nature et en espèces. Les impôts payés et les avantages reçus qui ont été retenus dans l'étude sont ceux qui ont l'effet le plus direct sur le revenu disponible de l'ouvrier et pour lesquels on dispose d'informations comparables au niveau international. Du côté des versements, il s'agit de l'impôt sur le revenu et des cotisations salariales obligatoires à la sécurité sociale. Toute autre forme de fiscalité est exclue, par exemple les impôts sur la consommation (impôts indirects) et sur la propriété immobilière. Du côté des avantages reçus, ont été retenus les abattements fiscaux et les prestations en espèces auxquelles donnent droit le mariage et les enfants ainsi que les déductions forfaitaires du revenu imposable accordées à tous les salariés. On exclut, par contre, dans le calcul du revenu disponible de l'ouvrier, les déductions du revenu imposable ou des prestations en espèces, plus ou moins importantes, qui sont accordées dans la plupart des pays de l'OCDE au titre de la maladie, de l'éducation, du logement, de la garde d'enfants, des assurances et du transport au lieu de travail.

(*) Pour que les données soient comparables entre les pays, on a supposé que "l'ouvrier moyen " n'a été ni en chômage, ni malade durant l'année; qu'il a reçu un montant moyen pour heures sti: piémentaires, primes, etc.; que son salaire constituait son seul revenu. On suppose égaiement, $\because$ st marié, que son épouse ne dispose elle-même d'aucun revenu, et, s`il a un ou deux enfants, que cc $\_x-c i$ sont d'âge scolaire et n'ont pas non plus de revenus. 


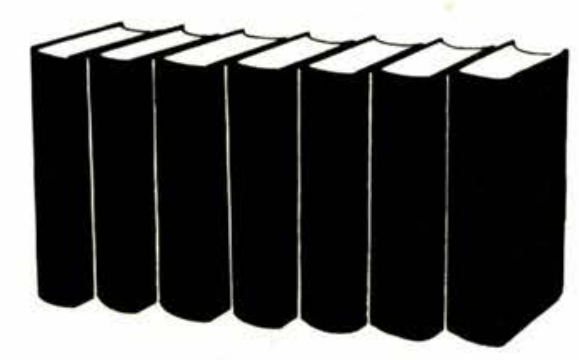

"Etudes économiques de l'OCDE" Série 1974.

TURQUIE (novembre 1974)

(1074 27 2) ISBN 92-64-21281-7

88 pages.

"Etudes économiques de l" OCDE". Série 1975

ISLANDE

(décembre 1974) (10 $75 \quad 17 \quad 2)$

ISBN 92-64-21282-5 64 pages

NORVEGE

(janvier 1975) $\left(\begin{array}{llll}10 & 75 & 22 & 1\end{array}\right)$

ISBN 92-64-21314-7 86 pages

ITALIE

(janvier 1975) (llllll

ISBN 92-64-21313-9 82 pages

FRANCE

(janvier 1975) (lllll $\left.1 \begin{array}{llll}10 & 75 & 14 & 2\end{array}\right)$

ISBN 92-64-21312-0 124 pages

Le fascicule ..... F F 7.00 \& $0.70 \$ 1.75$

$11075002)$ Abonnement à la série 1975

en cours de parution

F $90.00 \& 9.00 \$ 22.50$

RAPPORTS ANNUELS SUR LA POLITIQUE A L'ÉGARD DES CONSOMMATEURS DANS LES PAYS MEMBRES DE L'OCDE (janvier 1975). Série «Documents 》.

Décrivent l'évolution des organismes administratifs chargés d'appliquer la politique à l'égard des consommateurs. les réglementations nouvelles visant à protéger la santé et les intérêts économiques des consommateurs ainsi que les mesures destinées à les informer et à les éduquer.

(24 75012 ) ISBN 92-64-21315-5

122 pages … F F $17.00 \& 1.70 \$ 4.25$

LE FINANCEMENT DU LOGEMENT : PROBLEMES ACTUELS (décembre 1974)

Recherche de solutions aux pressants problèmes du financement du logement, engendrés par les restrictions de crédit et le niveau élevé des taux d'intérêt, dans une situation d'inflation généralisée.

(21 7402 2) ISBN 92-64-21277-9

110 pages … F F $18.00 \& 180 \$ 4.50$

FUSIONS ET POLITIQUE DE CONCURRENCE (janvier 1975)

Voir p. 34

(2474042) ISBN 92.64.21257-4

84 pages …F F $20.00 ₹ 2.00 \$ 5.00$

RAPPORTS ANNUELS SUR LA POLITIQUE DE CONCURRENCE DANS LES PAYS MEMBRES DE L'OCDE (janvier 1975). Série "Documents"

Cés rapports sont établis par les délégués des pays Membres afin d'être examinés par le Comité d'experts en matière de pratiques commerciales restrictives de 1"OCDE à chacune de ses réunions biannuelles. A cette fin. les pays sont divisés en deux groupes. chaque pays soumettant un rapport annuel. Comme ces rapports peuvent constituer, pour les personnes (février 1975)

Nouvelles publications de

intéressées aux problèmes de la concurrence, une utile source de renseignements, I'OCDE a décidé de les publier régulièrement deux fois par an dans le cadre de la série spéciale "Documents de l'OCDE ". (247406 2) ISBN 92-64-21291-4 120 pages $\ldots$ F F $15.00 \& 1.50 \$ 3.75$

DOUBLE IMPOSITION DU REVENU ET DE LA FORTUNE, 1974 (janvier 1975).

Rassemble les textes des vingt articles du projet de convention de 1963 qui ont été révisés, ainsi que les commentaires correspondants.

(2375012) ISBN 92-64-21311-2 172 pages ...FF F $25.00 £ 2.50 \$ 6.25$

STATISTIQUES DE RECETTES PUBLIQUES DES PAYS MEMBRES DE L'OCDE, 1965-1972 / REVENUE STATISTICS OF OECD MEMBER COUNTRIES 1965-1972 (mars 1975).

Présente, selon une classification en 47 rubriques, des données comparables concernant les recettes fiscales et les prélèvements de sécurité sociale, ainsi qu'une analyse de ces données.

(23 7502 3) ISBN 92-64-01322.9 260 pages, bilingue. F $33.00 \leqslant 3.30 \$ 8.25$

STATISTIQUES PÉTROLIĖRES. Approvisionnement et consommation, 1973 / OIL STATISTICS. Supply and disposal (avril 1975). Statistiques couvrant l'ensemble des pays Membres et contenant des renseignements sur les approvisionnements et affectations de pétrole brut, produits d'alimentation. produits de mélange et produits pétroliers: origine des importations: traitement de pétrole brut. produits d'alimentation et gaz naturel: production par les raffineries et consom. mation des principaux produits pétroliers.

(61 75203 ) ISBN 92-64.01324-5

182 pages, bilingue. F $35.00 £ 3.50 \$ 8.75$

STATISTIQUES PÉTROLIERES PROVISOIRES PAR TRIMESTRE. 2e trimestre 1974 / PROVISIONAL OIL STATISTICS BY QUARTERS (janvier 1975)

22 pages, bulingue.

(60 7402 3) ISBN 92-64.01269.9

STATISTIQUES PÉTROLIERES PROVISOIRES PAR TRIMESTRE. 3e trimestre 1974 / PROVISIONAL OIL STATISTICS BY QUARTERS

22 pages, bilingue :

Le numéro..... F $6.00 \$ 0.60 \$ 1.50$ Abonnement .... F F $18.00 £ 1.80 \$ 4.50$

L'INDUSTRIE DE L'ÉLECTRICITÉ. $23^{\circ}$ enquête / THE ELECTRICITY

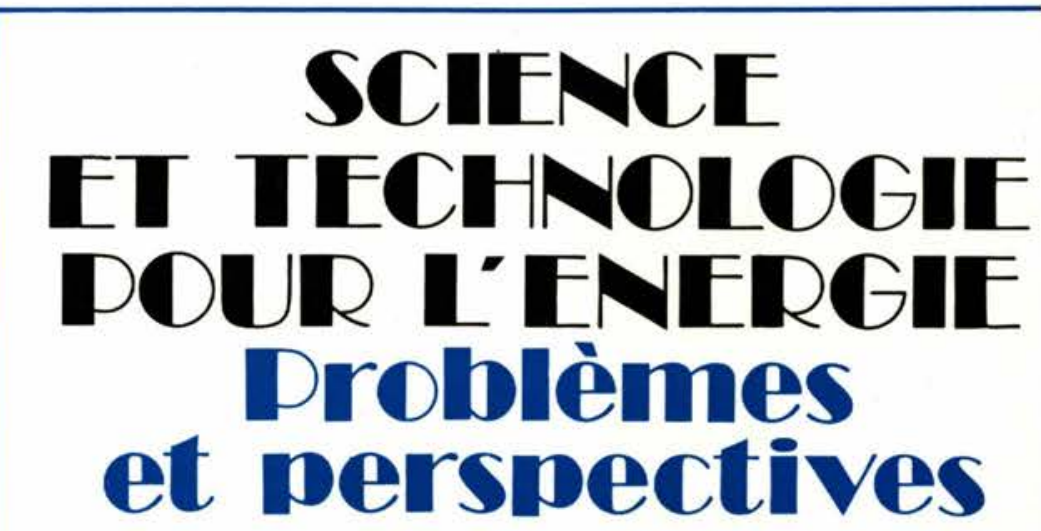

"Comme il n'existe aucune source d'énergie qui s'impose indiscutablement et pour toujours, la stratégie à long terme devrait explicitement viser à maintenir ouvert un nombre suffisant de choix"'. C'est une des recommandations du rapport de l'OCDE intitulé

Science et technologie pour l'énergie (1)

préparé - dans le contexte des Perspectives énergétiques jusqu'en 1985 - sous les auspices d'un groupe du Comité de la politique scientifique et technologique, présidé par Umberto Colombo.

Le rapport s'efforce de donner une vue d'ensemble

des aspects scientifiques et technologiques

des problèmes énergétiques en décrivant

les besoins de recherche et les possibilités offertes

par la recherche et le développement.

Les conclusions d'ordre politique sont résumées ci-dessous.

'in interférence des facteurs politiques, économiques et sociaux, pour ne pas mentionner les facteurs militaires, tempère l'optimisme que pourrait inspirer aux pays de I'OCDE la multiplicité et la diversité des perspectives à moyen et à long termes offertes par la science et la technologie. En effet, l'énergie est d'abord liée à la structure et aux choix des sociétés : l'évolution future dépendra avant tout des décisions d'ordre politique qui seront prises par les pays sur le type de leur croissance économique et de leur structure sociale.

A l'intérieur du cadre constitué par ces décisions de caractère socio-politique, la science et la technologie peuvent apporter une contribution décisive à condition que soit entrepris, dès maintenant, le vaste effort de R-D qu'implique le nombre même des perspectives évoquées plus haut. Effort qui ne pourra prendre tout son sens que s'il procède de politiques cohérentes sur les plans national et international.

L'énergie illustre à cet égard particulièrement bien les problèmes qui se posent actuellement aux politiques de la science et 
SUPPLY INDUSTRY, 23rd Enquiry (décembre 1974)

Enquête annuelle qui couvre l'industrie électrique (production, consommation. puissance installée. investissements et consommation de combustibles par les centrales électriques) et rassemble les données pour les deux années les plus récentes, ainsi que les prévisions pour les six prochaines années.

de la technologie. Les besoins énergétiques, à la fois permanents et changeants, constituent l'exemple même de la "cible mouvante » qui appelle des progrès continus. En outre, on ne saurait trop insister sur la nécessité de prendre pleinement en considération - c'est-à-dire à temps - les délais inhérents à toute activité de R-D : les programmes de recherche entrepris aujourd'hui ne commenceront à porter leurs fruits que dans dix ans au plus tôt et plus probablement dans quinze ou vingt ans.

Rien n'est par conséquent moins approprié au domaine de l'énergie qu'une politique de crash programmes répondant à des crises déjà survenues, dont les données évoluent très vite, et qui présentent en plus le défaut de perpétuer les inconvénients des politiques " en coup d'accordéon ». La détermination des priorités devrait faire partie d'une stratégie à long terme fondée sur l'évaluation des problèmes et besoins futurs. II va de soi que de telles évaluations, et donc les stratégies qui en résultent, devraient être régulièrement révisées à la lumière des faits nouveaux qui ne manqueront pas de se produire, à condition que ces faits ne soient pas seulement des phénomènes conjoncturels, mais entraînent véritablement un infléchissement significatif des tendances. Comme, par ailleurs, il n'existe aucune source d'énergie qui s'impose indiscutablement et pour toujours à la fois sur les plans de l'économie, de la sécurité des approvisionnements et sur celui de l'environnement, ces stratégies devraient explicitement viser à maintenir ouvert un nombre suffisant de choix. En outre, la mise en œuvre des stratégies de $R-D$ relatives à l'énergie devrait être intégrée dans le cadre plus large de la gestion des ressources naturelles.

Enfin, en raison de l'importance des problèmes énergétiques des pays en voie de développement - pour eux-mêmes comme pour les pays industrialisés - il est capital d'entreprendre une étude approfondie sur la contribution que pourraient y apporter la science et la technologie ainsi que sur les directions et les modalités que devraient prendre les actions de coopération internationale en ce domaine.

(1) Publiée sous la responsabilité du Comité de la politique scientifique et technologique, cette étude a été menée par une équipe de la Direction de la science, de la technologie et de l'industrie, sous la direction de JeanJacques Salomon, chef de la Division politiques de la science. L'équipe était composée de Gabriel Drilhon, Bruna Teso et Salomon Wald. En outre, Geneviève Schmeder a contribué au chapitre concernant les problèmes énergétiques des pays en développement.

Les quatorze thèmes de recherche ci-dessous ont été retenus dans le rapport comme étant les plus appropriés à un développement immédiat de la coopération internationale

exploration et évaluation des ressources énergétiques - stockage des combustibles fossiles sous terre ou au fond de la mer $\bullet$ secteur du charbon (technologies d'extraction, de combustion, de gazéification et de liquéfaction) sûreté des installations nucléaires - gestion des déchets radio-actifs - fusion thermonucléaire contrôlée • énergie solaire énergie géothermique - utilisation des déchets industriels et urbains pour la production d'énergie piles à combustibles utilisation de la chaleur en tant que vecteur d'énergie (ce thème inclut non seulement l'utilisation de la chaleur résiduelle des centrales électriques mais aussi le transport et le stockage de la chaleur) - nouveaux vecteurs d'énergie (méthanol, hydrogène et plus généralement les vecteurs permettant de transporter l'énergie sous forme d'énergie de liaison chimique) - économies d'énergie - études générales portant sur l'ensemble des systèmes énergétiques.

(937502 2) ISBN 92-64-21331-7 274 pages F $35.00 \quad £ 3.50 \quad \$ 8.75$ sauf pour les combustibles utilisés en centrales électriques (une année de prévision)

(617410 3) ISBN 92-64-01268-0

108 pages, bulingue. F $24.00 £ 2.40 \$ 8.00$

L'INDUSTRIE DU CIMENT. Statistiques 1973. Tendance 1974 , THE CEMENT INDUSTRY. Statistics 1973. Trend 1974 (décembre 1974).

Donne l'évolution de l'industrie du ciment dans les pays Membres en 1973 et les projets d'installation de nouvelles capacités en 1974 et 1975. II en ressort qu'après l'augmentation importante des capacités installées en 1973, aucun ralentissement n'est prévu pour 1974 et 1975

(71 74903 ) ISBN 92.64.01300-8

38 pages, bilingue. . F $11.00 \& 1.10 \$ 2.75$

L'INDUSTRIE DES MÉTAUX NON FERREUX, 1973 I THE NONFERROUS METALS INDUSTRY, 1973 (février 1975)

Contient quatre séries de tableaux statistiques concernant la produc tion et la consommation, les échan ges, le premier stade de transforma tion des principaux métaux non ferreux, et un tableau des utilisations finales de l'aluminium.

(71 7430 3) ISBN 92.64.01320-2 100 pages, bilingue. F $20.00 £ 2.00 \$ 5.00$ L'INDUSTRIE TEXTILE DANS LES PAYS DE L'OCDE, 1972-1973 / TEXTILE INDUSTRY IN OECD COUNTRIES, 1972-1973 (janvier 1975).

Examine la situation de l'industrie textile et met en particulier l'accent sur l'évolution des échanges de chacun des pays Membres au cours de la dernière décennie. (71 75703 ) ISBN 92-64.01307.5 170 pages, bilingue. F $24.00 £ 2.40 \$ 6.00$

PATES ET PAPIERS. Statistiques trimestrielles, 1974-3 / PULP AND PAPER. Quarterly statistics, 1974-3 (janvier 1975).

(73 7403 3) ISBN 92.64.01267-2

64 pages. bilingue

Le numéro..... F F $12.00 \& 1.20 \$ 3.00$ Abonnement... F F $36.00 \& 3.60 \$ 9.00$

STATISTIQUES FINANCIERES DE L'OCDE No 8 - Tome I I OECD FINANCIAL STATISTICS (novembre 1974).

554 pages, bilingue.

STATISTIQUES FINANCIÉRES DE L'OCDE No 8 - Tome II / OECD FINANCIAL STATISTICS (janvier 1975)

(2074103) ISBN 92.64-01266-4 408 pages, bilingue
$N \circ 8$ (les 2 tomes)

$F 80.00 £ 8.00 \$ 20.00$ Abonnement annuel F $150.00 £ 15.00 \$ 37.50$ BULLETIN DE LIAISON ENTRE INSTITUTS DE RECHERCHE ET DE FORMATION EN MATIERE DE DÉVELOPPEMENT N॰4 - 1974 (février 1975)

Une liste des bibliographies sur le développement publiées au cours de "la première décennie du développement ". On y trouvera 231 informations bibliographiques classées par sujet et 505 classées par régions et, enfin, une liste détaillée des éditeurs des ouvrages cités. (4074043) ISBN 92-64-07308-3 736 pages. bilingue. F $8.00 £ 0.80 \$ 2.00$
TRANSFERT DE TECHNOLOGIE AUX PETITES INDUSTRIES (janvier 1975). Série "Documents".

Le programme était conçu comme un échange de vues au sein d'un groupe de participants préoccupés par la question de l'assimilation progressive de la technologie dans le secteur traditionnel de l'industrie. (417409 2) ISBN 92-64-21296-5

258 pages ...F F $34.00 ₹ 3.40 \$ 8.50$

Série "Etudes du Centre de développement \#.

LE ROLE DE COOPÉRANT. Identité, motivations, attitudes de quel. ques échantillons d'agents, par Denyse Harari (janvier 1975). Série "Documents".

Dans cette étude l'accent est mis sur le coopérant en tant qu'homme. dans sa relation avec son environnement social d'origine et avec le milieu où il exerce ses activités. (4174082) ISBN 92-64-21295-7 160 pages $\ldots$ F F $24.00 \& 2.40 \$ 6.00$

Série "OCDE. Rapports sur les politiques agricoles $"$ :

Rapports issus des discussions du Groupe de travail des politiques agricoles de I'OCDE qui analysent les problèmes de l'agriculture dans chaque pays Membre et décrivent les politiques suivies dans les domaines des marchés, des prix. des structures.

LA POLITIQUE AGRICOLE EN SUEDE (janvier 1975)

(5174172) ISBN 92-64-21284-1

66 pages .....F F $12.00 £ 1.20 \$ 3.00$

LA POLITIQUE AGRICOLE EN ALLEMAGNE (janvier 1975)

(5174162) ISBN 92-64-21283-3

68 pages …… F $12.00 £ 1.20 \$ 3.00$

LA POLITIQUE AGRICOLE AU LUXEMBOURG (janvier 1975)

(51 74192 ) ISBN 92-64-21310.4

38 pages …FF F $8.00 £ 0.80 \$ 2.00$

Série "Marchés et produits agricoles " :

LA TRANSFORMATION DES FRUITS ET LÉGUMES DANS LES PAYS MEMBRES DE L'OCDE (novembre 1974). Série «Documents $)$.

(5174152) ISBN 92-64-21240-X

44 pages … F F $7.00 \& 0.70 \$ 1.75$

LES PRODUCTEURS FACE A

L'ÉVOLUTION DE LA TRANSFORMATION ET DE LA DISTRIBUTION DU LAIT ET DES PRODUITS LAI. TIERS Volume 2 - DANEMARK ÉTATS-UNIS, NOUVELLE ZÉLANDE, ROYAUME-UNI ET RAP. PORT GÉNÉRAL (février 1975).

(5174182) ISBN 92-64-21293-0 424 pages $\ldots$ F F $44.00 \& 4.40 \$ 11.00$

BILANS DU LAIT ET DES PRODUITS LAITIERS DANS LES PAYS MEMBRES DE L'OCDE, 1960$1973 /$ MILK AND MILK PRODUCTS IN OECD \.IEMBER COUN. TRIES (mars 1975) Série "Documents "

$(5) 7507$ 3) ISBN 32.64.01323.

164 pages. blingue. F $28.0022 .80 \$ 7.00$

BULLETIN DE DROIT NUCLÉAIRE No 14 (janvier 1975).

(6774142) 90 pages.

Abonnement (2 nos et suppléments)

F $18.00 \div 1.80 \div 4.50$ 
GESTION DES DÉCHETS SOLIDES CONTAMINESS PAR DU PLUTO NIUM. Compte rendu du sémi naire de I'AEN, Marcoule 1974/ MANAGEMENT OF PLUTONIUM-CONTAMINATED SOLID WASTES. Proceedings of the NEA Seminar, Marcoule 1974 (février 1975).

Techniques et expériences de gestion des déchets solides radio actifs contenant des traces de plutonium-239 ainsi que d'autres radionucléides émetteurs alpha à longue période.

(66 7501 3) ISBN 92-64-01309-1

252 pages, bilingue. F $38.00 £ 3.80 \$ 9.50$

"Recherche routière" :

MODELES DE CIRCULATION

URBAINE : Possibilités de simplification (novembre 1974).

Examine les modèles, pour ordinateurs, de transports urbains et plus particulièrement les possibilités de les simplifier. Expose la structure des modèles stratégiques de trafic et les conséquences des simplifications. Décrit de nouvelles approches en matière de transports urbains.

(7774022) ISBN 92.64.21249.3

140 Pages … F $20.00 \leqslant 2.00 \$ 5.00$

CAPACITÉ DES CARREFOURS PLANS (mars 1975)

Examen des modes de calcul de la capacité de la circulation et des méthodes de régulation les plus appropriées à un trafic important. Considérations des facteurs sécurité et intégration des carrefours plans dans l'environnement (aspects liés aux municipalités et point de vue de l'utilisateur) Résumé des besoins de recherches et recommandations pratiques pour les ingénieurs routiers.

(77 75012 ) ISBN 92-64-21317-1

176 pages … F $24.00 \& 2.40 \$ 6.00$

ACTION DU GEL SUR LES CHAUSSÉES (décembre 1974).

(77 74032 2) ISBN 92-64-21251-5

238 pages $\ldots$ F $26.00 \& 2.60 \$ 6.50$

RÉÉVALUATION DES POLITIQUES RÉGIONALES DANS LES PAYS DE L'OCDE (février 1975)

Évaluation des expériences des politiques mises en place. Descrip tion des questions principales qu se posent aux gouvernements dans l'élaboration et l'application des politiques de développement régional.

(70 7402 2) ISBN 92-64-21286-8

204 pages …FF F $28.00 \& 2.80 \$ 7.00$

" CEMT"

STRUCTURE ET DIMENSION OPTIMA DES ENTREPRISES DE TRANSPORT ROUTIER DE MAR CHANDISES (EFFETS POSITIFS ET NÉGATIFS DE LA SPÉCIALISATION). 23e Table Ronde (novembre 1974).

(75 74 O8 2) ISBN 92-821-2024-4 48 pages .... F F $10.00 \& 1.00 \$ 2.50$

RECHERCHE EN MAT!ÉRE D'ÉCO NOMIE DES TRANSPORTS. Vol. VII-N० 2/RESEARCH ON TRANS PORT ECONOMICS (janvier 1975). (74 74023 ) ISBN 92-821-0025496 pages, bilingue
Abonnement F $120.00 \& 10.60 \$ 28.00$
PROBLEMES MAJEURS CONCERNANT LA POLLUTION DE L'AIR. L'EXPÉRIENCE JAPONAISE (novembre 1974) Série " Documents".

Décrit l'expérience japonaise sur (a) la réduction de la pollution atmosphérique par les oxydes de soufre. (b) les techniques de contrôle. surveillance et simulation par l'application des politiques de lutte contre la pollution de l'air, et (c) la pollution photochimique par les oxydants.

(9474042) ISBN 92-64-21255-8

186 pages $\ldots$ F $22.00 \& 2.20 \$ 5.50$

LES COUTS DES DOMMAGES CAUSÉS A L'ENVIRONNEMENT (février 1975).

Documents de travail établis pour un séminaire dont la tâche était d'apprécier dans quelle mesure l'évaluation aussi bien des coûts des dommages causés à l'environnement que de la probabilité des dommagess éventuels peut être utile pour la formulation d'une politique de l'environnement. Les documents portent sur la définition, I'utilisation, l'estimation et le développement des éléments des dommages, ainsi que le risque et la perception des méfaits causés à l'environnement.

(97 75012 ) ISBN 92-64-21330-9

364 pages $\ldots$ F $45.00 £ 4.50 \$ 11.25$

"Programme d'élaboration des indicateurs sociaux de I'OCDE"

ÉLÉMENTS SUBJECTIFS DU BIEN-ÊTRE. Série "Documents " (décembre 1974).

Fait le point sur les indicateurs psychologiques du changement social, explore les nouveaux domaines d'enquête mesure divers phénomènes subjectifs ou psychologiques, et dresse un schéma programme indiquant les priorités de recherche.

(81 74 O5 2) ISBN 92-64-21256-6

226 pages $\ldots . . F \quad F 26.00 \& 2.60 \$ 6.50$

Examens des politiques nationales de la science" :

IRLANDE (janvier 1975)

(92 7401 1) ISBN 92-64.21176-4

32 pages .... F $19.00 \& 1.90 \$ 4.75$

PRINCIPES MÉTHODOLOGIQUES POUR L'ÉVALUATION SOCIALE DE LA TECHNOLOGIE. Série « Documents » (mars 1975).

Fournit un cadre commun aux études d'évaluation sociale de la technologie et permet ainsi la comparaison entre les études effectuées dans différents pays.

(92 75012 ) ISBN 92-64-21319-8

176 pages $\ldots$ F $22.00 £ 2.20 \$ 5.50$

\section{"CERI"}

RAPPORT TECHNIQUE N 1 - LA CRÉATIVITÉ DE L'ÉCOLE. Rapport de situation par les pays Membres (mars 1975). Série "Documents». Huit documents nationaux (Belgique. France. Allemagne. PaysBas. Norvège. Portugal. RoyaumeUni et États-Unis) dans lesquels sont étudiés les différents aspects de la créativité de l'école et de l'innovation dans chacun de ces pays.

(96 74072 ) ISBN 92-64-21297-3

106 pages …F F $18.00 \& 1.80 \$ 4.50$
PROGRAMMATION BUDGETAIRE DEUXIEME ET TROISIEME CY CLES. Université de Technologie Chalmers (février 1975). Série «Documents $)$.

(96 74062 ) ISBN 92.64-21294-9
274 pages $\ldots$ F $40.00 £ 4.00 \$ 10.00$

TENDANCES NOUVELLES DE LA FORMATION ET DES TACHES DES ENSEIGNANTS. EXPERIENCES NATIONALES : BELGIQUE, FRANCE, ROYAUME-UN (décembre 1974). Série "Documents ".

Les expériences de formation continue des enseignants. L'expérience du collège d'enseignement secondaire de Marly-le-Roi et ses implications sur les tâches des enseignants. Tendances nouvelles en matière de formation initiale et continue des enseignants.

(91 74532 2) ISBN 92-64-21288.4

116 pages $\ldots$ F. F $22.00 \& 2.20 \$ 5.50$

POLITIQUES DE L'ENSEIGNEMENT SUPÉRIEUR. Rapport général (octobre 1974).

Une conférence de haut niveau sur les "structures futures de l'enseignement post-secondaire " a été tenue en juin 1973 à l'OCDE afin de débattre des principales questions de politique. Ce volume présente le rapport général de cette conférence et les éléments du déba sur les problèmes posés par le passage vers un enseignement supérieur de masse.

(91 7406 2) ISBN 92-64-21243.4

252 pages $\ldots$ F F $26.00 \& 2.60 \$ 6.50$

ANNUAIRE DES STATISTIQUES DE L'ENSEIGNEMENT. Vol. I -

Tableaux internationaux (décembre 1974) Série "Documents".

Première publication de I'OCDE présentant des chiffres comparables et standardisés sur l'enrôlement les dépenses et le degré de connaissances de l'enseignement dans les pays Membres de I'OCDE. (91 74102 ) ISBN 92-64-21289-2 66 pages ....F F $15.00 £ 1.50 \$ 3.75$

STRUCTURE DES ÉTUDES ET PLACE DE LA RECHERCHE DANS L'ENSEIGNEMENT SUPÉRIEUR DE MASSE (octobre 1974).

Le présent volume contient quatre rapports dont deux se préoccupent plus particulièrement de la place de la recherche et les deux autres s'attachent à la nouvelle structure des études en rapport avec le nouveau rôle confié à la recherche dans l'enseignement supérieur.

(92 74022 ) ISBN 92-64-21202-7

164 pages …F F $20.00 £ 2.00 \$ 5.00$

L'ENSEIGNEMENT DANS LES PAYS EN VOIE DE DÉVELOPPEMENT DE L'OCDE. TENDANCES ET PERSPECTIVES (février 1975).

$\mathrm{Ce}$ volume analyse les problèmes de l'enseignement en Grèce, au Portugal, en Espagne, en Turquie et en Yougoslavie. Les domaines spécifiquement abordés sont les suivants : les finalités des politiques de développement de l'enseignement. les caractéristiques de l'expansion de l'enseignement dans ces pays au cours des années 60 . les changements importants devant

intervenir dans les structures de lenseignement les perspectives de croissance dans le domaine éducatif au cours des années 70 et les secteurs stratégiques soule vant des problèmes de politique générale.

(917407 2) ISBN 92-64-21244-2

318 pages … F F $32.00 \& 3.20 \$ 8.00$

PLANIFICATION PARTICIPATIVE DANS L'ENSEIGNEMENT (février 1975).

Contient un résumé des principales caractéristiques de la planification dans l'enseignement, examine quelques-uns des problèmes rencontrés et décrit et analyse l'expérience de certains pays.

(917408 2) ISBN 92-64-21259-0

528 pages $\ldots$ F $54.00 \& 5.40 \$ 13.50$

POLITIQUES NATIONALES DE L'INFORMATION SCIENTIFIQUE ET TECHNIQUE : ESPAGNE (janvier 1975). Série "Documents".

(937403 2) ISBN 92-64-21275-2

190 pages $\ldots F \quad F 14.00 \times 1.40 \$ 3.50$

"Etudes d'informatique " No 6 . L'ÉVALUATION DE L'EFFICACITÉ DES SYSTEMES INFORMATIQUES (janvier 1975).

L'informatique est un moyen d'améliorer les services de ladministration publique et de permettre de dégager des économies substantielles. Les méthodes et les systèmes couramment employés pour gére lutilisation et contrôler les coûts sont analysés.

(93 74012 ) ISBN 92-64-21273-6

180 pages …F F $22.00 £ 2.20 \$ 5.50$

"Etudes d'informatique " No 7 L'INFORMATIQUE ET LES COLLECTIVITÉS LOCALES (décembre 1974).

Ce rapport contient une revue du développement de systèmes d'information fondés sur ordinateurs. pouvant servir à la gestion et à la planification dans les collectivités 


\section{Diu obtemir les publications de l' OCDE}

ALLEMAGNE

Verlag Weltarchiv G.m.b.H.,

D - 2000 Hamburg 36, Neuer Jungfernstieg 21. Tél. 040-35 62500 .

\section{ARGENTINE}

Carlos Hirsch S.R.L.,

Florida 165, BUENOS-AIRES.

Tél. 33-1787-2391 Y 30-7122

\section{AUSTRALIE}

B.C.N. Agencies Pty., Ltd. :

161 Sturt St., South Melbourne, Vic. 3205.

Tél. 69.7601 .

658 Pittwater Road, Brookvale NSW 2100.

Tél. 9382267.

\section{AUTRICHE}

Gerold \& Co., Graben 31, WIEN 1.

Tél. 52.22.35.

\section{BELGIQUE}

Librairie des Sciences,

Coudenberg 76-78,

B 1000 BRUXelles I. Tél. 13.37.36./12.05.60

\section{BRÉSIL}

Mestre Jou S.A.,

Rua Guaipá 518, Caixa Postal 24090, 05089 Sao Paulo 10.

Tél. 256.2746/262.1609.

Rua Senador Dantas 19 s/205-6

Rio DE JANEIRO - GB. Tél. 232.07.32.

CANADA

Information Canada, 171 Slater

OtTAWA KIA OS9. Tél. (613) 992-9738.

\section{DANEMARK}

Munksgaards International Booksellers,

Nørregade 6, DK-1165 COPENHAGEN K. Tél. (01) 12.69.70.

\section{ESPAGNE}

Libreria Mundi Prensa, Castelló 37, MADRID 1 Tél. 275.46.55/276.02.53.

Libreria Bastinos de José Bosch,

Pelayo 52, Barcelona 1. Tél. 222.06.00.

\section{ÉTATS-UNIS}

OECD Publications Center,

Suite 1207,

1750 Pennsylvania Ave, N.W.,

WASHINGTON, D.C. 20006. Tél. (202) 298.8755.

\section{FINLANDE}

Akateeminen Kirjakauppa,

Keskuskatu 1, 00100 HeLsinKI 10.

Tél. 625.901.

\section{FRANCE}

Bureau des Publications de l'OCDE,

2 rue André-Pascal, F 75775 PARIS CEDEX 16. Tél. 524.81.67.

Principaux correspondants :

13602 AIX-EN-PROVENCE : Librairie de

1'Université. Tél. 26.18.08.

38000 Grenoble : Arthaud. Tél. 87.25.11.

31000 TOulouse : Privat. Tél. 21.09.26.

\section{GRÈCE}

Librairie Kauffmann,

28 rue du Stade, AtHÈnes 132. Tél. 322.21.60.

INDE

Oxford Book and Stationery Co. :

Scindia House, New Delhi I. Tél. 47388.

17 Park Street, Calcutra. Tél. 24083.

IRLANDE

Eason \& Son, P.O.B. 42 ,

40-41 Lower O'Connell Street, Dublin I.

Tél. 01-41161.

\section{ISLANDE}

Snæbjörn Jónsson \& Co., h. f.,

Hafnarstræti 4 and 9,

P.O.B. 1131 - REYKJAVIK.

Tél. 13133/14281/11936.

ISRAËL

Emanuel Brown :

9 Shlomzion Hamalka Street, Jerusalem.

35 Allenby Road, Tel Aviv.

Tél. 234807.

Tél. 51049/54082.

and 48 Nahlath Benjamin St, Tel Aviv.

Tél. 53276.

\section{ITALIE}

Libreria Commissionaria Sansoni,

Via Lamarmora 45, 50121 FirenZE.

Tél. 579751/2/3.

Via Bartolini 29, 20155 Milano. Tél. 365083.

Sub-depositari :

Herder Editrice e Libreria,

Piazza Montecitorio 120, 00186 Roma.

Libreria Hoepli

Tél. 674628.

Via Hoepli 5, 20121 Milano. Tél. 865446.

Libreria Lattes

Via Garibaldi 3, 10122 Torino. Tél. 519274.

La diffusione delle edizioni OECD è inoltre assicurata dalle migliori librerie nelle città più importanti.

\section{JAPON}

OECD Publications Centre,

Akasaka Park Building,

2-3-4- Akasaka, Minato-ku

ToKyo 107. Tél. 586-2016.

Maruzen Company Ltd.,

6 Tori-Nichome Nihonbashi, ToKyo 103,

P.O.B. 5050, Tokyo International 100-31.

Tél. 272-7211.

\section{LIBAN}

Documenta Scientifica/Redico,

Edison Building, Bliss Street,

P.O. Box 5641, Beirut. Tél. 354429-344425.

\section{NORVÈGE}

Johan Grundt Tanums Bokhandel,

Karl Johansgate 41/43, OsLo 1. Tél. 02-332980.

\section{NOUVELLE-ZÉLANDE}

The Publications Officer

Government Printing Office,

Mulgrave Street (Private Bag),

WelLington. Tél. 46.807. and Government Bookshops at

AUCKLAND (P.O.B. 5344). Tél. 32.919.

Christchurch (P.O.B. 1721). Tél. 50.331.

Hamilton (P.O.B. 857). Tél. 80.103.

DUNEDIN (P.O.B. 1104). Tél. 78.294.

\section{PAKISTAN}

Mirza Book Agency,

65 Shahrah Quaid-E-Azam, LAHORE 3.

Tél. 66839 .

\section{PAYS-BAS}

W.P. Van Stockum,

Buitenhof 36, Den HaAG. Tél. 070-65.68.08.

\section{PHILIPPINES}

R.M. Garcia Publishing House,

903 Quezon Blvd. Ext., Quezon CITY,

P.O. Box 1860 - MaNILA. Tél. 99.98.47.

\section{PORTUGAL}

Livraria Portugal,

Rua do Carmo 70-74, LisBoA 2. Tél. 360582.

ROYAUME-UNI et

COLONIES DE LA COURONNE

H.M. Stationery Office

P.O. Box 569, LoNDON SE1 9NH

Tél. 01.928.6977, Ext. 410.

or

49 High Holborn

LoNDON WC1V 6HB (personal callers)

Branches at : EdINBURGH, BIRMINGHAM,

Bristol, Manchester, Cardiff, Belfast.

SUÈDE

Fritzes, Kungl. Hovbokhandel,

Fredsgatan 2, 11152 Sтоскноцм 16. Tél. 08/23.89.00.

\section{SUISSE}

Librairie Payot,

6 rue Grenus, 1211 Genève 11.

Tél. 022-31.89.50.

\section{TAIWAN}

Books and Scientific Supplies Services, Ltd. P.O.B. 83, TAIPEI

\section{TURQUIE}

Librairie Hachette,

469 Istiklal Caddesi, Beyoglu, IstanbuL.

Tél. 44.94.70

and 14 E Ziya Gökalp Caddesi, ANKARA.

Tél. 12.10.80.

\section{VENEZUELA}

Libreria del Este,

Avda F. Miranda 52, Aptdo. 60337, Edificio

Galipan, CARACAS 106.

Tél. 32.23.01/33.26.04/33.24.73.

\section{YOUGOSLAVIE}

Jugoslovenska Knjiga, Terazije 27,

P.O.B. 36, BEOGRAD. Tél. 621.992.

Les commandes en provenance de pays où l'OCDE n'a pas encore désigné de dépositaire peuvent être adressées au Bureau des Publications de l'OCDE, 2 rue André-Pascal, F 75775 PARIS CEDEX 16. 


\section{Organisation de Coopération et de Développement Economiques}

Pays Membres :

Allemagne

Australie

Autriche

Belgique

Canada

Danemark

Espagne

États-Unis

Finlande

France

Grèce

Irlande

Islande

Italie

Japon

Luxembourg

Norvège -

Nouvelle-Zélande

Pays-Bas

Portugal

Royaume-Uni

Suède

Suisse

Turquie

Pays à Statut spécial :

Yougoslavie 